\title{
Signaling with Reform: How the Threat of Corruption Prevents Informed Policymaking*
}

\author{
Keith E. Schnakenberg ${ }^{\dagger} \quad$ Ian R. Turner ${ }^{\ddagger}$
}

February 2019

\section{Published in the American Political Science Review ${ }^{1}$}

\begin{abstract}
Lobbying is a potential source of corruption but is also a valuable source of information for policymakers. We analyze a game-theoretic model that shows how the threat of corruption affects the incentives of non-corrupt politicians to enlist the help of lobbyists to make more informed decisions. Politicians face a dilemma because voters cannot always tell whether a politician allows access to lobbyists in order to solicit corruption or to seek information. Thus, a non-corrupt politician may deny access to lobbyists to signal that she is non-corrupt even though doing so impedes her ability to make good policy. This signaling may decrease the welfare of the voters depending on the value of the lost policy information relative to the value of screening out corrupt politicians.
\end{abstract}

Keywords: Electoral Accountability; Campaigns; Lobbying; Signaling; Pandering

${ }^{*}$ The authors would like to thank Stephane Wolton, Carlo Prato, Jon Woon, Richard Van Weelden, Chris Cotton, Thomas Groll, Arnaud Dellis, Philippe De Donder, Torun Dewan, Tasos Kalandrakis, Andrea Aldrich, Bill Clark, as well as seminar audiences at Texas A\&M University, Université du Québec à Montréal, University of Pittsburgh, Washington University in St. Louis, and the London School of Economics and Political Science for very helpful discussions and feedback. Errors are ours alone.

${ }^{\dagger}$ Assistant Professor of Political Science, Washington University in St. Louis. Contact: keschnak@wustl.edu.

*Assistant Professor of Political Science, Yale University. Contact: ian.turner@yale.edu.

${ }^{1}$ Full citation: Schnakenberg, Keith E. and Ian R. Turner. 2019. "Signaling with Reform: How the Threat of Corruption Prevents Informed Policymaking” American Political Science Review 113(3): 762-777. 
Political scientists are usually skeptical of blanket statements about the evils of special interest groups. Though corruption may explain some lobbying behavior (Grossman and Helpman, 2001), interest groups can also provide helpful policy information (Austen-Smith and Wright, 1992, 1994; Wright, 1996), increase the work-capacity of legislators (Hall and Deardorff, 2006), and provide a connection between the public and the policy process. However, most campaigns focus on the potential negative effects of lobbying. It is hard to imagine a candidate emphasizing how her cozy relationship with lobbyists will make her more effective in office. In this article, we propose an explanation for this contrast: politicians may try to signal that they are non-corrupt by taking a combative stance toward interest groups even when this adversely affects their ability to govern.

We develop a game-theoretic model of electoral competition in which two politicians vie for office, committing themselves to either banning or granting interest group access should they win. Politician choices over group access can inform voters about whether or not politicians are corrupt. Once a politician wins office an interest group, if access was granted, interacts with the winning politician. The group can engage in two types of lobbying by either providing policy-relevant information or initiating a quid pro quo. The type of politician in office dictates which lobbying tactic is most effective. The best case scenario from voters' perspectives is to elect an honest politician who grants interest group access for informational lobbying. However, voters are uncertain about which politicians are honest and which are corrupt and therefore use access decisions to attempt to screen out corrupt politicians. This comes at the cost of information as sincere politicians will often ban interest group access to attempt to communicate their sincerity to voters, a behavior we refer to as signaling with reform.

To illustrate our argument, consider a hypothetical election in which banking regulation is a central issue. During the campaign, the politicians can commit themselves to a policy which either allows or denies access to Wall Street interest groups. For instance, some politicians may indicate a need to work with the industry to develop effective regulations while others may emphasize a belief that the regulatory process is rigged in favor of moneyed interests and promise a closeddoor policy toward industry lobbyists. These politicians may even support similar regulations 
while maintaining different positions toward interest group participation. Now suppose that some proportion of politicians seek access to secure campaign contributions from Wall Street. These politicians will always grant access to interest groups and will ultimately act in the interests of the industry. The problem is that voters cannot tell the difference between politicians who grant access because they are corrupt and those who grant access to better serve the voters' interests. Thus, sincere politicians may deny themselves the information needed to make good policy by shutting out interest groups in order to convince voters that they are not corrupt.

\section{Related literature}

\subsection{Lobbying tactics}

Our model builds on the idea that lobbying includes multiple tactics with countervailing implications for voter welfare. We will focus on two well-studied lobbying tactics. We model socially unproductive lobbying as quid pro quo exchange between interest groups and politicians. Socially productive lobbying is modeled as policy-relevant information transmission. These two lobbying tactics are chosen because they have an important place in the lobbying literature and an unambiguous relationship to voter utility in our model. In principle, either quid pro quo or information transmission could be replaced by some other notion of lobbying and the main insights of the model would be similar. The most important assumptions needed are that (a) the socially productive lobbying method produces a good valued by the voter as well as by non-corrupt politicians, (b) socially destructive lobbying produces a good valued only by corrupt politicians and imposes costs on voters and non-corrupt politicians, and (c) the lobbying tactic chosen in equilibrium depends mainly on whether or not the elected politician is corrupt.

Quid pro quo lobbying. Quid pro quo lobbying is most often modeled as an exchange of something valuable (e.g., money) in exchange for policy favors (Baron, 1989; Denzau and Munger, 1986; Grossman and Helpman, 1994). Evidence of quid pro quo bargaining is necessarily indirect and varies across countries and contexts. For instance, outside of the United States, firms garner 
significant financial returns on political connections and pursue these connections more aggressively in countries where corruption is high (Faccio, 2006; Fisman, 2001). ${ }^{2}$ Some theoretically informed research has focused on the question of whether legislators can credibly commit to deliver on promised policy favors after payments from interest groups have changed hands (McCarty and Rothenberg, 1996). We are interested in the implications of potential quid pro quo exchanges rather than the conditions under which they are possible, so we sidestep this issue by assuming that corrupt politicians have a preference for reciprocity (see Lambsdorff, 2012).

The concept of corruption in our model should not be taken too literally. Corruption is a standin for any mode of lobbying that benefits the politician and interest group, but not the voter. For instance, lobbying is often seen as a way for interest groups to subsidize politicians' efforts on their shared objectives (Hall and Deardorff, 2006). In cases where this distorts the policy agenda away from issues the voter cares about, this can harm voter welfare. Though this behavior does not constitute corruption, it fits in our model equally well.

Informational lobbying. In information-based models, interest groups are influential to the extent that they transmit policy-relevant information to policymakers. Potters and Van Winden (1990) demonstrates the effectiveness of informational lobbying in a dynamic game between one interest group and one legislator. Potters and Van Winden (1992) shows how lobbying costs may expand the set of circumstances for which informational lobbying is credible. Austen-Smith and Wright $(1992,1994)$ analyze models in which two interest groups attempt to persuade a policymaker and draw implications for patterns of lobbying in the face of competition. Austen-Smith (1995) and Cotton (2012) show how campaign contributions may be used to signal information which causes lobbies to be granted access for the purpose of informational lobbying. In these articles information transmission improves the quality of the policymakers' decisions, as it does in our model. ${ }^{3}$

Informational lobbying is a prominent explanation of lobbying behavior in empirical work. Interest group surveys show that a great deal of lobbyists' time is spent conducting research and presenting arguments to elected officials (Schlozman and Tierney, 1986; Baumgartner et al., 2009).

\footnotetext{
${ }^{2}$ This evidence is not as strong in the United States (e.g. Fowler, Garro and Spenkuch, Forthcoming).

${ }^{3}$ An exception to this rule occurs when multiple policymakers make decisions by voting as in Schnakenberg (2017).
} 
Case studies also support informational lobbying. For instance, Hansen (1991) argues that the farm lobby's influence was attributable in large part to informational lobbying.

Much of the existing literature focuses on the conditions under which information transmission is credible in a lobbying environment. Our purpose is to build on existing theoretical and empirical work by focusing on the cases in which both quid pro quo and informational lobbying are possible and illustrating the resulting trade-offs that politicians face. To that end, our treatment of informational lobbying focuses on the case of verifiable information. ${ }^{4}$

Mixed lobbying tactics. Several other papers juxtapose multiple lobbying tactics within a single game-theoretic model. In Wolton (2016), political contributions are influential because they signal a group's strength at grassroots lobbying. In Ellis and Groll (2017), interest groups can engage in informational lobbying or give contributions in the form of legislative subsidy. Bennedsen and Feldmann (2006) shows how acquiring information creates externalities that raise the cost of bribing politicians. Dahm and Porteiro (2008) analyzes a model in which interest groups can provide information and apply political pressure and show how attitudes toward risk affect the choice of tactics. In contrast to these existing studies we do not focus on the interest group's choice of tactic, which in our model is a simple matter of matching the tactic to the type of politician. Instead, we focus on how the voter's uncertainty about the type of lobbying solicited by politicians affects politicians' incentives to signal to voters.

\subsection{Pandering and populism}

This article also relates to the political economy literature on pandering. Pandering refers to a policymaker's decision to ignore relevant information and instead take the action ex ante preferred by the voters, often to bolster her reputation. Politicians may engage in this behavior in order to signal congruence with the voter (Maskin and Tirole, 2004; Morelli and Weelden, 2013; Morris, 2001) or to signal competence (Ashworth and Shotts, 2010; Canes-Wrone, Herron and Shotts, 2001; Prat, 2005). Our results are similar in that reputational concerns lead the politician to forgo

\footnotetext{
${ }^{4}$ Other papers on lobbying with verifiable information include Caillaud and Tirole (2007) and Cotton (2012).
} 
acquiring information at all in order to signal that they are non-corrupt. However, the mechanisms driving our model differ from pandering. For instance, pandering occurs when the voter may see policy choices but not whether they were successful. In the dynamic model in Section 3.2 we show that signaling with reform can be supported even when voters observe outcomes of policy choices.

In a related article, Coate and Morris (1995) develop an argument in which politicians engage in inefficient behavior in order to avoid revealing themselves as beholden to special interests. Inefficiencies may be introduced due to "bad" politicians mimicking "good" politicians by implementing public programs to transfer resources to special interests when a direct transfer would be more efficient. Similarly, good politicians may pool with bad politicians by not implementing public programs when their private information suggests they should. They do so to safeguard their already favorable reputations in order to maximize chances for reelection. Thus, inefficiency arises through politicians pooling to conceal their type. A related inefficiency arises in our model but through a separating equilibrium in which good politicians reveal themselves at some cost to efficiency. This difference is important in our welfare analysis which turns on the relative benefits of screening out corruption versus good policymaking by non-corrupt politicians.

Acemoglu, Egorov and Sonin's (2013) model of populism also features an argument similar to ours. In their model corrupt politicians can be influenced by a wealthy elite with preferences to the right of the median voter. Honest politicians signal that they are incorruptible by choosing a policy to the left of the median voter. Thus, the desire to signal honesty can lead to policies that harm the welfare of the voter, as in our model. ${ }^{5}$ We obtain a similar result but the effects on voter welfare are driven by information acquisition rather than spatial preferences over policy. Overall, these previous models do not speak to information acquisition or direct decisions about interest group access, which are central to the insights in this article.

\footnotetext{
${ }^{5}$ Duggan and Martinelli (2015) show that this negative effect of signaling can occur whenever voter preferences are single-peaked but politicians' marginal utilities for policy are ordered by type, obtaining the Acemoglu, Egorov and Sonin (2013) setup as a special case of their model.
} 


\section{Baseline model}

The model captures a situation in which an interest group lobbies for a policy which, depending on its private information, may or may not be in the best interests of the voters. Private information is captured by a variable $\theta$ which determines the policy preferred by a majority of voters. The interest group, however, would prefer the same policy no matter what it believed about $\theta$. For instance, if it were known that unregulated financial derivatives would harm the economy, a majority would support regulation. However, a firm specializing in these derivatives would still like to keep them unregulated. The interest group can engage in one of two tactics, which we term "informational lobbying" (e.g., creating a white paper) or "bribes" (e.g., offering campaign contributions). The types of the politicians determine their susceptibility to each tactic, with sincere types persuaded by information and corrupt types persuaded by contributions. The behavior of the politicians is driven by their desire to demonstrate to the voters that they are sincere.

The players are two politicians $(A$ and $B)$, a representative voter $V$, and an interest group $G$. Politicians are either sincere or corrupt. During the campaign, politicians commit to platforms that effectively allow or deny access to the interest group. In Section 3 we relax this commitment assumption. Once the winning politician takes office, he decides whether to enact a new policy. If the interest group has access to the politician, it may influence policy by either providing information or paying a bribe.

Sequence of play. The sequence of play is as follows. First, nature draws each politician's type $\tau_{i} \in\{S, C\}$ (sincere or corrupt). The prior probability that a politician is sincere is $\pi:=\operatorname{Pr}\left[\tau_{i}=S\right]$ and is private information. Nature also draws a state of the world $\theta \in\{0,1\}$ that determines which policy is best for the voter. For instance, if the policy is a banking regulation, $\theta$ may represent information on how the new regulation will affect lending practices. The voter prefers regulation if it will not severely limit access to credit but not if it would make it too difficult for consumers to borrow money. Prior beliefs are that $\operatorname{Pr}[\theta=0]=q>1 / 2$. The state $\theta$ is private information to the interest group, which specializes in the policy area. Next, both politicians publicly announce their 
campaign platforms. Each politician can either run on a reform platform $(p=0)$ that effectively bans group access should the politician take office or an access platform $(p=1)$ that leads to interaction with the group after winning office. Following politician announcements a representative voter elects politician $A$ or $B$.

If the winning politician ran on a reform platform then he will simply choose a policy $x \in\{0,1\}$ to implement. If the winning politician ran on an access platform lobbying occurs before policy is chosen. In the lobbying stage, the interest group learns the politician's type, ${ }^{6}$ the interest group's information about $\theta$ is revealed and it can choose to offer the politician a bribe: $b \in\{0,1\}$ where $b=1$ denotes a bribe. ${ }^{7}$ If the politician in office ran on a reform platform then $b=0$ and the group's information about $\theta$ is not revealed. The bribe may be interpreted as a literal bribe, an implied revolving door job offer, or anything else that materially benefits the politician but does not aid in policymaking. Substantive lobbying is captured through the verifiable information about $\theta$ that is revealed by the interest group through white papers or the like. Once the lobbying stage concludes, the politician updates her beliefs about $\theta$ and chooses a policy.

Preferences and equilibrium. The voter wants the chosen policy to match the state of the world. Her preferences are given by the following utility function,

$$
u_{V}(x, \theta)=-|x-\theta|
$$

The interest group's policy preferences are independent of the state: it always prefers $x=1$ whether or not that policy is good for the voter. Furthermore, the interest group pays a cost, $\kappa \in(0,1)$ for

\footnotetext{
${ }^{6}$ The assumption that the interest group learns the politician's type before lobbying is useful in that it allows the lobbying tactic to be matched to the type of the politician. This assumption is not strong given our assumptions about preferences because both types of politician have a strict incentive for his type to be revealed to the interest group. Thus, if types were not revealed they could easily be transmitted by cheap talk or by allowing the interest group to give the politician a choice between an informational report or a bribe.

${ }^{7} \mathrm{We}$ simply assume that the group's information is revealed if it has access. Alternatively, the group could choose whether or not to reveal the information in which case it would reveal when $\theta=1$ and therefore non-revelation would allow the politician to infer that $\theta=0$.
} 
bribes. ${ }^{8}$ The interest group's utility function is,

$$
u_{G}(x, \theta, b)=x-\kappa b .
$$

Politician preferences depend on their types. Our assumptions about politician preferences are designed to make the contrast between types as stark as possible: sincere types only want to choose the policy that is best for the voter and corrupt types only want to pursue exchanges with the group. ${ }^{9}$ Accordingly, politician preferences are represented by the utility function,

$$
u_{i}(x, \theta, b)= \begin{cases}-|x-\theta| & \text { if } \tau_{i}=S, \\ b x-(1-b) x & \text { if } \tau_{i}=C .\end{cases}
$$

We analyze symmetric pure strategy perfect Bayesian equilibria in weakly undominated strategies. ${ }^{10}$ We also focus on equilibria that satisfy the Intuitive Criterion (Cho and Kreps, 1987).

\subsection{Interest group access and informed policymaking}

To begin the analysis, note that any time interest group access was banned all politicians set $x=0$. Corrupt politicians choose $x=0$ because they are not bribed and sincere politicians choose $x=0$ because their prior beliefs place a higher probability on $\theta=0$. This further implies that with probability $1-q$ the wrong policy, from the voter's perspective, will be implemented.

When the interest group does have access policy choices vary. Consider a corrupt politician that won office after running on an access platform. He is solely motivated by rent-seeking and therefore will choose the group's preferred policy, $x=1$, only if he receives a bribe, $b=1$, and implements $x=0$ otherwise. The group understands this and therefore knows that a bribe will lead to its most preferred policy. In equilibrium, when the interest group learns a corrupt politician has won office it optimally pays the bribe. Sincere politicians' policy choices respond to information,

\footnotetext{
${ }^{8}$ We assume $\kappa<1$ to ensure the costs of inducing politicians to implement $x=1$ do not exceed the benefits.

${ }^{9}$ These assumptions are stronger than necessary. The results are similar as long as different types are more easily swayed by different tactics.

${ }^{10}$ Appendix Section A.3 shows that our results are robust to asymmetric strategies and probabilities of corruption.
} 
not bribery. Thus, the interest group has no incentive to bribe sincere politicians. When a sincere politician runs on an access platform and wins he learns $\theta$ because the group's private information is verifiable. This allows him to match policy to the state, $x(\theta)=\theta$, an outcome that is optimal for both him and the voter. The foregoing analysis yields a unique equilibrium to the lobbying stage of the game.

Proposition 1. The unique equilibrium to the lobbying stage consists of the following collection of strategies when access was granted.

- The interest group reveals $\theta$ to sincere politicians and bribes corrupt politicians, $b=1$.

- Corrupt politicians implement the interest group's preferred policy, $x=1$, only if $b=1$ and implement $x=0$ otherwise.

- Sincere politicians implement the interest group's preferred policy, $x=1$, only if they learn $\theta=1$ and implement $x=0$ otherwise.

To summarize Proposition 1, when access was granted the interest group always bribes a corrupt politician and always reveals $\theta$ to a sincere politician. A corrupt politician sets $x=1$ if and only if he is bribed and a sincere politician sets $x=\theta$ after learning $\theta$.

\subsection{Signaling with reform}

In this section we characterize platform decisions. There are two types of equilibria. A reform equilibrium is a separating equilibrium in which sincere politicians run on reform platforms and corrupt politicians run on access platforms. Voters can infer sincerity in this case and screen out corrupt politicians, but sincere politicians sacrifice policy-relevant information by banning group participation. An access equilibrium is a pooling equilibrium in which all politicians run on access platforms. In this case the voter cannot infer politician types, but if a sincere politician wins office he is able to make informed policy choices. Therein lies the fundamental trade-off at the heart of this article: improved screening for corruption comes at the cost of informed policymaking. 
Equilibrium voting. The voter attempts to elect sincere over corrupt politicians. In a reform equilibrium she can perfectly infer politician types. If both politicians run on reform and ban group access then she is indifferent since both are sincere and $x=0$ is implemented regardless of who she elects. If both politicians run on access then she knows that both are corrupt and is again indifferent since $x=1$ will ultimately be implemented. Finally, when one politician is sincere and runs on reform and one is corrupt and runs on access she votes for the sincere politician that will implement $x=0$ over the corrupt politician that will implement $x=1$. Since $\theta=0$ is ex ante more likely this choice yields higher expected utility than electing a corrupt politician.

In an access equilibrium the voter cannot infer politician types and retains her prior belief, implying that either politician is equally likely to be sincere. In that case the voter can do no better than voting for either politician with equal probability. She expects to lose nothing on policy with probability $\pi$ since in that case the politician is sincere and policy is implemented to match the state. In contrast, with probability $1-\pi$ the winning politician is corrupt and $x=1$ is implemented for sure, leading to an expected policy loss proportional to the probability that $\theta=0$.

Equilibrium platforms. To illuminate the issues at stake when considering platform decisions, consider again the case of banking regulation discussed in the introduction. For corrupt politicians, public office is seen as an avenue for private rents and, therefore, will always grant access to banking groups and subsequently choose policy that is favorable to those groups. For sincere politicians, there is a trade-off involved. Granting access to banking groups (i.e., enlisting their advice in crafting policy) carries significant informational benefits. In fact, the informational advantage of those in the banking industry is often seen as an important reason for these groups to be included in the regulatory process (e.g., Omarova, 2010). However, consulting with interest groups may lead voters to question whether the politician is sincere. When will sincere politicians eschew policy-relevant information by running on reform in pursuit of revealing that they are sincere?

Consider first the incentives of corrupt politicians. Since they only respond to bribes the maximum payoff for running on reform is zero since that precludes the group's ability to pay bribes. In contrast, if corrupt politicians run on access platforms, depending on the type of their opponents, 
they may win office and receive a bribe from the group. Thus, it is always beneficial for corrupt politicians to run on an access platform.

Sincere politicians have different incentives since they pursue policy rather than bribes. Consider the reform equilibrium environment. Corrupt politicians run on access while sincere politicians run on reform. A sincere politician's expected payoff for banning access in this environment is given by,

$$
E U_{i}\left(p_{i}^{*}=0 \mid \tau_{i}=S, p_{-i}^{*}, x^{*}\right)=-(1-q) .
$$

The implemented policy outcome when two sincere politicians compete against one another is the same: both will set $x=0$ since neither receive information from the interest group. This yields an expected payoff of $-(1-q) .{ }^{11}$ If instead he faces a corrupt politician he wins the election for sure but receives no information since lobbying is banned. He therefore sets $x=0$, which again yields an expected payoff of $-(1-q)$. Thus, regardless of his opponent's type a sincere politician's expected payoff is $-(1-q)$ when he runs on reform.

If instead a sincere politician deviates and runs on access his expected payoff is,

$$
E U_{i}\left(p_{i}=1 \mid \tau_{i}=S, p_{-i}^{*}, x^{*}\right)=-\pi(1-q)-\frac{1}{2}(1-\pi) q
$$

If he deviates he loses when he runs against another sincere politician since now his platform signals to the voter that he is corrupt. In this case the politician expects to lose $-(1-q)$ since that is the likelihood the uninformed sincere politician that won office will fail to match policy to the state. If he faces a corrupt politician then the voter elects either with equal probability since she believes both are corrupt. If the sincere politician wins then he is able to perfectly match policy to the state since the group has access and provides information about $\theta$. If he loses then the corrupt winner will implement $x=1$ which will fail to match the state with probability $q$.

\footnotetext{
${ }^{11}$ Because sincere politicians only care about policy they also gain and lose utility based on the policy chosen by their opponent following an electoral loss.
} 
It is incentive compatible for a sincere politician to run on a reform platform if,

$$
-(1-q) \geq-\pi(1-q)-\frac{1}{2}(1-\pi) q
$$

which is satisfied for all $\pi \in(0,1)$ when $q \geq \frac{2}{3}$. Combined with the fact that corrupt politicians always run on access in this environment, this yields the necessary and sufficient condition to support a reform equilibrium: $q^{\operatorname{Reform}}(\pi):=\frac{2}{3}$. So long as $q \geq q^{\operatorname{Reform}}(\pi)-$ the probability that $\theta=0$ is sufficiently high - there is a reform equilibrium.

Now consider the access equilibrium environment in which all politicians run on access. The upside to this situation is that sincere politicians, if they win, are able to make fully informed policy choices. The downside is that the voter cannot differentiate politicians and therefore may elect a corrupt politician. Corrupt politicians have even stronger incentive to run on access in this case since they no longer lose with certainty when facing a sincere politician.

Sincere politicians would prefer to run on access for its informational value, conditional on winning the election. However, doing so precludes the sincere politician from revealing he is sincere and therefore he risks losing the election to a corrupt politician. A sincere politician's expected payoff from running on access in this case is,

$$
E U_{i}\left(p_{i}^{*}=1 \mid \tau_{i}=S, p_{-i}^{*}, x^{*}\right)=-\frac{1}{2}(1-\pi) q
$$

If he faces another sincere politician then regardless of who wins policy is implemented to match the state and he receives zero. If he runs against a corrupt politician then he runs the risk of losing and having $x=1$ implemented for sure, which will mismatch the state with probability $q$, yielding his expected policy losses in that case. If a sincere politician instead deviates to running on reform and banning access he foregoes the opportunity to make informed policy should he win, but ensures that he will win the election with certainty since the voter correctly believes he is sincere. ${ }^{12}$ This

\footnotetext{
${ }^{12}$ This is the only off-path voter belief that survives Intuitive Criterion refinement.
} 
deviation yields the following expected payoff,

$$
E U_{i}\left(p_{i}=0 \mid \tau_{i}=S, p_{-i}^{*}, x^{*}\right)=-(1-q)
$$

Regardless of what type of politician his opponent is, the sincere politician will win the election but will learn nothing about $\theta$. Thus, he will follow his prior information, implement $x=0$, and policy will not match the state with probability $1-q$. To support the posited sincere politician behavior in the access equilibrium incentive compatibility requires that,

$$
-\frac{1}{2}(1-\pi) q \geq-(1-q)
$$

which is satisfied for all $\pi \in(0,1)$ when $q \in\left(\frac{1}{2}, \frac{2}{3-\pi}\right]$. Since corrupt politicians always run on access platforms, this incentive compatibility condition is necessary and sufficient to support an access equilibrium. Define this condition as $q^{\operatorname{Access}}(\pi):=\frac{2}{3-\pi}$. As long as $q \leq q^{\text {Access }}(\pi)-$ the probability that $\theta=0$ is sufficiently low - there is an access equilibrium.

The conditions on $q$ that support the separating reform and the pooling access equilibria are not distinct. In fact for any $\pi \in(0,1)$ there exists a region in which both reform and access equilibria are possible: $q \in\left[q^{\operatorname{Reform}}(\pi), q^{\text {Access }}(\pi)\right]$.

Proposition 2. Define $q^{\text {Reform }}(\pi):=\frac{2}{3}$ and $q^{\text {Access }}(\pi):=\frac{2}{3-\pi}$. Then for all $\pi \in(0,1)$ we have the following equilibria conditional on the magnitude of $q$.

- If $q^{\text {Reform }}(\pi) \leq q^{\text {Access }}(\pi)<q$ then the separating reform equilibrium is unique.

- If $q<q^{\text {Reform }}(\pi) \leq q^{\text {Access }}(\pi)$ then the pooling access equilibrium is unique.

- If $q^{\text {Reform }}(\pi)<q<q^{\text {Access }}(\pi)$ then both the separating reform and the pooling access equilibria can be supported.

The range of $q$ in which reform and access equilibria both exist varies in the likelihood of corruption, $\pi$. Specifically, $q^{\text {Access }}(\pi)$ is increasing in $\pi$, which yields the following corollary. 


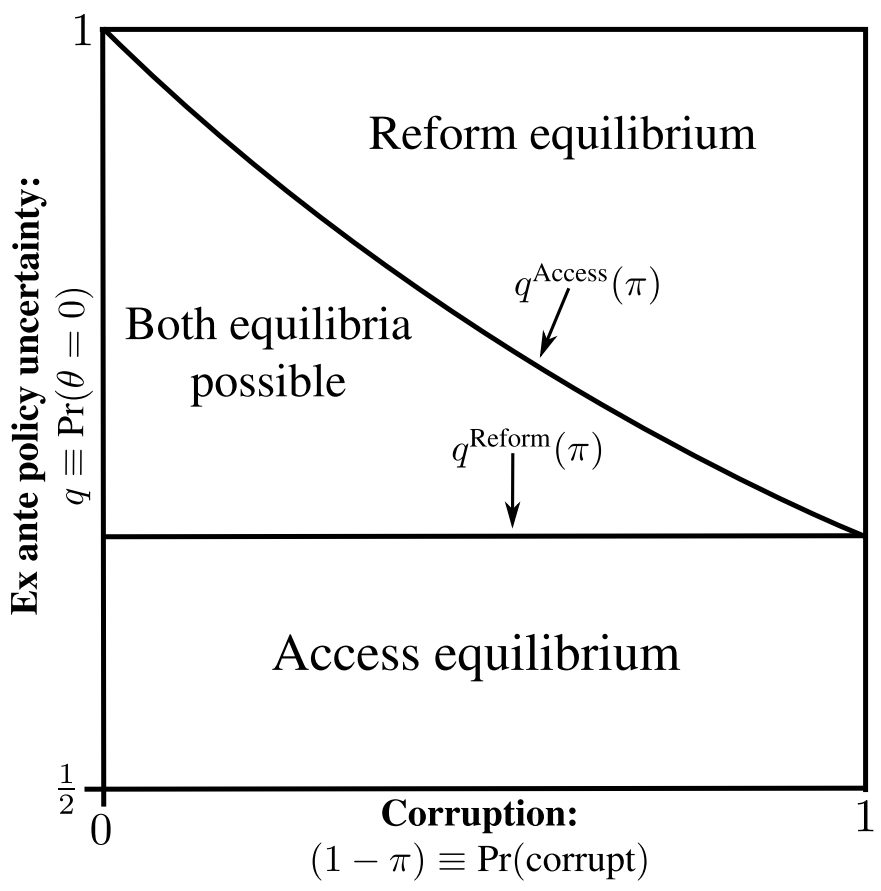

Figure 1: Equilibrium regions

Note: The $y$-axis denotes $q=\operatorname{Pr}[\theta=0]$. Policy uncertainty decreases as $q$ increases. The $x$-axis denotes $(1-\pi)=\operatorname{Pr}\left[\tau_{i}=C\right]$. Likelihood of corruption is increasing left-to-right.

Corollary 1. As $\pi \rightarrow 0$ corruption is almost certain and we have either a reform equilibrium or an access equilibrium depending on whether $q \gtrless \frac{2}{3}$. As $\pi \rightarrow 1$ there is little chance of corruption and an access equilibrium always exists, whereas a reform equilibrium only exists if $q \geq \frac{2}{3}$.

As corruption becomes increasingly likely there is little overlap in the regions that support both reform and access equilibria. That is, when it is almost certain that politicians are corrupt either there is a reform equilibrium, if $q$ is sufficiently high, or an access equilibrium, if $q$ is sufficiently low. Substantively, this implies that when information is highly valuable all politicians prefer to run on access to preserve the possibility of learning about $\theta$ from the interest group while when information is not particularly valuable, sincere politicians prefer to identify themselves by running on reform and banning group access. Conversely, as corruption becomes highly unlikely there is almost always an access equilibrium while the conditions to support a reform equilibrium remain unchanged. As it becomes more likely that all politicians are sincere there are weaker incentives 
to signal sincerity through reform. Sincere politicians and the voter prefer access to be granted for informational purposes conditional on there being no corruption in the political system. Figure 1 displays the results from Proposition 2 and Corollary 1 graphically.

\subsection{Voter welfare: when is reform better than access?}

Our analysis so far suggests that, for many situations, there are two plausible equilibria with very different political behavior. In one equilibrium, all politicians run on access, so sincere politicians will have good information if they are elected but voters cannot distinguish sincere from corrupt politicians. In another equilibrium, sincere politicians signal their types to voters by running on reform, so voters know whether or not politicians are sincere but sincere politicians lack valuable information that they could have obtained from interest groups. Thus, we turn our attention to a key normative question: under what circumstances will one equilibrium improve voter welfare relative to the other?

The welfare implications of the equilibria are not obvious because both types of equilibria provide different advantages to voters. For instance, in the case of banking regulation the voter has two interests. First, the voter may want help in distinguishing between politicians who are truly interested in which regulations most benefit consumers from those seeking private office rents. In this way, the reform equilibrium is good for the voter because it perfectly sorts these types of politicians. Second, the voter is interested in sincere politicians' ability to make good policy once in office. For this purpose, the voter would benefit from having sincere politicians and banking industry representatives in the same room to discuss market conditions and match regulations to the current economic climate. In this way, the access equilibrium is good for the voter because it allows sincere politicians to take full advantage of industry expertise when making decisions. The welfare implications of a reform versus an access equilibrium depend on the relative weight placed on these two forces, as we further explain below.

To begin the analysis, consider the voter's welfare from the reform equilibrium:

$$
W_{V}^{\text {Reform }}(p, x)=-\left(\pi^{2}+2(1-\pi) \pi\right)(1-q)-(1-\pi)^{2} q .
$$


Since the voter can perfectly infer sincerity her ex ante welfare simply depends on whether a sincere politician is running for office. This occurs with probability $\pi^{2}+2(1-\pi) \pi$. In this case the voter elects a sincere politician, but still expects policy to mismatch the state with probability $1-q$, since access was denied and the interest group cannot reveal $\theta$. With probability $(1-\pi)^{2}$ both politicians are corrupt and the winner will receive a bribe and implement $x=1$, which mismatches the state with probability $q$.

In comparison, the voter's welfare in an access equilibrium is,

$$
W_{V}^{\mathrm{Access}}(p, x)=-(1-\pi) q
$$

Since the voter cannot differentiate between sincere and corrupt politicians she elects either politician with equal probability. If the winning politician is sincere there is zero policy loss since a sincere politician that wins office learns $\theta$ from the interest group and sets policy accordingly. However, with probability $1-\pi$ the winning politician will be corrupt. In this case, the interest group bribes the corrupt politician to implement $x=1$, which in expectation does not match the state with probability $q$. Thus, the voter can expect to lose utility equal to the product of the probability a given politician is corrupt and the probability that policy will not match the state.

Taken together, these two expressions imply that a reform equilibrium is preferred to an access equilbrium from the perspective of voter welfare if,

$$
-\left(\pi^{2}+2 \pi(1-\pi)\right)(1-q)-(1-\pi)^{2} q>-(1-\pi) q
$$

Which equilibrium is preferred depends on the relative importance of screening out corruption $(\pi)$ compared to the value of information in policymaking $(q)$.

Proposition 3. Define $q^{\text {Welfare }}(\pi):=\frac{\pi-2}{2 \pi-3}$. From the perspective of ex ante voter welfare, the reform equilibrium is preferred to the access equilibrium if $q>q^{\text {Welfare }}(\pi)$, otherwise the access equilibrium is welfare-preferred to the reform equilibrium. Moreover, $\frac{d}{d \pi}\left(q^{\text {Welfare }}(\pi)\right)>0$. 


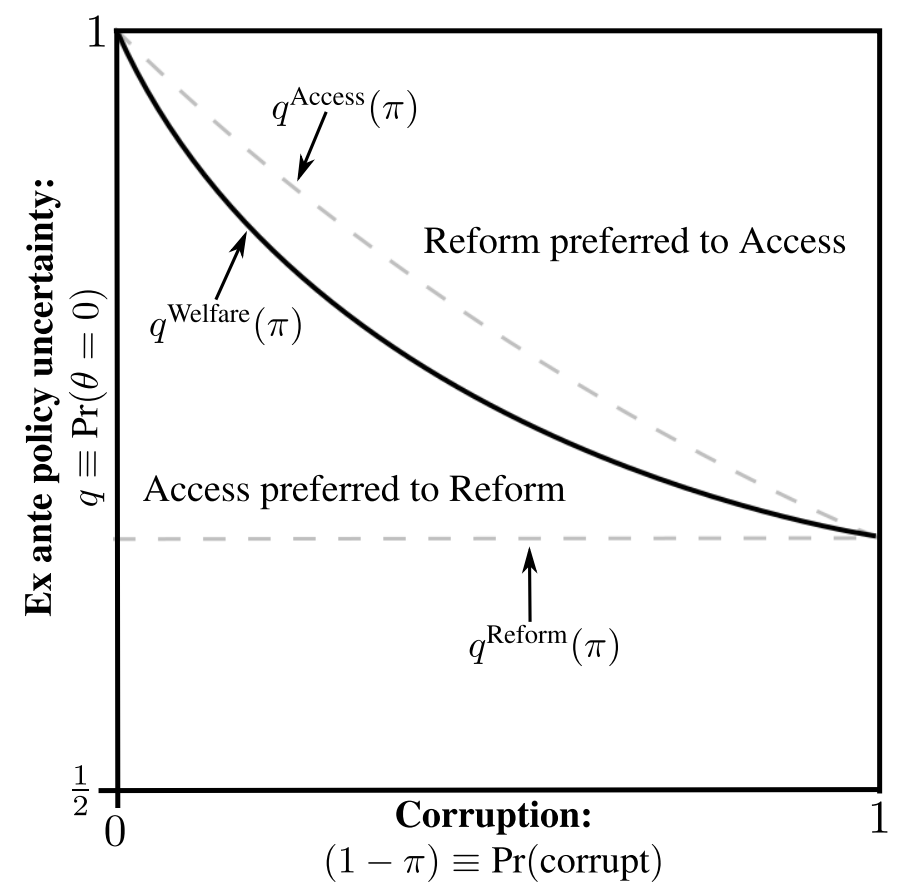

Figure 2: Voter welfare in reform versus access equilibria

Note: $q^{\text {Welfare }}(\pi):=\frac{\pi-2}{2 \pi-3}$. If $q>q^{\text {Welfare }}(\pi)$ the voter prefers reform equilibrium and if $q<$ $q^{\text {Welfare }}(\pi)$ the voter prefers access equilibrium.

Figure 2 displays the result in Proposition 3 graphically. Which equilibrium benefits the voter depends on the relationship between $q$ and $\pi$. To see the intuition behind the result consider what $q$ and $\pi$ jointly represent from the voter's perspective. When $q$ is sufficiently high information is relatively less valuable and the voter benefits from improved ability to screen politicians. Thus, the separating reform equilibrium is welfare-preferred. However, when $q$ is relatively low information is more valuable and the voter benefits from risking election of corrupt politicians in exchange for improved policymaking when sincere politicians take office. Moreover, $q^{\text {Welfare }}(\pi)$ is increasing in $\pi$, which implies that the value of information has to decrease as the threat of corruption increases for the benefits of improved screening to outweigh the benefits from informed policymaking. 


\subsection{Interest group self-regulation}

Our model provides an instrumental foundation for why interest groups may support legislation that strengthens lobbying regulations, as well as why it may be beneficial to join trade associations with more stringent internal enforcement. Since the possibility of bribery may lead sincere politicians to ban special interest participation interest groups can benefit from supporting policies that effectively remove the possibility of bribery to induce sincere politicians, whom the group wants to influence with information, to allow special interests a seat at the table. This may help explain why lobbyists themselves have at various times organized to advocate for stronger transparency and lobbying regulation (Leech, 2013, Ch. 1). When might interest groups benefit from self-regulating and committing to not bribing corrupt politicians?

In an access equilibrium the interest group never benefits from self-regulating. In this case the only thing that self-regulation does is preclude the ability to induce corrupt politicians to implement $x=1$, with no effect on sincere politicians that win office. Thus, the group only loses utility from self-regulation in an access equilibrium. However, in a reform equilibrium the interest group can benefit from policies that preclude bribery. This follows from the effects self-regulation has on sincere politician incentives. Corrupt politicians still have no strict incentive to run on reform. Sincere politicians benefit from abandoning reform and running on access when groups self-regulate because the risk of $x=1$ always being implemented due to bribery is removed. There is only upside to sincere politicians deviating to access platforms when groups self-regulate because it increases the likelihood they can match policy to the state.

Accordingly, in a reform equilibrium the interest group's choice to self-regulate depends on whether it benefits from sincere politicians running on reform or access. Consider the group's welfare if they do not self-regulate and politicians play reform equilibrium strategies,

$$
W_{G}(\text { Bribes } \mid \text { Reform })=(1-\pi)^{2}(1-\kappa) .
$$

If a sincere politician wins office then the group receives zero since in this case the politician ran 
on reform, banned group access, and always implements $x=0$. However, with probability $(1-\pi)^{2}$ both politicians are corrupt, ensuring a corrupt politician wins office. The group then bribes the politician to implement $x=1$, yielding a payoff of $1-\kappa$.

In contrast, group welfare from self-regulating and inducing access equilibrium behavior is,

$$
W_{G}(\text { No bribes } \mid \text { Access })=\pi(1-q) \text {. }
$$

In this case, either politician wins with equal probability. The winning politician is sincere with probability $\pi$ and, because the group has access, the politician implements $x(\theta)=\theta$ which benefits the group when $\theta=1$ and yields an expected payoff of $(1-q)$. If a corrupt politician wins office then the group receives zero since it cannot bribe. Combining these expressions yields the condition for the group to benefit from self-regulation,

$$
\pi(1-q)>(1-\pi)^{2}(1-\kappa)
$$

which is satisfied when $\frac{1}{2}\left(\frac{2 \kappa+q-3}{\kappa-1}-\sqrt{\frac{(q-1)(4 \kappa+q-5)}{(\kappa-1)^{2}}}\right):=\pi_{G}^{\text {Regulate }}(q, \kappa)<\pi<1$.

Proposition 4. Suppose politicians play reform equilibrium strategies when the interest group can bribe. The interest group benefits from self-regulation if $\pi>\pi_{G}^{\text {Regulate }}(q, \kappa)$. Moreover, $\pi_{G}^{\text {Regulate }}(q, \kappa)$ is increasing in $q$ and decreasing in $\kappa$.

Proposition 4 shows the interest group benefits from self-regulation when the probability of sincere politicians, $\pi$, is sufficiently high. The key trade-off for the group is having access to sincere politicians, which allows them to provide information and get their preferred policy when $\theta=1$, versus precluding their ability to bribe corrupt politicians. The less likely it is that a given politician is corrupt, the more the group benefits from self-regulation because it induces sincere politicians to grant access. Thus, so long as the probability of a politician being corrupt is sufficiently low the group prefers tying its own hands so that sincere politicians will grant access. ${ }^{13}$

\footnotetext{
${ }^{13}$ Corollary A.1 in the online appendix also provides conditions for when the interest group will self-regulate when politicians play either equilibrium with positive, complementary probability.
} 


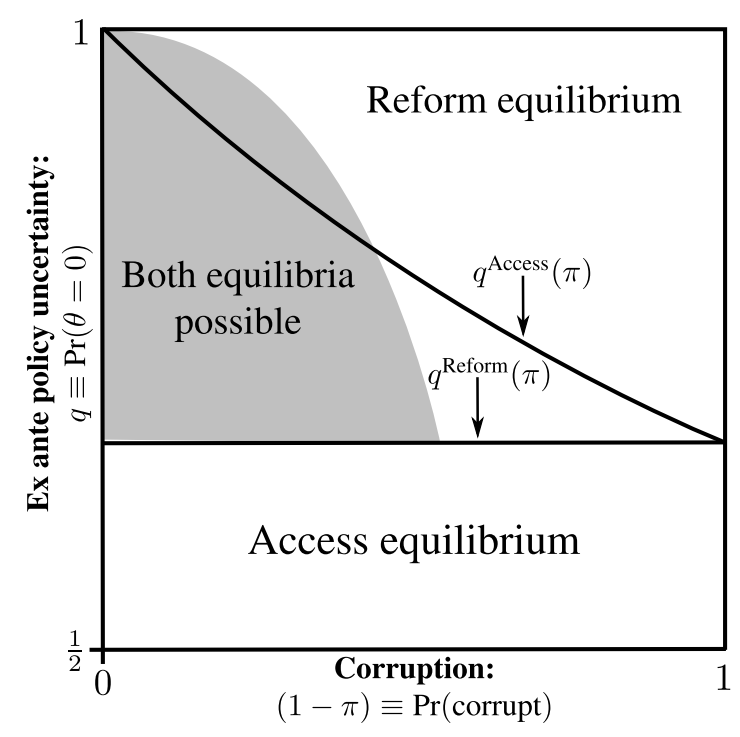

(a) Low cost of bribery: $\kappa=\frac{1}{4}$

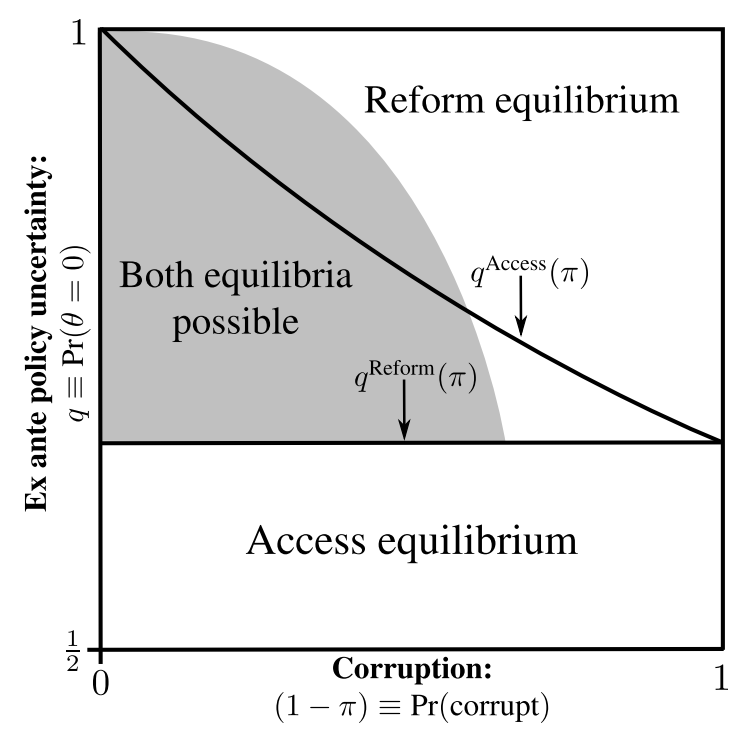

(b) High cost of bribery: $\kappa=\frac{3}{4}$

Figure 3: Interest group self-regulation

Note: Shaded areas represent regions in which the interest group benefits from self-regulation given a reform equilibrium.

Additionally, as $q$ increases the condition is less likely to be satisfied, implying that the more likely it is that $\theta$ cuts against group interests the less likely it is the group will self-regulate. Intuitively, the more costly bribery becomes the more likely it is that the group benefits from self-regulation. Figure 3 displays these intuitions graphically.

\section{Relaxing platform commitment}

In the baseline model we assumed that politicians could commit to platforms that ban interest group access following the election. While that facilitates concise communication of our main insights, full commitment is a strong assumption. In this section we relax this assumption and show that our main insights continue to hold. First, we analyze a model that replaces platform commitment with costly campaign announcements. Second, we analyze a dynamic model without campaign announcements and instead analyze incumbent choices regarding interest group access.

One related concern that is not directly addressed in the extensions below is that sincere politicians could consult with interest groups and allow them to provide information without voters 
learning they had done so. In this way the key assumption is verifiability of access rather than commitment. However, the issue of access verifiability does not pose major problems for our results. While politicians could allow interest groups to provide information without being detected, they could not act on that information without revealing they had done so. Furthermore, if these contacts are not verifiable then the voters cannot readily tell whether the politician changed her mind due to information or bribes. Thus, the possibility of clandestine interaction with interest groups does not free sincere politicians from the need for costly signaling.

\subsection{Costly campaign announcements}

In this section we analyze an alternative model that does not assume platform commitment. Instead, we model platforms as costly campaign announcements. Politician platform choice affects the cost of access that interest groups must pay to interact with incumbents. Access costs are higher when the politician in office ran on a reform platform. ${ }^{14}$ This makes platform choices costly to politicians by lowering the probability they will interact with the interest group if they take office after running on reform, which harms sincere politicians' ability to learn policy-relevant information and corrupt politicians' ability to solicit exchanges. The group's access costs can be understood as absorbing reputational costs that politicians must bear if they meet with special interests after running on reform. This is consistent with a competitive lobbying market in which interest groups subsidize any costs politicians must bear to meet with them in exchange for access.

As in the baseline model, the game begins with Nature drawing politician types and the state of the world with the same prior probabilities, $\pi=\operatorname{Pr}\left(\tau_{i}=S\right)$ and $q=\operatorname{Pr}(\theta=0)>1 / 2$. Then politicians announce reform or access platforms, $p_{i} \in\{0,1\}$, followed by the voter electing one of the politicians. In contrast to the baseline model, once a politician takes office Nature draws a cost of access, $\alpha_{G} \sim U[0, \bar{\alpha}]$ with $\bar{\alpha}>1$. This stochastic cost allows the interest group to buy access even if the winning politician ran on reform. Formally, the interest group chooses whether to access the politician $\left(a_{G}=1\right)$ or not $\left(a_{G}=0\right)$. If the group chooses $a_{G}=1$ then it pays $\left(1-p_{i}\right) \alpha_{G}$. If

\footnotetext{
${ }^{14}$ We normalize access costs to zero when the politician in office ran on an access platform. The important point is that it is more costly for interest groups to access politicians that ran on reform platforms than those that did not.
} 
the politician ran on an access platform, $p_{i}=1$, then the group can access the politician without paying $\alpha_{G}$ and if the politician ran on a reform platform, $p_{i}=0$, then the group must pay $\alpha_{G}$ for access. The likelihood that access costs will be realized low enough that the group will pay to access a politician that ran on a reform platform depends on the magnitude of the upper bound of the $\alpha_{G}$ distribution, $\bar{\alpha}$. The probability that $\alpha_{G}$ is realized low enough that the group pays to access politicians that ran on reform is decreasing as $\bar{\alpha}$ increases. ${ }^{15}$ Once a politician takes office the interest group observes his type and chooses whether to pay for access. If it does then $\theta$ is revealed and the group can choose to offer a bribe, as before. Following this interaction (or lack thereof) the politician sets policy, $x \in\{0,1\}$, as in the baseline.

Only the interest group's utility function differs from the baseline model. Incorporating the group's access choice and platform-conditional access cost its utility function is,

$$
u_{G}\left(x, \theta, b, \alpha_{G}\right)=x-a_{G}\left(1-p_{i}\right) \alpha_{G}-\kappa b .
$$

We again analyze symmetric pure strategy perfect Bayesian equilibrium.

\subsubsection{Interest group access and informed policymaking}

Politician policymaking behavior is equivalent to the baseline model. Sincere politicians match policy to the state when they learn $\theta$ and implement $x=0$ otherwise. Corrupt politicians implement $x=1$ if bribed and $x=0$ otherwise. In contrast to the baseline model, the interest group can now pay to access politicians following the election even if they ran on reform platforms.

When the winning politician ran on an access platform, access is costless. If the winner is corrupt, the interest group is strictly better off gaining accessa nd paying a bribe to induce $x=1$. If the winner is sincere then the interest group is strictly better off gaining access and providing information when $\theta=1$. When $\theta=0$ the outcome does not depend on whether or not the interest group provides information since an uninformed sincere politician would set $x=0$ anyway.

Access dynamics change when the politician in office ran on a reform platform since now the

\footnotetext{
${ }^{15}$ When $\bar{\alpha} \rightarrow \infty$ the model approaches the baseline model with full platform commitment.
} 
group must pay $\alpha_{G}$ for access. If a sincere politician wins office when $\theta=1$ the group will pay for access provided the cost of doing so does not exceed the benefit of revealing $\theta$ to induce $x=1$, which requires that $1>\alpha_{G}$. If $\theta=0$ the group strictly prefers to eschew access but if $1>\alpha_{G}$ then the politician infers $\theta$ from the group's decision not to pursue access. Thus, the sincere politician learns $\theta$ when $\alpha_{G}$ is less than 1. If a corrupt politician wins office the interest group will pay for access only if after paying $\alpha_{G}$ it can still afford to pay $\kappa$ and bribe the corrupt politician to implement $x=1$. Access is useless for the group unless it can also bribe and have their preferred policy implemented. This implies that the group pays for access to corrupt politicians only if $1>\alpha_{G}+\kappa$, which is a more demanding condition than when a sincere politician is in office.

The conditions for the group to buy access also yield the ex ante probabilities of sincere politicians learning $\theta$ and corrupt politicians being bribed after running on reform platforms. Since $\alpha_{G}$ is distributed uniform over $[0, \bar{\alpha}]$, the ex ante probability sincere politicians learn $\theta$ after running on reform is $\operatorname{Pr}\left(\alpha_{G} \leq 1 \mid \bar{\alpha}\right)=1 / \bar{\alpha}$ and the ex ante probability corrupt politicians are bribed after running on reform is $\operatorname{Pr}\left(\alpha_{G} \leq 1-\kappa \mid \bar{\alpha}, \kappa\right)=(1-\kappa) / \bar{\alpha}$. Sincere politicians have a higher probability of learning $\theta$ even after running on reform than corrupt politicians have of being bribed, which is due to the additional cost of bribery.

\subsubsection{Signaling with reform}

The reform equilibrium and access equilibrium from the baseline also exist in this model, but we can now support a third equilibrium that we refer to as an anti-interest group equilibrium. The anti-interest group equilibrium is a pooling equilibrium in which both types of politicians run on reform platforms. As before, in the reform equilibrium the voter can perfectly infer politician types and in either pooling equilibrium the voter learns nothing about politician types. Thus, equilibrium voting behavior is equivalent to the baseline model.

Reform and access equilibria. Assuming corrupt politicians run on access platforms, the incentives for sincere politicians are similar to the baseline model. When information is relatively less valuable (i.e., $q$ is sufficiently high) sincere politicians are willing to trade off the likelihood of ac- 
quiring information about $\theta$ to credibly signal their sincerity and improve their electoral prospects by running on reform platforms. Similarly, when information is relatively more valuable (i.e., $q$ is sufficiently low) sincere politicians are willing to run on access platforms and trade off their electoral prospects for learning $\theta$ when they win office. Additionally, as the probability of corruption decreases sincere politicians are more likely to value running on access platforms to increase the probability they learn $\theta$ when they win office. The magnitude of $\bar{\alpha}$ strengthens the commitmentlike properties of campaign announcements: As $\bar{\alpha}$ increases it becomes harder to support sincere politicians running on reform but easier to prevent corrupt politicians from mimicking.

In contrast to the baseline, it is not always optimal for corrupt politicians to run on access platforms since there is now a positive probability they will be bribed after running on reform. Assuming sincere politicians run on reform platforms, corrupt types would deviate and mimic sincere types by choosing reform if $\pi$ is too high relative to the likelihood of gaining access after choosing reform. If $\pi$ is large then it is likely a corrupt politician will run against a sincere politician, which leads to electoral loss. In this case corrupt politicians prefer to mimic sincere politicians to improve their probability of taking office even though it reduces the probability they will be bribed should they win. As the probability that corrupt politicians will be bribed after running on reform decreases, which occurs when $\bar{\alpha}$ and/or $\kappa$ increases, this condition is easier to satisfy.

Anti-interest group equilibrium. Finally, consider the anti-interest group equilibrium in which all politicians run on reform platforms. In this case politicians that deviate to running on access lose the election for sure since voters infer politicians that deviate to access are corrupt. Sincere politicians have no incentive to deviate to an access platform as sticking with reform preserves a positive probability of winning the election and learning $\theta$, since now the interest group may still gain access. Corrupt politicians also have no incentive to deviate since if they do they lose with certainty, cannot be bribed, and receive nothing whereas if they stick with reform then there is a positive probability of winning the election and being bribed.

In the baseline model this equilibrium was ruled out by the requirement that in equilibrium players only play weakly undominated strategies. In an environment in which sincere politicians 


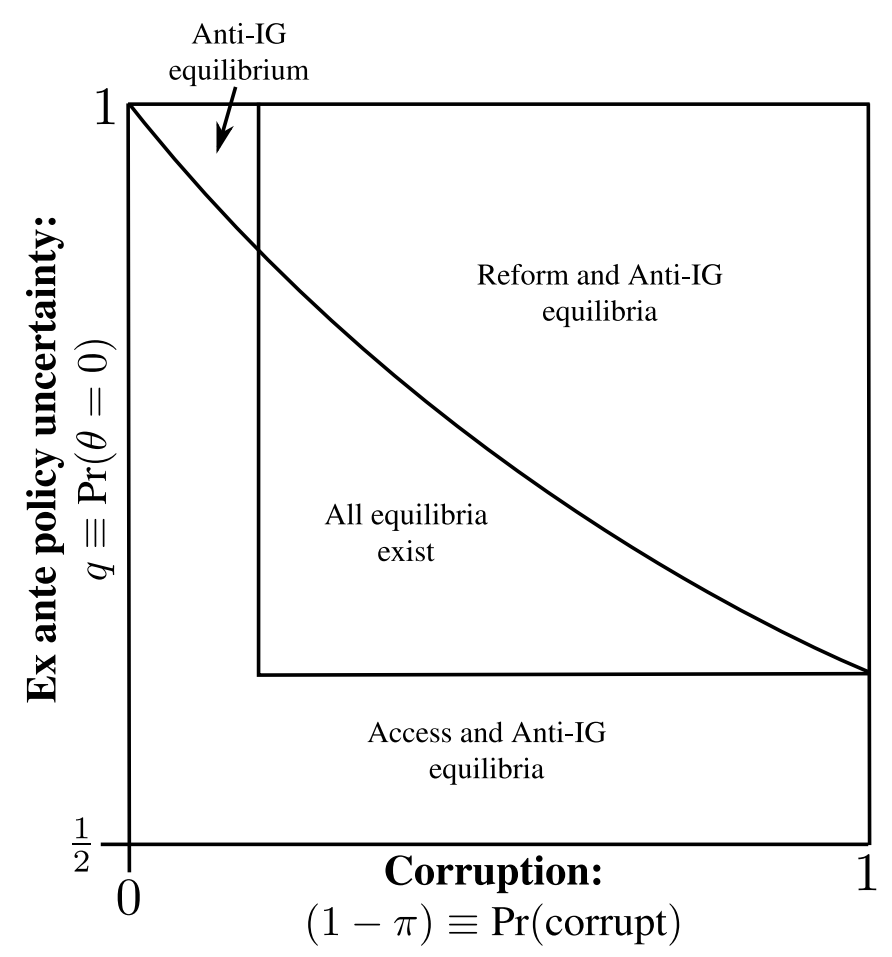

Figure 4: Equilibrium regions when $\bar{\alpha}=5$ and $\kappa=1 / 4$

ran on reform corrupt politicians were indifferent between running on a reform platform and an access platform. If they were to run on an access platform then they would lose with certainty to a sincere politician and therefore could not be bribed. If they instead ran on reform then they might win, but since running on reform is a commitment to ban group access they still could not be bribed, which rendered them indifferent. By replacing platform commitments with costly campaign announcements this model opens the door for the anti-interest group equilibrium.

Proposition 5 formalizes the preceding arguments. ${ }^{16}$ Figure 4 illustrates equilibrium regions.

Proposition 5. Define $q_{C C}^{\text {Reform }}(\bar{\alpha}):=\frac{2 \bar{\alpha}-2}{3 \bar{\alpha}-2}, \pi_{C C}^{\text {Reform }}(\bar{\alpha}, \kappa):=\frac{\bar{\alpha}+2 \kappa-2}{\bar{\alpha}+\kappa-1}, \kappa_{C C}^{\text {Reform }}(\bar{\alpha}):=\frac{2-\bar{\alpha}}{\bar{\alpha}}, \bar{\alpha}_{C C}^{\text {Access }}(\pi):=$ $\frac{2}{1+\pi}, q_{C C}^{\text {Access }}(\bar{\alpha}, \pi):=\frac{2 \bar{\alpha}-2}{3 \bar{\alpha}-2-\bar{\alpha} \pi}$, and $\kappa_{C C}^{\text {Access }}(\bar{\alpha}):=\frac{2-\bar{\alpha}}{2}$.

- A separating reform equilibrium to the costly campaign announcements game exists if $q \geq$ $q_{C C}^{R e f o r m}(\bar{\alpha}), \pi \leq \pi_{C C}^{\text {Reform }}(\bar{\alpha}, \kappa)$, and $\kappa>\kappa_{C C}^{\text {Reform }}(\bar{\alpha})$.

\footnotetext{
${ }^{16}$ Derivations of thresholds for existence can be found in online appendix B.
} 
- A pooling access equilibrium to the costly campaign announcements game exists if $\bar{\alpha} \geq$ $\bar{\alpha}_{C C}^{\text {Access }}(\pi), q<q_{C C}^{\text {Access }}(\bar{\alpha}, \pi)$, and $\kappa \geq \kappa_{C C}^{\text {Access }}(\bar{\alpha})$.

Additionally, a pooling anti-interest group equilibrium in which both sincere and corrupt politicians run on reform platforms always exists in the costly campaign announcements game.

\subsubsection{Voter welfare}

Similar to the baseline model, sometimes the voter benefits from the reform equilibrium and other times benefits from politicians pooling on campaign platforms. Proposition 6 states the main welfare result and Figure 5 provides graphical illustration.

Proposition 6. Define $\pi_{\text {Access }}^{\text {Welfare }}(\bar{\alpha}, q):=\frac{2(1-\bar{\alpha})+q(3 \bar{\alpha}-2)}{1-\bar{\alpha}+q(2 \bar{\alpha}-1)}$ and $\pi_{\text {Anti-IG }}^{\text {Welfare }}(\bar{\alpha}, q, \kappa):=\frac{1+2 q(\bar{\alpha}+\kappa-1)-\bar{\alpha}-\kappa}{1+q(2 \bar{\alpha}-1)-\bar{\alpha}}$. In terms of ex ante voter welfare, reform equilibrium is preferred to access equilibrium when both exist if $\pi<\pi_{\text {Access }}^{\text {Welfare }}(\bar{\alpha}, q)$ and reform equilibrium is preferred to anti-interest group equilibrium when both exist if $\pi>\pi_{\text {Anti-IG }}^{\text {Welfare }}(\bar{\alpha}, q, \kappa)$.

As in the baseline model, whether the voter prefers a reform or access equilibrium depends on the value of information relative to improved screening. As $q$ increases the relative value of information decreases and the voter is more likely to benefit from the improved screening facilitated by reform equilibrium. Conversely, as $q$ decreases information becomes more valuable and the voter is more likely to benefit from access equilibrium. As $\pi$ decreases it is more likely that a given politician is corrupt, which increases the likelihood the voter prefers reform equilibrium and the improved screening it provides. These dynamics are amplified by the fact that sincere politicians may learn $\theta$ even after running on reform. As $\bar{\alpha}$ decreases the probability sincere politicians learn $\theta$ after running on reform increases, which improves the likelihood the voter benefits from the reform equilibrium since she is better able to screen out corruption without sacrificing as much in terms of information. Figure 5a presents these intuitions graphically.

The implications of reform versus anti-interest group equilibria for voter welfare are two-fold. First, the reform equilibrium helps the voter screen out corrupt politicians and the anti-interest group equilibrium does not. Second, the anti-interest group equilibrium limits bribery of corrupt 


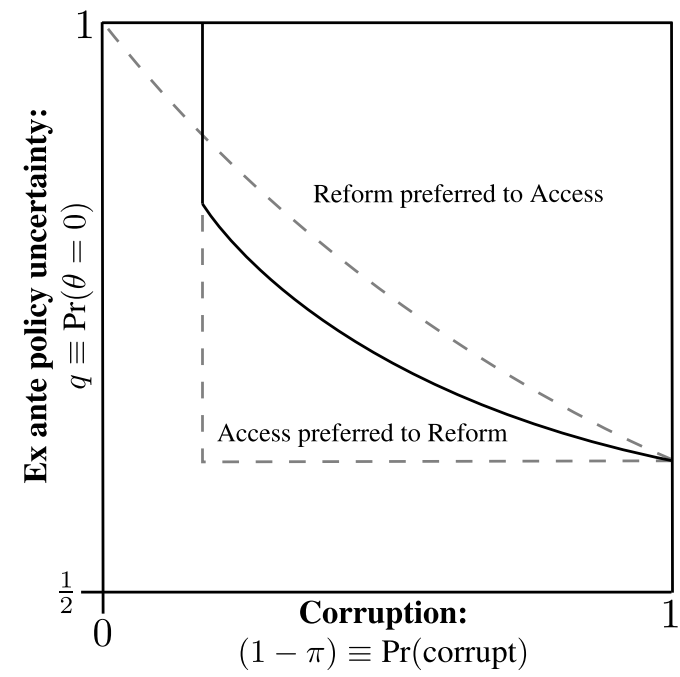

(a) Voter welfare in reform versus access equilibria

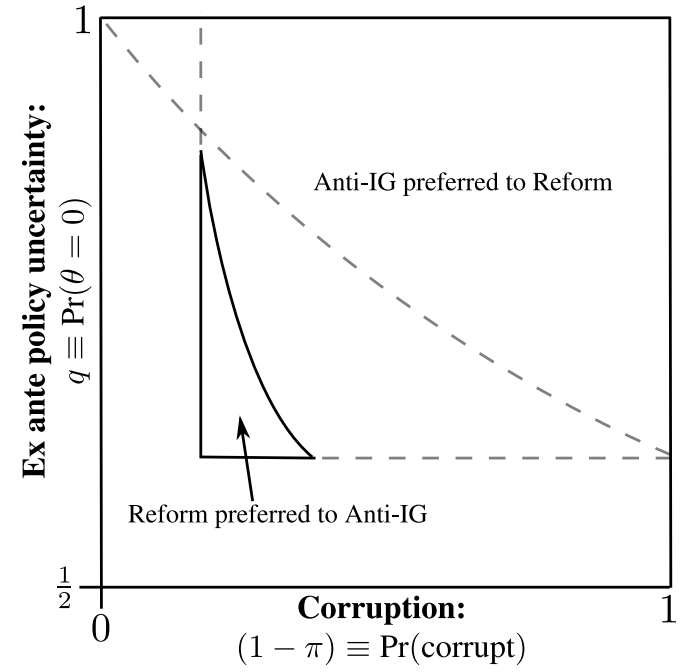

(b) Voter welfare in reform versus anti-IG equilibria

Figure 5: Voter welfare comparisons when $\bar{\alpha}=5$ and $\kappa=\frac{1}{4}$

politicians when they do take office while the reform equilibrium does not. The voter's preference between these equilibria depends on the relative importance of these two factors. When $\pi$ is large the reform equilibrium tends to be preferred because screening becomes very effective and the risk of bad behavior by corrupt politicians is relatively small. In addition, the voter is more likely to prefer the anti-interest group equilibrium as $\bar{\alpha}$ increases because it lowers the probability corrupt politicians are bribed should they win office. Figure $5 \mathrm{~b}$ illustrates these dynamics.

This model relaxed the commitment assumption from the baseline model by adding costly campaign announcements. Next we analyze a dynamic model with no campaign announcements, and therefore no commitment.

\subsection{Dynamic no-commitment game}

In this section we analyze a model of repeated elections with lobbying. This version of the model falls into the category of political agency models with adverse selection and moral hazard. ${ }^{17}$ The players are the same as in the baseline model and elections occur over an infinite horizon, with time periods indexed by $t=1,2, \ldots$. The first time period begins with a randomly selected incumbent.

\footnotetext{
${ }^{17}$ Besley (2006) provides a useful survey of political agency models.
} 
The sequence of play in each time period is as follows:

1. Nature chooses the state of the world $\theta_{t}$ for period $t$, with $\operatorname{Pr}\left[\theta_{t}=0\right]=q>\frac{1}{2}$. If the incumbent is sincere, Nature makes him corrupt with some probability $\varepsilon \in(0, \min \{\pi, 1-\pi\})$.

2. The incumbent chooses whether to grant access $\left(p_{t}=1\right)$ or not $\left(p_{t}=0\right)$.

3. The state of the world $\theta_{t}$ and the incumbent's type are revealed to the interest group. If $p_{t}=1$ then lobbying occurs. Lobbying strategies do not substantially change so we simply assume that if $p_{t}=1$ and the incumbent is sincere then $\theta$ is revealed and if $p_{t}=1$ and the incumbent is corrupt then a bribe is paid. We set $b_{t}=1$ if a bribe is offered. If $p_{t}=0$ then the game simply moves to the next step with no lobbying.

4. The incumbent chooses a policy $x_{t} \in\{0,1\}$. An outcome (i.e., the voter's utility) is $u_{V}\left(x_{t}, \theta_{t}\right)=$ $1-\left|x_{t}-\theta_{t}\right|$

5. The voter learns the incumbent's access choice. With probability $r$ she also learns the policy choice and her utility (with probability $1-r$ she learns neither policy nor her utility). ${ }^{18}$

6. Nature chooses whether the challenger is sincere (with probability $\pi$ ) or corrupt (with probability $1-\pi$ ). The voter (without observing the challenger's type) decides whether to retain the incumbent or replace her with the challenger.

Stage-game preferences are similar to the baseline model. The voter and sincere politicians receive a payoff of 1 if $\theta_{t}=x_{t}$ and 0 otherwise. ${ }^{19}$ When they are in office corrupt politicians receive a payoff of 1 if they are offered a bribe and choose the interest group's preferred policy $x=1$, and zero otherwise. An issue that did not arise in the one-shot game but is relevant to the dynamic model is what payoff politicians receive when they are not in office. We assume that, regardless of type, politicians are identical to the voter when they are not in office, receiving a

\footnotetext{
${ }^{18}$ We reveal the voter's utility every time we reveal policy choices in order to eliminate the possibility of pandering when the sincere type learns the state of the world.

${ }^{19}$ Relative to the baseline model this adds a constant of 1 to the voter's and sincere politician's payoff but represents the same preferences. This is to keep payoffs on the same scale as corrupt politicians.
} 
payoff of 1 if the policy matches the state and 0 otherwise. The results are similar if politicians receive a constant payoff once out of office. The utility of the voter and politician $i$ in time $t$ are denoted $u_{V}\left(x_{t}, \theta_{t}\right)$ and $u_{i}\left(x_{t}, \theta_{t}, b_{t}\right)$, respectively. At any time period the players maximize the discounted present value of their utilities: $\sum_{t=1}^{\infty} \delta^{t-1} u_{V}\left(x_{t}, \theta_{t}\right)$ for voters and $\sum_{t=1}^{\infty} \delta^{t-1} u_{i}\left(x_{t}, \theta_{t}, b_{t}\right)$ for politicians, where $\delta \in(0,1)$ is a discount factor. We characterize stationary perfect Bayesian equilibria in weakly undominated strategies.

Remarks on modeling assumptions. We have made two major alterations to the baseline model beyond extending the time horizon and eliminating the commitment assumption. First, we allow for the possibility that sincere politicians may be corrupted at some point in the future if they remain in office. This serves two substantive purposes. First, it captures the idea that politicians may become entrenched in powerful networks and lose sight of their constituents' welfare the longer they are in office. This effect does not need to be particularly large, and in fact we will consider what happens in the limit as the probability of this occurring goes to zero. Second, it ensures that the voters' beliefs about the incumbent's type will not be degenerate after one period of signaling. This serves the technical purpose of creating some value to signaling in each time period. It also adds to the realism of the model since it is unlikely that voters' information sets are ever so perfect that there is no more they could learn. The second purpose could also be satisfied by some other source of noise, like errors in politicians' actions or in voters' observations of those actions without much change in results.

The second departure from the baseline model is that the voter observes policy choices and outcomes with probability $r$. The purpose of this parameter is to highlight how the welfare comparisons between equilibria depend on the quality of voters' information. This also adds realism to the model: the quality of voters' information on a particular issue depends on its salience in the news media, the transparency of the policymaking process in the relevant committee or executive agency, the quality of inter-branch oversight, and a number of other variables that may change over time for reasons that are outside the model. 
Reform and access equilibria. In a reform equilibrium, sincere politicians choose $p_{t}=0$ at all $t$ and corrupt politicians choose $p_{t}=1$. This implies that the voter always learns the incumbent's type on the path of play. Therefore, the voter always retains the incumbent when $p_{t}=0$ and never retains the incumbent when $p_{t}=1$. Existence of a reform equilibrium is driven by the same factors as in the baseline: when $q$ is sufficiently high and $\pi$ sufficiently low, sincere politicians consider the risk of being replaced by a corrupt politician high enough and the returns to policy information low enough to deny access in exchange for reelection. Since there is no commitment in this game, signaling is driven by the expectation of staying in office in the future, so existence of reform equilibrium also depends on agents being sufficiently patient and on the probability that the sincere politician is corrupted while serving in office.

One key difference between the dynamic model and the baseline model is that the access equilibrium always exists. In this equilibrium profile, both politician types grant access and voter decision-making is based solely on observed policy outcomes. If the voter does not observe outcomes, which happens with probability $1-r$, then she simply retains the incumbent. If instead she does observe outcomes then she retains the incumbent when she learns her utility in that period is 1 and replaces the incumbent when she learns her utility in that period is 0 . Finally, if the voter observed an incumbent who denied access off the path-of-play, she would believe that incumbent is sincere and therefore retain. This is required by the Intuitive Criterion since denying access is equilibrium-dominated for corrupt politicians. In turn, there is no reason for either politician type to deviate from granting access. The argument for corrupt politicians in the separating equilibrium implies that they would not deviate to denying access even if it guaranteed them reelection. For sincere politicians, granting access guarantees the best policy outcome in the current period. Furthermore, since the voter updates solely on policy outcomes (and retains when she learns nothing), this guarantees reelection for sincere politicians. Thus, regardless of type, no politician has an incentive to deviate to banning access.

Proposition 7. Define $q_{D}^{\text {Reform }}(\pi, \delta, \varepsilon):=\frac{\delta(\varepsilon-1)+1}{(\delta+1)(\delta(\varepsilon-1)+1)+(\delta-1) \delta \pi}$. A separating reform equilibrium to the dynamic no-commitment game exists if $q \geq q_{D}^{\text {Reform }}(\pi, \delta, \varepsilon)$. Additionally, an access 
equilibrium always exists.

Universal existence of an access equilibrium hinges on the knife-edge assumption that the probability a challenger is sincere is the same as for incumbents. This assumption implies that the voter is indifferent between retaining and replacing the incumbent when she does not learn policy outcomes in the access equilibrium. If some incumbents were considered more likely to be corrupt than a random challenger - perhaps because politicians who serve in office longer are more likely to be corrupt - then they would not be retained in an access equilibrium when voters do not learn about outcomes prior to voting. Therefore, when $r$ is small, sincere incumbents would have a strict incentive to reveal their sincerity in order to stay in office and the access equilibrium would no longer survive the equilibrium refinements applied in the baseline model. This caveat means that the universal existence of access equilibria is not a strong positive prediction of the dynamic game. That said, since our focus is on the welfare comparisons across reform and access equilibria this case serves as a useful baseline for analyzing voter welfare.

Before turning to voter welfare comparisons we briefly discuss comparative statics on the threshold for reform equilibrium: $q_{D}^{\mathrm{Reform}}(\pi, \delta, \varepsilon)$. First, $q_{D}^{\mathrm{Reform}}(\pi, \delta, \varepsilon)$ is increasing in the probability a given incumbent is sincere, $\pi$. Since $q_{D}^{\text {Reform }}$ is a lower bound on $q$ for existence of a reform equilibrium, reform is less likely when most politicians are sincere. The reason for this is that sincere politicians are policy-motivated and therefore have a stronger desire to hold office when their opponent is more likely to be corrupt. Second, $q_{D}^{\operatorname{Reform}}(\pi, \delta, \varepsilon)$ is decreasing in $\delta$ which means reform equilibria become more likely with patience. This is because, by choosing reform, sincere politicians forgo better policymaking in the current period in order to stay in office in the future. Finally, $q_{D}^{\text {Reform }}(\pi, \delta, \varepsilon)$ is decreasing in $\varepsilon$ which means separating equilibria become more likely as sincere politicians become more likely to be corrupted in the future. The main reason for this is that forward-looking politicians weigh their potential future payoffs for becoming corrupt and accepting a bribe, which adds to the expected value of retaining office.

Voter welfare. In this section we compare voter welfare in the reform and access equilibria when both exist in the dynamic no-commitment game. As in the baseline and costly campaign 
announcement models, we show that either equilibrium may be welfare-preferred from the voter's perspective. Proposition 8 states the main welfare result. First, Proposition 8 shows that the reform equilibrium is only preferred to the access equilibrium for sufficiently high values of $q$, holding the other parameters constant. The intuition for this is similar to the intuition for the baseline model. As $q \rightarrow 1 / 2$ two things happen. First, a sincere politician who denies access is not much better than a corrupt politician who grants access. Second, information about $\theta_{t}$ becomes increasingly valuable. Both of these factors favor the access equilibrium over the reform equilibrium because learning about $\theta_{t}$ becomes relatively more valuable than screening. Conversely, as $q$ increases, screening politicians becomes very important and information about $\theta_{t}$ becomes less valuable, which favors the reform equilibrium. This logic leads to a cutoff for $q$ such that the reform equilibrium is preferred by the voter if $q$ is above the cutoff and the access equilibrium is preferred otherwise.

Additionally, Proposition 8 clarifies the impact of $r$, the probability that the voter learns the policy choice and outcome prior to the next election, on the comparison of the reform and access equilibrium. The parameter $r$ tells us how much moral hazard exists with respect to policy. As $r \rightarrow$ 0 the voter faces a severe moral hazard problem and can never update on the incumbent's type in the access equilibrium. As $r \rightarrow 1$ there is very little moral hazard and the voter can very effectively remove corrupt politicians from office in the access equilibrium. The welfare comparison of the reform and access equilibria at extreme values of $r$ follow closely from this logic. If $r=0$ the voter can only remove corrupt politicians from office through signaling with reform dynamics, so the reform equilibrium is always preferred. If $r=1$ the voter is very effective at throwing corrupt politicians out of office without signaling so the access equilibrium is always preferred.

Proposition 8. There exists a cutoff $q_{D}^{W}(\pi, \delta, \varepsilon, r)$ such that the reform equilibrium produces a higher ex ante expected utility to the voter than the access equilibrium if and only if $q \geq$ $q_{D}^{W}(\pi, \delta, \varepsilon, r)$. Furthermore, when the reform equilibrium exists, this condition always holds as $r \rightarrow 0$ and never holds as $r \rightarrow 1$.

To highlight how the dynamics of the expanded model relate to those of the baseline model, we illustrate the results by fixing parameters other than $\pi$ and $q$ and visualizing the regions under 
which reform equilibria exist and are preferred to the access equilibrium. Specifically, in Figure 6 we fix $\delta=.95$, set the value of $r$ at two different intermediate values (1/4 and 3/4), and visualize the limit of equilibria as $\varepsilon \rightarrow 0 .{ }^{20}$ The lower left region in each plot represents the lowest levels of corruption (high levels of $\pi$ ) and of policy certainty. In this region, the reform equilibrium does not exist. The upper-right regions represent the highest levels of corruption and the highest levels of certainty that $\theta_{t}=0$. In this region both equilibria exist and the reform equilibrium is preferred by the voter. The middle region represents the region for which both equilibria exist and the reform equilibrium is dominated by the access equilibrium. Consistent with our intuition from Proposition 8 about moral hazard in the access equilibrium, increasing $r$ also increases the size of the region in which the access equilibrium dominates. In the region where the access equilibrium dominates reform we can think of signaling with reform as an accountability trap. This is true despite the fact that corrupt politicians may stay in office for multiple periods in the access equilibrium and never in the reform equilibrium. The policy cost incurred in order to separate sincere from corrupt politicians is simply not worth the benefits to the voter.

The relationship between the quality of the voter's information about incumbent performance $(r)$ and the welfare effects of reform is instructive. When voters are unable to fully evaluate policy outcomes before making reelection decisions, costly signaling that harms policy information may be good for voters. Conversely, when voters can discriminate between sincere and corrupt politicians reasonably well from observing their behavior in office, the voters are better off without such signals. This can be related to policy variables such as the rate at which government audits occur. From this perspective, increasing the rate of audits (i.e., increasing $r$ ) can have two good effects for voters: the direct effect is to improve voters' information to select good politicians and the indirect effect is to reduce the need for politicians to engage in inefficient signaling.

\footnotetext{
${ }^{20}$ The equilibria are not valid if $\varepsilon=0$ since the voter's beliefs would be degenerate in the reform equilibrium after the incumbent has served one term. However, the equilibria are valid for any strictly positive $\varepsilon$ so the limit as $\varepsilon \rightarrow 0$ is well-defined.
} 


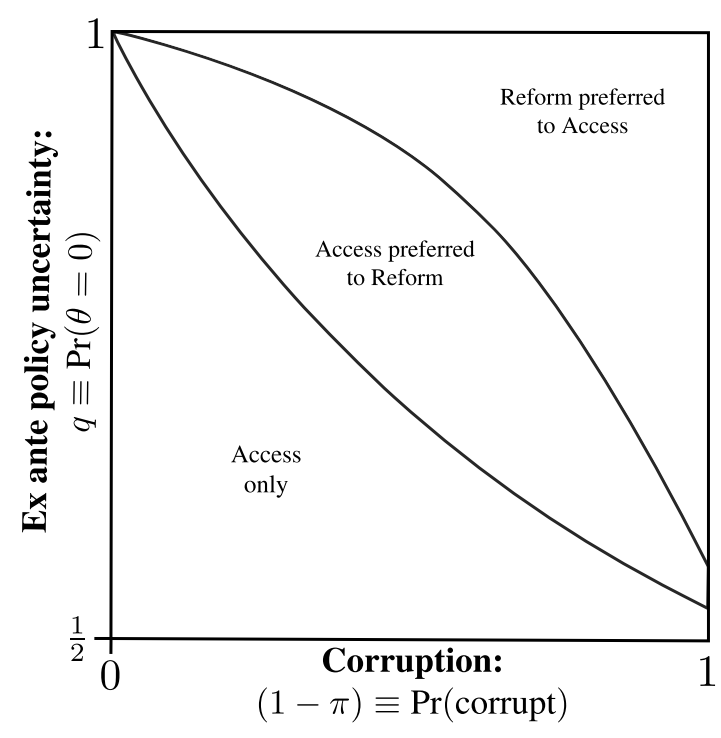

(a) Low probability of revelation: $r=\frac{1}{4}$

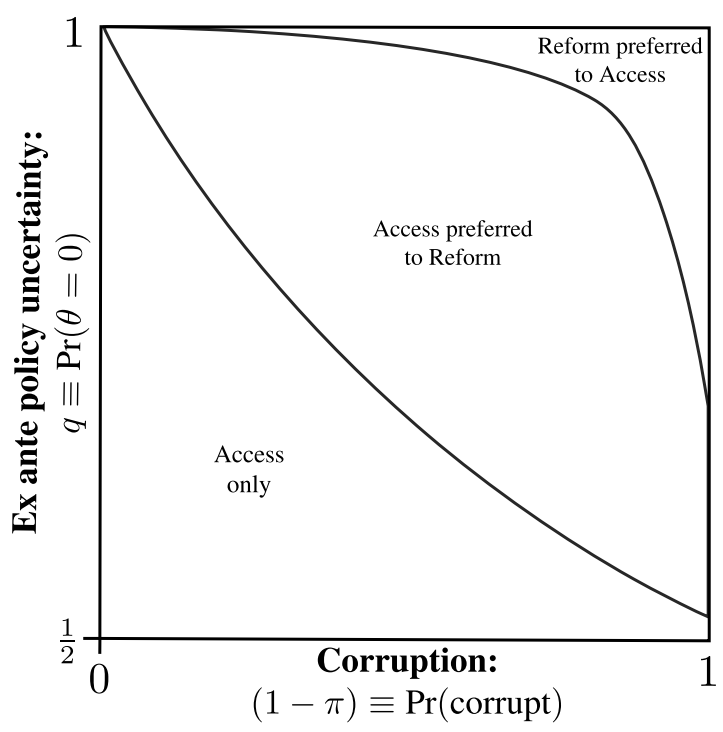

(b) High probability of revelation: $r=\frac{3}{4}$

Figure 6: Voter welfare comparisons

\section{Conclusion}

We have analyzed a series of models in which interest group influence may take two forms. If lobbying is directed toward sincere politicians then it may provide valuable policy information that benefit voters. If lobbying is directed toward corrupt politicians then it may take the form of an economic exchange that tempts the politician away from the policy most likely to benefit voters. The voter's problem is that she does not know whether a given politician is sincere or corrupt and therefore cannot always predict whether lobbying will be beneficial or harmful. This informational problem gives sincere politicians an incentive to signal their type by running on campaign platforms advocating restrictions to special interests' role in the policymaking process. Notably, equilibria of this sort exist even when the probability of corruption is quite small. Thus, our model describes one rationale for why politicians may run campaigns on their freedom from lobbyists' influence even in cases where lobbyists' influence is primarily positive. Put another way, the substantive insights we provide in this article suggest one explanation for why politicians seem to find it beneficial to run against special interests: they benefit from signaling they are not 
the sort of politicians who will be corrupted by those interests and that they share voters' concerns about the corrupting influence of those interests. Furthermore, the model shows why some reformthemed campaigns for getting money out of politics may work to the detriment of voters while others may improve their welfare by helping them select sincere politicians.

Our results highlight yet another social cost of corruption in democratic societies: the perception of corruption and the desire to signal to voters may eliminate avenues for socially productive relationships between interest groups and non-corrupt politicians. This may have particularly troubling normative consequences since institutional factors such as low legislative professionalism have been associated with higher corruption (Meier and Holbrook, 1992), as well as increased demand for information provision by interest groups (Berkman, 2001). The trade-off between preventing corruption and allowing socially productive lobbying should be an ongoing subject of theoretical and empirical research.

\section{References}

Acemoglu, Daron, Georgy Egorov and Konstantin Sonin. 2013. "A Political Theory of Populism.” Quarterly Journal of Economics 128(2): 771-805.

Ashworth, Scott and Kenneth W. Shotts. 2010. "Does Informative Media Commentary Reduce Politicians' Incentive to Pander?” Journal of Public Economics 94: 838-847.

Austen-Smith, David. 1995. "Campaign Contributions and Access.” American Political Science Review 89(3): 566-581.

Austen-Smith, David and John R. Wright. 1992. “Competitive Lobbying for a Legislator's Vote.” Social Choice and Welfare 9(3): 229-257.

Austen-Smith, David and John R. Wright. 1994. "Counteractive Lobbying." American Journal of Political Science 38(1): 25-44.

Baron, David P. 1989. “Service-Induced Campaign Contributions and the Electoral Equilibrium.” Quarterly Journal of Economics 104(1): 45-72. 
Baumgartner, Frank R., Jeffrey M. Berry, Marie Hojnacki, Beth L. Leech and David C. Kimball. 2009. Lobbying and Policy Change: Who Wins, Who Loses, and Why. Chicago, IL: University of Chicago Press.

Bennedsen, Morten and Sven E. Feldmann. 2006. "Informational Lobbying and Political Contributions." Journal of Public Economics 90(4): 631-656.

Berkman, Michael B. 2001. "Legislative Professionalism and the Demand for Groups: The Institutional Context of Interest Population Density." Legislative Studies Quarterly 26(4): 661-679.

Besley, Timothy. 2006. Principled Agents? The Political Economy of Good Government. New York, NY: Oxford University Press.

Caillaud, Bernard and Jean Tirole. 2007. "Consensus Building: How to Persuade a Group.” American Economic Review 97(5): 1877-1900.

Canes-Wrone, Brandice, Michael C. Herron and Kenneth W. Shotts. 2001. "Leadership and Pandering: A Theory of Executive Policymaking." American Journal of Political Science 45(3): $532-550$.

Cho, In-Koo and David M. Kreps. 1987. “Signaling Games and Stable Equilibria.” Quarterly Journal of Economics 102(2): 179-221.

Coate, Stephen and Stephen Morris. 1995. “On the Form of Transfers to Special Interests.” Journal of Political Economy 103(6): 1210-1235.

Cotton, Christopher. 2012. "Pay-to-Play Politics: Informational Lobbying and Contribution Limits when Money Buys Access.” Journal of Public Economics 96(3-4): 369-386.

Dahm, Matthias and Nicolás Porteiro. 2008. "Informational Lobbying Under the Shadow of Political Pressure." Social Choice and Welfare 30(4): 531-559.

Denzau, Arthur T. and Michael C. Munger. 1986. "Legislators and Interest Groups: How Unorganized Interests get Represented.” American Political Science Review 80(1): 89-106. 
Duggan, John and César Martinelli. 2015. "Electoral Accountability and Responsive Democracy." GMU Working Paper in Economics No. 15-31.

URL: https://papers.ssrn.com/sol3/papers.cfm?abstract_id=2606481

Ellis, Christopher J. and Thomas Groll. 2017. "Strategic Legislative Subsidies: Informational Lobbying and the Cost of Policy." Unpublished Manuscript. Columbia University.

Faccio, Mara. 2006. "Politically Connected Firms.” American Economic Review 96(1): 369-386.

Fisman, Raymond. 2001. "Estimating the Value of Political Connections." American Economic Review 91(4): 1095-1102.

Fowler, Anthony, Haritz Garro and Jörg L. Spenkuch. Forthcoming. "Quid Pro Quo? Corporate Returns to Campaign Contributions." Journal of Politics.

Grossman, Gene M. and Elhanan Helpman. 1994. "Protection for Sale." American Economic Review 84: 833-850.

Grossman, Gene M. and Elhanan Helpman. 2001. Special Interest Politics. Cambridge, MA: MIT Press.

Hall, Richard L. and Alan V. Deardorff. 2006. "Lobbying as Legislative Subsidy." American Political Science Review 100(1): 69-84.

Hansen, John Mark. 1991. Gaining Access: Congress and the Farm Lobby, 1919-1981. Chicago, IL: University of Chicago Press.

Lambsdorff, Johann Graf. 2012. "Behavioral and Experimental Economics as a Guidance to Anticorruption." In New Advances in Experimental Research on Corruption, edited by Danila Serra and Leonard Wantchekon, 279-300. Emerald Group Publishing.

Leech, Beth L. 2013. Lobbyists at Work. New York, NY: Springer. 
Maskin, Eric and Jean Tirole. 2004. "The Politician and the Judge: Accountability in Government." American Economic Review 94(4): 1034-1054.

McCarty, Nolan and Lawrence S. Rothenberg. 1996. "Commitment and the Campaign Contribution Contract.” American Journal of Political Science 40(3): 872-904.

Meier, Kenneth J. and Thomas M. Holbrook. 1992. ““I Seen My Opportunities and I Took 'Em:” Political Corruption in the American States.” Journal of Politics 54(1): 135-155.

Morelli, Massimo and Richard Van Weelden. 2013. "Ideology and Information in Policymaking." Journal of Theoretical Politics 25(3): 412-439.

Morris, Stephen. 2001. "Political Correctness.” Journal of Political Economy 109(2): 231-265.

Omarova, Saule T. 2010. "Rethinking the Future of Self-Regulation in the Financial Industry." Brooklyn Journal of International Law 35(3): 665-706.

Potters, Jan and Frans Van Winden. 1990. "Modelling political pressure as transmission of information.” European Journal of Political Economy 6(1): 61-88.

Potters, Jan and Frans Van Winden. 1992. “Lobbying and asymmetric information.” Public Choice 74(3): 269-292.

Prat, Andrea. 2005. “The Wrong Kind of Transparency.” American Economic Review 95(3): 862877.

Schlozman, Kay Lehman and John T. Tierney. 1986. Organized Interests and American Democracy. New York, NY: Harper \& Row.

Schnakenberg, Keith E. 2017. “Informational Lobbying and Legislative Voting.” American Journal of Political Science 61(1): 129-145. 
Wolton, Stephane. 2016. “Lobbying, Inside and Out: How Special Interest Groups Influence Policy Choices." Unpublished Manuscript. London School of Economics.

URL: https://papers.ssrn.com/sol3/papers.cfm?abstract_id=2190685

Wright, John R. 1996. Interest Groups and Congress: Lobbying, Contributions, and Influence. Boston, MA: Allyn and Bacon. 


\title{
Online Supporting Information Signaling with Reform: How the Threat of Corruption Prevents Informed Policymaking
}

\author{
Keith E. Schnakenberg* $\quad$ Ian R. Turner ${ }^{\dagger}$
}

\section{Contents}

A Baseline model $\quad 2$

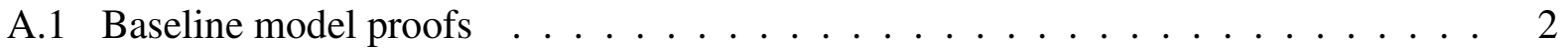

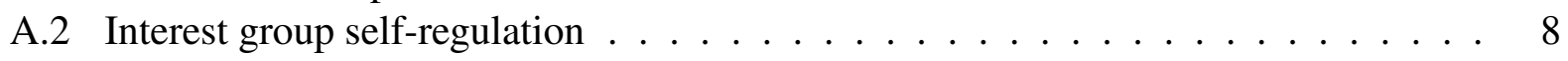

A.3 Asymmetric corruption . . . . . . . . . . . . . . . . 13

B Costly campaign announcements $r$

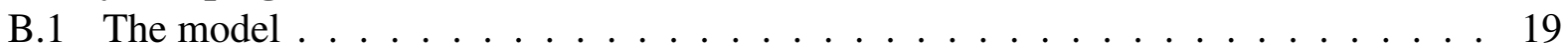

B.2 Access and policymaking . . . . . . . . . . . . . . . . 20

B.3 Signaling with reform . . . . . . . . . . . . . . 23

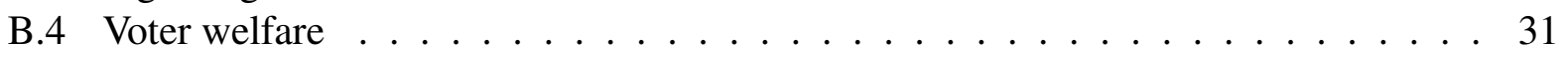

C Dynamic political agency 33

C.1 Equilibrium existence . . . . . . . . . . . . . . . . 33

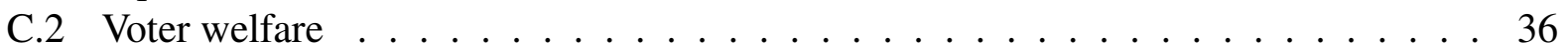

*Assistant Professor of Political Science, Washington University in St. Louis. Contact: keschnak@wustl.edu.

${ }^{\dagger}$ Assistant Professor of Political Science, Yale University. Contact: ian.turner@yale.edu. 


\section{A Baseline model}

\section{A.1 Baseline model proofs}

Proposition 1. The unique equilibrium to the lobbying stage consists of the following collection of strategies when access was granted.

- The interest group always bribes corrupt politicians, $b=1$, if possible.

- Corrupt politicians implement the interest group's preferred policy, $x=1$, only if $b=1$ and implement $x=0$ otherwise.

- Sincere politicians implement the interest group's preferred policy, $x=1$, only if they learn $\theta=1$ and implement $x=0$ otherwise.

Proof of Proposition 1. Corrupt politicians' payoffs when $b^{*}=1$ are,

$$
\begin{aligned}
u_{i}\left(x \mid \tau_{i}=C, b^{*}\right) & =b x-(1-b) x \\
& =x
\end{aligned}
$$

$u_{i}\left(x_{i}^{*}\left(b^{*}\right)=1 \mid \tau_{i}=C, b^{*}\right)=1>u_{i}\left(x_{i}\left(b^{*}\right)=0 \mid \tau_{i}=C, b^{*}\right)=0$ so he sets $x=1$. In contrast, corrupt politicians' payoffs when $b=0$ are,

$$
\begin{aligned}
u_{i}\left(x \mid \tau_{i}=C, b=0\right) & =b x-(1-b) x \\
& =-x
\end{aligned}
$$

Clearly it is optimal to set $x_{i}^{*}(b)=0$. Thus, corrupt politicians set $x_{i}^{*}(1)=1$ and $x_{i}^{*}(0)=0$.

Now consider the group's strategy when a corrupt politician wins office. Since corrupt politicians do not respond to information we need only analyze whether it is optimal for the group to bribe. The group's payoff when a corrupt politician is in office is then,

$$
u_{G}\left(b, m=0 \mid \tau_{i}=C, x_{i}^{*}\right)=x-\kappa b .
$$

If $b=1$ then $x_{i}^{*}(1)=1$. This yields $u_{G}\left(b=1, m=0 \mid \tau_{i}=C, x_{i}^{*}\right)=x-\kappa b=1-\kappa$, which is strictly positive since $\kappa \in(0,1)$. In contrast, if $b=0$ then $x_{i}^{*}(0)=0$, yielding $u_{G}\left(b=0, m=0 \mid \tau_{i}=C, x_{i}^{*}\right)=$ $x-\kappa b=0$. Thus, the group will always bribe corrupt politicians, $b^{*}\left(\tau_{i}=C\right)=1, \forall \theta$.

Sincere politician's respond to information, but not bribery. Suppose that a sincere politician wins office. Then $\theta$ is revealed due to the interest group possessing verifiable information. The 
sincere politician's payoff for matching policy to the state is,

$$
\begin{aligned}
u_{i}\left(x(\theta)=\theta \mid \tau_{i}=S, \theta\right) & =-|\theta-\theta| \\
& =0 .
\end{aligned}
$$

His analogous payoff for choosing $x(\theta) \neq \theta$ is given by,

$$
u_{i}\left(x(\theta) \neq \theta \mid \tau_{i}=S, \theta\right)=-1
$$

Clearly, it is optimal for the sincere politician to set $x(\theta)=\theta$ when he learns $\theta$. Now consider the politician's analogous payoff if he does not learn $\theta$ (i.e., does not interact with the interest group) and sets $x=0$ :

$$
\begin{aligned}
u_{i}\left(x=0 \mid \tau_{i}=S, q\right) & =q(-|0-0|)+(1-q)(-|0-1|) \\
& =-(1-q)
\end{aligned}
$$

His payoff for instead setting $x=1$ when he does not learn $\theta$ is given by,

$$
\begin{aligned}
u_{i}\left(x=1 \mid \tau_{i}=S, q\right) & =q(-|1-0|)+(1-q)(-|1-1|) \\
& =-q .
\end{aligned}
$$

Since $q>\frac{1}{2}, u_{i}\left(x=0 \mid \tau_{i}=S, a_{G}=0\right)=-(1-q)>u_{i}\left(x=1 \mid \tau_{i}=S, a_{G}=0\right)=-q$ implying that the sincere politician optimally sets $x=0$ any time he does not learn $\theta$.

Lemma A.1. The voter chooses a politician according to the following strategy,

$$
v^{*}\left(p_{A}, p_{B}\right)= \begin{cases}A & \text { if } \operatorname{Pr}\left(\tau_{A}=S \mid p_{A}, p_{B}\right)>\operatorname{Pr}\left(\tau_{B}=S \mid p_{A}, p_{B}\right), \\ B & \text { if } \operatorname{Pr}\left(\tau_{A}=S \mid p_{A}, p_{B}\right)<\operatorname{Pr}\left(\tau_{B}=S \mid p_{A}, p_{B}\right), \\ \left(\frac{1}{2} A, \frac{1}{2} B\right) & \text { if } \operatorname{Pr}\left(\tau_{A}=S \mid p_{A}, p_{B}\right)=\operatorname{Pr}\left(\tau_{B}=S \mid p_{A}, p_{B}\right) .\end{cases}
$$

Proof of Lemma A.1. We show two cases: (1) the voter does not want to deviate from voting for the politician that is more likely to be sincere, and (2) the voter does not want to deviate from voting for each politician with equal probability when she believes both are equally likely to be sincere. Denote $\hat{\pi}_{i} \equiv \operatorname{Pr}\left[\tau_{i}=S \mid p_{i}\right]$.

Case (1). In this case the voter believes that one politician is more likely to be sincere. Without loss of generality let politician $A$ be the politician the voter believes is more likely to be sincere. This implies that $p_{A} \neq p_{B}$ since if $p_{A}=p_{B}$ the voter would have learned nothing about politician types. Moreover, since $p_{i} \in\{0,1\}$ and we have restricted attention to symmetric pure strategies, 
the voter must believe that the politician more likely to be sincere is sincere with probability one while the other politician is corrupt with probability one. Thus, in this case $\operatorname{Pr}\left(\tau_{A}=S \mid p_{A}, p_{B}\right)=1$ and $\operatorname{Pr}\left(\tau_{B}=S \mid p_{A}, p_{B}\right)=0$. Suppose first that politician $A$ chose $p_{A}=0$ and politician $B$ chose $p_{B}=1$. The voter's expected payoff for electing $A$ over $B$ is,

$$
\begin{aligned}
E U_{V}\left(v=A \mid \hat{\pi}_{A}, x_{A}^{*}\right) & =-(q|0-0|+(1-q)|0-1|) \\
& =-(1-q)
\end{aligned}
$$

In contrast, her expected payoff for electing $B$ over $A$ is,

$$
\begin{aligned}
E U_{V}\left(v=B \mid \hat{\pi}_{B}, x_{B}^{*}\right) & =-|x-\theta| \\
& =-(q|1-0|+(1-q)|1-1|), \\
& =-q .
\end{aligned}
$$

Thus, it is incentive compatible to elect politician $A$ if,

$$
-(1-q) \geq-q
$$

which is satisfied since $q>\frac{1}{2}$. Now suppose that $p_{A}=1$ and $p_{B}=0$. In this case the voter's expected payoff for electing $A$ is,

$$
\begin{aligned}
E U_{V}\left(v=A \mid \hat{\pi}_{A}, x_{A}^{*}\right) & =-|\theta-\theta|, \\
& =0 .
\end{aligned}
$$

Her expected payoff for electing $B$ is,

$$
\begin{aligned}
E U_{V}\left(v=B \mid \hat{\pi}_{B}, x_{B}^{*}\right) & =-(q|0-0|+(1-q)|0-1|) \\
& =-(1-q)
\end{aligned}
$$

The voter elects $A$ if, $0 \geq-(1-q)$, which holds for all $q \in\left(\frac{1}{2}, 1\right]$. Thus, regardless of the sincere politician's platform announcement the voter never wants to deviate from electing him.

Case (2). In this case the voter believes both politicians are equally likely to be sincere. This implies $p_{A}=p_{B}$. Since the probability of a given politician being sincere is independent across politicians both politician are believed to be sincere with probability $\pi$. This implies the voter's expected payoff for electing either politician is equal. Thus, the voter has no incentive to deviate from choosing $A$ or $B$ with equal probability.

Lemma A.2. Corrupt politicians always run on access platforms in weakly undominated strate- 
gies.

Proof of Lemma A.2. When a corrupt politician runs on access there is a positive probability that he will win office, the group will pay the bribe, he will implement $x=1$, and his payoff will be strictly positive. Suppose that the corrupt politician chooses to run on reform and ban access. In that case we know $b=0$ if he wins and he will implement $x=0$. If he loses his payoff is always zero. Thus, his maximum payoff for banning access is zero, whereas, his maximum payoff for granting access is positive.

Proposition 2. Define $q^{\text {Reform }}(\pi):=\frac{2}{3}$ and $q^{\text {Access }}(\pi):=\frac{2}{3-\pi}$. Then for all $\pi \in(0,1)$ we have the following equilibria conditional on the magnitude of $q$.

- If $q^{\text {Reform }}(\pi) \leq q^{\text {Access }}(\pi)<q$ then the separating reform equilibrium is unique.

- If $q<q^{\text {Reform }}(\pi) \leq q^{\text {Access }}(\pi)$ then the pooling access equilibrium is unique.

- If $q^{\text {Reform }}(\pi)<q<q^{\text {Access }}(\pi)$ then both the separating reform and the pooling access equilibria can be supported.

Proof of Proposition 2. Lemma A.2 shows that corrupt politicians always prefer to run on access. Thus, we only need to characterize the conditions in which sincere politicians prefer to separate by running on reform and banning group access and pool by running on access. Consider the first case in which sincere politicians run on reform, $p_{i}^{*}=0$. His expected payoff in that case is given by,

$$
\begin{aligned}
E U_{i}\left(p_{i}^{*}=0 \mid \tau_{i}=S, p_{-i}\right)= & \pi\left(\frac{1}{2}(q(-|0-0|)+(1-q)(-|0-1|))\right. \\
& \left.+\frac{1}{2}(q(-|0-0|)+(1-q)(-|0-1|))\right) \\
& +(1-\pi)(q(-|0-0|)+(1-q)(-|0-1|)) \\
= & -(1-q)
\end{aligned}
$$

In contrast, consider a sincere politician's expected payoff if he deviates to $p=1$,

$$
\begin{aligned}
E U_{i}\left(p_{i}=1 \mid \tau_{i}=S, p_{-i}\right)= & \pi(q(-|0-0|)+(1-q)(-|0-1|))+(1-\pi)\left(\frac{1}{2}(q(-|0-0|)\right. \\
& \left.+(1-q)(-|1-1|))+\frac{1}{2}(q(-|1-0|)+(1-q)(-|1-1|))\right) \\
= & -\pi(1-q)-\frac{1}{2} q(1-\pi) .
\end{aligned}
$$


Given that corrupt politicians choose $p=1$ and sincere politicians play symmetric strategies, a sincere politician will run on access $(p=0)$ if,

$$
-(1-q) \geq-\pi(1-q)-\frac{1}{2} q(1-\pi)
$$

which holds for all $q \in\left[\frac{2}{3}, 1\right], \pi \in(0,1)$. Let $q^{\operatorname{Reform}}(\pi):=\frac{2}{3} . q \geq q^{\operatorname{Reform}}(\pi)$ is necessary and sufficient to support a (separating) reform equilibrium.

Now consider the following equilibrium behavior: sincere and corrupt politicians both run on access, $p=1$. Further, set off-path beliefs so that if the voter observes a deviation to $p=0$ she places full mass on that deviation being made by a sincere type. A sincere politician's payoff for pooling on $p=1$ is given by,

$$
\begin{aligned}
E U_{i}\left(p_{i}=1 \mid \tau_{i}=S, p_{-i}=1\right)= & \pi\left(\frac{1}{2}(0)+\frac{1}{2}(0)\right) \\
& +(1-\pi)\left(\frac{1}{2}(0)+\frac{1}{2}(q(-|1-0|)+(1-q)(-|1-1|))\right), \\
= & -\frac{1}{2} q(1-\pi) .
\end{aligned}
$$

Finally, consider a sincere politician's payoff for deviating to $p=0$, which ensures he will win the election with certainty,

$$
\begin{aligned}
E U_{i}\left(p_{i}=0 \mid \tau_{i}=S, p_{-i}=1\right)= & \pi(q(-|0-0|)+(1-q)(-|0-1|) \\
& +(1-\pi)(q(-|0-0|)+(1-q)(-|0-1|)), \\
= & -(1-q) .
\end{aligned}
$$

The sincere politician will pool if,

$$
-\frac{1}{2} q(1-\pi) \geq-(1-q)
$$

which is satisfied for all $\pi \in(0,1)$ when $q \in\left(\frac{1}{2}, \frac{2}{3-\pi}\right]$. Define $q^{\text {Access }}(\pi):=\frac{2}{3-\pi}$. So long as $q \leq q^{\text {Access }}(\pi)$ an access equilibrium is supported. Furthermore, since no type strictly prefers to deviate from this equilibrium to running on reform and denying access for any voter beliefs, this survives the Intuitive Criterion.

To support the uniqueness of separating equilibrium when $q^{\operatorname{Reform}}(\pi)<q^{\text {Access }}(\pi)<q$ we show that the pooling equilibrium violates the Intuitive Criterion under these circumstances. Note that (1) The corrupt type of politician should never deviate from the access equilibrium to reform since doing so yields a payoff of at most zero, which is lower than that type's expected payoff 
in the access pooling equilibrium, which gives that type a bribe with positive probability, (2) The sincere type would be willing to deviate to reform and denying access if doing so convinces the voter that he is not a corrupt type (this follows from the fact that a separating equilibrium exists). Thus, in these circumstances the pooling equilibrium violates the Intuitive Criterion.

Finally, note that $q^{\text {Access }}(\pi)=\frac{2}{3-\pi}>q^{\operatorname{Reform}}(\pi)=\frac{2}{3}$ for all $\pi \in(0,1)$. Thus, when $q \in$ $\left[q^{\operatorname{Reform}}(\pi), q^{\text {Access }}(\pi)\right]$ both the reform and access equilibrium can be supported.

Corollary 1. As $\pi \rightarrow 0$ corruption is almost certain and we have either a reform equilibrium or an access equilibrium depending on whether $q \gtrless \frac{2}{3}$. As $\pi \rightarrow 1$ there is little chance of corruption and an access equilibrium always exists, whereas a reform equilibrium only exists if $q \geq \frac{2}{3}$.

Proof of Corollary 1. As $\pi \rightarrow 0, q^{\text {Access }} \rightarrow \frac{2}{3}:=q^{\text {Reform }}$. This implies that $\left[\frac{2}{3}, \frac{2}{3-\pi}\right] \rightarrow\left[\frac{2}{3}, \frac{2}{3}\right]$. In contrast, as $\pi \rightarrow 1, q^{\text {Access }} \rightarrow 1$. This implies that $\left[\frac{2}{3}, \frac{2}{3-\pi}\right] \rightarrow\left[\frac{2}{3}, 1\right]$, which further implies that an access equilibrium always exists ( $\operatorname{since} q<1$ ) and a reform equilibrium only exists when $q \in\left(\frac{2}{3}, 1\right]$.

Proposition 3. Define $q^{\text {Welfare }}(\pi):=\frac{\pi-2}{2 \pi-3}$. From the perspective of ex ante voter welfare, the reform equilibrium is preferred to the access equilibrium if $q>q^{\text {Welfare }}(\pi)$, otherwise the access equilibrium is welfare-preferred to the reform equilibrium. Moreover, $\frac{d}{d \pi}\left(q^{\text {Welfare }}(\pi)\right)>0$.

Proof of Proposition 3. First, in a reform equilibrium the voter is able to identify sincere politicians when there is one running for office. Accordingly, if the voter elects a sincere politician then $x=0$ is implemented for sure and if she elects a corrupt politician then $x=1$ for sure. Thus, the voter's ex ante welfare in a reform equilibrium is,

$$
\begin{aligned}
W_{V}^{\text {Reform }}(p, x) & =\operatorname{Pr}\left(\tau_{A}=\tau_{B}=S\right)\left(u_{V}(x=0)\right)+\operatorname{Pr}\left(\tau_{A}=S \text { or } \tau_{B}=S\right)\left(u_{V}(x=0)\right) \\
& +\operatorname{Pr}\left(\tau_{A}=\tau_{B}=C\right)\left(u_{V}(x=1)\right), \\
& =\pi^{2}(-(1-q))+2(1-\pi) \pi(-(1-q))+(1-\pi)^{2}(-q), \\
& =-\left(\pi^{2}+2 \pi(1-\pi)\right)(1-q)-(1-\pi)^{2} q .
\end{aligned}
$$

In an access equilibrium the voter cannot differentiate between politicians. In this case sincere politicians, if elected, will always set $x=\theta$. Corrupt politicians always implement $x=1$. Since the voter elects either politician with equal probability, and receives $-q$ if a corrupt politician is 
elected and receives 0 if a sincere politician is elected we have the following welfare expression:

$$
\begin{aligned}
W_{V}^{\text {Access }}(p, x)= & \operatorname{Pr}(A \text { wins })\left(\operatorname{Pr}\left(\tau_{A}=S\right)\left(u_{V}(x=\theta)\right)+\operatorname{Pr}\left(\tau_{A}=C\right)\left(u_{V}(x=1)\right)\right) \\
& +\operatorname{Pr}(B \text { wins })\left(\operatorname{Pr}\left(\tau_{B}=S\right)\left(u_{V}(x=\theta)\right)+\operatorname{Pr}\left(\tau_{B}=C\right)\left(u_{V}(x=1)\right)\right), \\
= & \frac{1}{2}(\pi(0)+(1-\pi)(-q))+\frac{1}{2}(\pi(0)+(1-\pi)(-q)), \\
= & -(1-\pi) q .
\end{aligned}
$$

For the reform equilibrium to welfare-dominate the access equilibrium it must be that,

$$
-\left(\pi^{2}+2 \pi(1-\pi)\right)(1-q)-(1-\pi)^{2} q>-(1-\pi) q .
$$

Re-arranging in terms of $q$ yields the level of $q$ in which reform welfare-dominates access,

$$
\begin{aligned}
-\left(\pi^{2}+2 \pi(1-\pi)\right)(1-q)-(1-\pi)^{2} q & >-(1-\pi) q, \\
q(2 \pi-3)-\pi+2 & \leq 0, \\
q & \geq \frac{\pi-2}{2 \pi-3} .
\end{aligned}
$$

Define $q^{\text {Welfare }}(\pi):=\frac{\pi-2}{2 \pi-3}$. Reform equilibrium is welfare-preferred if and only if $q>q^{\text {Welfare }}$. Finally, note that

$$
\frac{d}{d \pi}\left(\frac{\pi-2}{2 \pi-3}\right)=\frac{1}{(2 \pi-3)^{2}}>0
$$

so $q^{\text {Welfare }}(\pi)$ is increasing in $\pi$.

\section{A.2 Interest group self-regulation}

In this section we explore whether and when the interest group may benefit from self-regulation. That is, when will the interest group benefit from committing ex ante to not bribing corrupt politicians? We explore this question from the perspective of interest group ex ante welfare.

Suppose that the interest group has committed to no longer bribe corrupt politicians that win office, but it can still engage in substantive lobbying. So $b=0$ always. Nothing in the policymaking stage of the game changes except that the interest group can no longer bribe corrupt politicians that have won office. Thus, corrupt politicians always implement $x=0$ since $b=0$, sincere politicians always implement $x(\theta)=\theta$ when they learn $\theta$ and $x=0$ otherwise. Similarly, the voter's voting strategy still does not change: she votes for the politician most likely to be sincere and elects either politician with equal probability when each politician is equally likely to be sincere.

To begin the analysis we first show that the interest group never benefits from committing to no bribery when the politicians play access equilibrium strategies. 
Lemma A.3. The interest group never benefits from self-regulating by committing to no bribery when politicians play access equilibrium strategies.

Proof of Lemma A.3. First, consider the interest group's welfare when there is no bribery and all politicians run on access. In this case each politician wins the election with equal probability since the voter cannot differentiate politician types. If the group cannot bribe corrupt politicians then its ex ante expected welfare in a pooling access equilibrium is given by,

$$
\begin{aligned}
W_{G}(\text { No bribes } \mid \text { Access }) & =\pi(q(0)+(1-q) 1)+(1-\pi)(0), \\
& =\pi(1-q))
\end{aligned}
$$

With probability $\pi$ the winning politician is sincere. In this case the group receives zero if $\theta=0$ and one if $\theta=1$ since $\theta$ is revealed to the politician and sets $x(\theta)=\theta$ in equilibrium. With probability $1-\pi$ the winner is corrupt, but since bribery has been banned the group can not affect the politician's implementation of $x=0$, which yields a payoff of zero. Compare this with the interest group's welfare in the pooling access equilibrium when bribing corrupt politicians is possible:

$$
\begin{aligned}
W_{G}(\text { Bribes } \mid \text { Access }) & =\pi(q(0)+(1-q) 1)+(1-\pi)(1-\kappa), \\
& =\pi(1-q)+(1-\pi)(1-\kappa) .
\end{aligned}
$$

The group's expected payoffs when a sincere politician wins are the same as above. When the winning politician is corrupt the group pays a bribe $b=1$ at cost $\kappa$, the politician implements $x=1$, and the group receives $1-\kappa$. This last component of group welfare is the difference between bribery and no bribery. That is, the net welfare from the interest group's perspective when bribery is banned is given by,

$$
\begin{aligned}
W_{G}(\text { No bribes } \mid \text { Access })-W_{G}(\text { Bribes } \mid \text { Access }) & =\pi(1-q)-\pi(1-q)-(1-\pi)(1-\kappa) \\
& =-(1-\pi)(1-\kappa) .
\end{aligned}
$$

The group derives a net benefit from being able to bribe corrupt politicians equal to $(1-\pi)(1-\kappa)$ relative to not being able to bribe when all politicians run on access. Thus, the group always prefers to retain its ability to bribe when politicians will play access equilibrium strategies for sure.

Next, we establish that when the interest group has self-regulated by committing to no bribery sincere politicians no longer have incentives to separate by running on reform platforms.

Lemma A.4. Suppose that the interest group has committed to no bribery. Then all politicians run on access platforms. 
Proof of Lemma A.4. Corrupt politicians continue to grant group access by the argument in Lemma A.2. However, the incentives for sincere politicians to separate by banning access have changed. Consider a sincere politician's expected payoff for running on reform and banning access, given that corrupt politicians run on access:

$$
\begin{aligned}
E U_{i}\left(p_{i}=0 \mid \tau_{i}=S, p_{-i}, \pi\right) & =-\pi\left(\frac{1}{2}(1-q)+\frac{1}{2}(1-q)\right)-(1-\pi)(1-q), \\
& =-(1-q)
\end{aligned}
$$

If politician $i$ faces another sincere politician then no matter who wins $x=0$ is implemented and fails to match the state with probability $1-q$. Similarly, if $i$ faces a corrupt politician then he wins for sure, but since access was banned implements $x=0$ and fails to match policy to the state with probability $1-q$. In contrast, if a sincere politician $i$ deviates to running on access then his expected payoff is given by,

$$
\begin{aligned}
E U_{i}\left(p_{i}=1 \mid \tau_{i}=S, p_{-i}, \pi\right) & =-\pi(1-q)-(1-\pi)\left(\frac{1}{2}(0)+\frac{1}{2}(1-q)\right), \\
& =-\pi(1-q)-\frac{1}{2}(1-\pi)(1-q)
\end{aligned}
$$

With probability $\pi$ the sincere politician loses for sure because he is facing another sincere politician (who is still separating) and receives an expected payoff of $-(1-q)$. With probability $1-\pi$ the other politician is corrupt and the sincere politician wins half of the time and gets to match policy to the state, but half the time he loses and because bribery is banned the corrupt winner implements $x=0$, which yields an expected payoff of $-(1-q)$. We can no longer support sincere politicians optimally separating however since,

$$
-(1-q)<-\pi(1-q)-\frac{1}{2}(1-\pi)(1-q)
$$

for all $q \in\left(\frac{1}{2}, 1\right)$ and $\pi \in(0,1)$. Thus, now that the group committed to no bribery sincere politicians will no longer separate by running on reform and banning interest group access.

To complete the proof we show that when the interest group cannot bribe, sincere politicians prefer to pool on access. If a sincere politician who is running on access faces another sincere politician also granting access then each win with probability one-half, but no matter who wins policy will ultimately match the state, yielding zero policy loss. If a sincere politician running on access faces a corrupt politician also running on access then each win with probability onehalf. If the sincere politician wins he matches policy to the state. If the corrupt politician wins he implements $x=0$ since there is no bribery. This will fail to match the state with probability $1-q$. 
The sincere politician's expected payoff for pooling by running on access is then,

$$
\begin{aligned}
E U_{i}\left(p_{i}=1 \mid \tau_{i}=S, p_{-i}, \pi\right) & =-\pi\left(\frac{1}{2}(0)+\frac{1}{2}(0)\right)-(1-\pi)\left(\frac{1}{2}(0)+\frac{1}{2}(1-q)\right) \\
& =-\frac{1}{2}(1-\pi)(1-q)
\end{aligned}
$$

A deviation to running on reform and banning access leads the sincere politician to win with certainty regardless of his opponents type, but because he banned access he always implements $x=0$ which fails to match the state with probability $1-q$. This yields an expected payoff of $E U_{i}\left(a_{i}=0 \mid \tau_{i}=S, a_{-i}, \pi\right)=-(1-q)$. Thus, sincere politicians will always run on access so long as $-\frac{1}{2}(1-\pi)(1-q)>-(1-q)$, which is satisfied for all $q \in\left(\frac{1}{2}, 1\right)$ and $\pi \in(0,1)$.

Now suppose that we are in an environment in which politicians play a separating reform equilibrium. The following result is presented in the main text - proposition 4 - and characterizes when the interest group benefits from committing ex ante to not bribing corrupt politicians that win office. Lemma A.4 implies that in that case the politicians instead play a pooling access equilibrium. Thus, the trade-off for the interest group is between continuing to be able to bribe corrupt politicians but having sincere politicians identify themselves by banning access and self-regulating so they cannot bribe corrupt winners but inducing sincere politicians to grant them access.

Proposition 4. Suppose politicians play reform equilibrium strategies when the interest group can bribe. The interest group benefits from self-regulation if $\pi>\pi_{G}^{\text {Regulate }}(q, \kappa)$. Moreover, $\pi_{G}^{\text {Regulate }}(q, \kappa)$ is increasing in $q$ and decreasing in $\kappa$.

Proof of Proposition 4. Recall from the proof of Lemma A.4 that the group's welfare from selfregulating and inducing access equilibrium politician behavior is given by,

$$
\begin{aligned}
W_{G}(\text { No bribes } \mid \text { Access }) & =\pi(q(0)+(1-q) 1)+(1-\pi)(0) \\
& =\pi(1-q)
\end{aligned}
$$

Suppose instead that the interest group were to choose to keep the ability to bribe. In this environment, when bribery is allowed, and sincere politicians run on reform and ban access, any time a sincere politician is running the voter learns who is sincere and corrupt and a sincere politician wins office. The only time a reform equilibrium with bribery aids the interest group is when two corrupt politicians run against one another since this is the only instance in which the voter will elect a corrupt politician. The group's ex ante expected welfare when bribery is allowed and politicians 
separate with their platform decisions, revealing their types, is given by,

$$
\begin{aligned}
W_{G}(\text { Bribes } \mid \text { Reform }) & =\pi^{2}(0)+(2(1-\pi) \pi)(0)+(1-\pi)^{2}(1-\kappa), \\
& =(1-\pi)^{2}(1-\kappa) .
\end{aligned}
$$

With probability $\left(\pi^{2}+2(1-\pi) \pi\right)$ a sincere politician runs for and wins office, but since that politician won office by separating and effectively banning access the group cannot lobby and therefore, $x=0$ always and the group receives zero no matter what. With probability $(1-\pi)^{2}$ both politicians running are corrupt and therefore the winning politician will be corrupt. In this case the group pays the bribe at cost $\kappa$ in exchange for implementing $x=1$, leading to a payoff of $1-\kappa$. Comparing the two welfare expressions in this case yields,

$$
W_{G}(\text { No bribes } \mid \text { Access })-W_{G}(\text { Bribes } \mid \text { Reform })=\pi(1-q)-(1-\pi)^{2}(1-\kappa)
$$

Thus, an interest group would prefer to self-regulate and "tie its own hands" by ex ante committing to no bribery in a separating reform equilibrium environment so long as,

$$
\pi(1-q)-(1-\pi)^{2}(1-\kappa)>0
$$

which is satisfied for all $q \in\left(\frac{2}{3}, 1\right)$ when $\frac{1}{2}\left(\frac{2 \kappa+q-3}{\kappa-1}-\sqrt{\frac{(q-1)(4 \kappa+q-5)}{(\kappa-1)^{2}}}\right):=\pi_{G}^{\text {Regulate }}(q, \kappa)<\pi<1$. Therefore, an interest group benefits from self-regulation in a reform equilibrium environment so long as $\pi$ is sufficiently high.

Moreover,

$$
\frac{\partial \pi_{G}^{\text {Regulate }}(q, \kappa)}{\partial q}=\frac{1}{2}\left(\frac{1}{\kappa-1}-\frac{\frac{q-1}{(\kappa-1)^{2}}+\frac{4 \kappa+q-5}{(\kappa-1)^{2}}}{2 \sqrt{\frac{(q-1)(4 \kappa+q-5)}{(\kappa-1)^{2}}}}\right)>0
$$

and

$$
\frac{\partial \pi_{G}^{\text {Regulate }}(q, \kappa)}{\partial \kappa}=\frac{1}{2}\left(\frac{2}{\kappa-1}-\frac{2 \kappa+q-3}{(\kappa-1)^{2}}-\frac{\frac{4(q-1)}{(\kappa-1)^{2}}-\frac{2(q-1)(4 \kappa+1-5)}{(\kappa-1)^{3}}}{2 \sqrt{\frac{(q-1)(4 \kappa+q-5)}{(\kappa-1)^{2}}}}\right)<0,
$$

as stated in the result.

The result in proposition 4 only directly applies when politicians play a separating reform equilibrium for sure. Much of the region in which equation (1) is satisfied is also the region in which both the reform and access equilibrium are possible. We also know that in a pooling access environment the interest group always benefits from being allowed to bribe (from lemma A.3). Thus, committing to no bribery can be beneficial in a separating equilibrium but it is costly in a pooling access equilibrium. So to fully explore when the interest group benefits from committing 
to no bribery we must take into account both possibilities. There is no prima facie reason to expect one equilibrium is more likely to obtain than the other when both are possible so we take an agnostic view and simply assign complementary probabilities to each one to represent the interest group's beliefs about which equilibrium would be played.

Corollary A.1. Suppose both the reform equilibrium and access equilibrium are possible. Define $\beta \equiv \operatorname{Pr}($ Reform equilibrium $)$ and $1-\beta \equiv \operatorname{Pr}($ Access equilbrium $)$. So long as the reform equilibrium is sufficiently likely relative to the access equilibrium the interest group will self-regulate by committing to not bribing corrupt politicians.

Proof of Corollary A.1. Lemma A.3 shows that the interest group never wants to self-regulate when politicians play access equilibrium strategies for sure. Proposition 4 shows that there are conditions in which the interest group would prefer to self-regulate and commit to no bribery when politicians play reform equilibrium strategies for sure. Continuity of the interest group's expected utilities with respect to probabilities, derived in the proof of Proposition 4, implies that if the reform equilibrium is sufficiently likely relative to the access equilibrium - i.e., $\frac{\beta}{1-\beta}$ is sufficiently large - then the interest group will still prefer to self-regulate.

\section{A.3 Asymmetric corruption}

In this section we relax the assumption that each politician is equally likely to be sincere. We prove analogous results to those presented in the main body of the paper. The main difference is that we relax our focus on symmetric strategies to mirror our relaxation of model symmetry.

Suppose that politician $A$ is more likely to be corrupt than politician $B: \pi_{A}<\pi_{B}$. This means that politician $B$ has an ex ante electoral advantage. That is, in the absence of new information the voter retains her prior beliefs that $A$ and $B$ are sincere/corrupt and therefore elects politician $B$ in that case (as opposed to each politician being elected with equal probability in the symmetric corruption model). Note also that the policymaking strategies of winning politicians and the interest group strategies are equivalent because at that point of the game politician type is revealed to the group. So nothing changes from Proposition 1 in the baseline symmetric corruption model presented in text: corrupt politicians implement $x=1$ if $b=1$ and $x=0$ otherwise, sincere politicians implement $x(\theta)=\theta$ if they learn $\theta$ and $x=0$ otherwise, and the interest group always bribes corrupt politicians when given the opportunity. Moreover, it is still optimal for the voter to elect the politician most likely to be sincere and elect either politician with equal probability when they are both equally likely to be sincere.

The results do change when analyzing politician platform decisions. We proceed in a similar manner from the analysis of the symmetric corruption model presented in the main body of the paper. Notice first that Lemma A.2 still holds in this setting. Corrupt politicians have no incentive 
to run on reform and ban access by the argument in the proof of Lemma A.2. This is true regardless of the asymmetry between $\pi_{A}$ and $\pi_{B}$ since both are still positive and less than one. We proceed by establishing the conditions for a separating reform equilibrium, a pooling access equilibrium, and equilibria in asymmetric strategies in which one politician pools on access and one separates.

Separating reform equilibrium. The following result provides the conditions required to support a reform equilibrium when $\pi_{A}<\pi_{B}$.

Proposition A.1. Suppose $\pi_{A}<\pi_{B}$. The conditions to support a separating reform equilibrium are the same as in Proposition 2 (i.e., when $\pi_{A}=\pi_{B}=\pi$ ).

Proof of Proposition A.1. Notice first that the argument in Lemma A.2 implies that corrupt politicians always run on access. So we need to show the conditions that support sincere politicians running on reform and banning access. If politician $A$ is sincere and plays the posited strategy (banning access) then he wins with probability $\frac{1}{2}$ when $B$ is sincere since both play the same separating strategy and the voter correctly believes both to be sincere. If $B$ is corrupt then $A$ wins for sure. This yields the following expected utility for banning access,

$$
\begin{aligned}
E U_{A}\left(p_{A}=0 \mid \tau_{A}=S, \pi_{B}\right) & =-\pi_{B}\left(\frac{1}{2}(1-q)+\frac{1}{2}(1-q)\right)-\left(1-\pi_{B}\right)(1-q) \\
& =-(1-q) .
\end{aligned}
$$

In contrast, if $A$ deviates to $p_{A}=1$ then he loses for sure when $B$ is sincere since the voter believes he is corrupt and wins with probability one-half if $B$ is corrupt since the voter believes both are corrupt.

$$
\begin{aligned}
E U_{A}\left(p_{A}=1 \mid \tau_{A}=S, \pi_{B}\right) & =-\pi_{B}((1-q))-\left(1-\pi_{B}\right)\left(\frac{1}{2}(0)+\frac{1}{2} q\right) \\
& =-\pi_{B}(1-q)-\frac{1}{2}\left(1-\pi_{B}\right) q
\end{aligned}
$$

This yields the following incentive compatibility condition for politician $A$ to continue to run on reform when sincere (given $B$ does the same):

$$
-(1-q)>-\pi_{B}(1-q)-\frac{1}{2}\left(1-\pi_{B}\right) q
$$

which is satisfied for all $\pi_{B} \in(0,1)$ when $q \in\left(\frac{2}{3}, 1\right)$.

Expected utility calculations for politician $B$ are exactly the same once we substitute in $\pi_{A}$ for $\pi_{B}$. This is because we are assuming that both politicians play symmetric strategies in this equilibrium even though the probabilities of being corrupt are asymmetric across politicians. 
Thus, for all $\pi_{A}, \pi_{B} \in(0,1)$ we can support a separating equilibrium where sincere politicians ban access and corrupt politicians grant access, the voter learns politician types with certainty, and elects the politician identified as sincere or elects either politician with equal probability when both are of the same type so long as $q \in\left(\frac{2}{3}, 1\right)$. This is the same condition as in the case in which both politicians are sincere with equal probability: $q>q^{\operatorname{Reform}}(\pi)$.

Pooling access equilibrium. The following result provides the conditions required to support an access equilibrium when $\pi_{A}<\pi_{B}$. In this case the conditions to support a pooling equilibrium in which all politicians grant interest group access regardless of type are more demanding.

Proposition A.2. Suppose $\pi_{A}<\pi_{B}$. Then the conditions to support an access equilibrium are more demanding than when $\pi_{A}=\pi_{B}=\pi$. Specifically, instead of $q \in\left(\frac{1}{2}, \frac{2}{3-\pi}\right)$, the relevant condition is $q \in\left(\frac{1}{2}, \frac{1}{2-\pi_{B}}\right)$ for all $\pi_{B} \in(0,1)$.

Proof of Proposition A.2. $A$ is ex ante disadvantaged: $\pi_{A}<\pi_{B}$. This implies that politician $B$ wins the election for sure when both politicians pool on access platforms because the voter retains her prior about each politician and elects politician $B$ since he is ex ante more likely to be sincere. Lemma A.2 shows that corrupt politicians always want to run on access so we show the conditions for sincere politicians to also run on access.

politician $B$ 's expected utility for running on access given that $A$ also does so regardless of type is given by,

$$
\begin{aligned}
E U_{B}\left(p_{B}^{*}=1 \mid \tau_{B}=S, \pi_{A}\right) & =-\pi_{A}(0)-\left(1-\pi_{A}\right)(0) \\
& =0 .
\end{aligned}
$$

$B$ wins the election and, because he gains access to the group, learns $\theta$, implements policy accordingly and loses nothing in utility. His expected utility for deviating to $p_{B}=0$ is given by (assuming that the voter believes deviations of this sort signal sincerity),

$$
\begin{aligned}
E U_{B}\left(p_{B}=0 \mid \tau_{B}=S, \pi_{A}\right) & =-\pi_{A}(1-q)-\left(1-\pi_{A}\right)(1-q), \\
& =-(1-q) .
\end{aligned}
$$

In this case, $B$ still wins the election for sure, ${ }^{1}$ but now because interest group access was banned through reform does not receive information regarding $\theta$, implements $x=0$, and in expectation loses one with probability $(1-q)$. Obviously in this case politician $B$ always wants to pool on $p_{B}=1$ since $0>-(1-q)$ for all $q \in\left(\frac{1}{2}, 1\right)$.

\footnotetext{
${ }^{1}$ The same Intuitive Criterion argument in the proof of Proposition 2 applies here: the voter believes that this deviation identifies the politician as sincere.
} 
Now consider the incentives for politician $A$. A's expected utility for continuing to pool on $p_{A}=1$ is given by,

$$
\begin{aligned}
E U_{A}\left(p_{A}^{*}=1 \mid \tau_{A}=S, \pi_{B}\right) & =-\pi_{B}(0)-\left(1-\pi_{B}\right)(q), \\
& =-q\left(1-\pi_{B}\right) .
\end{aligned}
$$

In this case, $A$ always loses the election, but if $B$ is a sincere type $A$ loses nothing from a policy perspective since $B$ matches policy to the state. However, when $B$ is corrupt (with probability $\left.1-\pi_{B}\right) A$ expects to lose on policy with probability $q$ since $B$ will always implement $x=1$. If $A$ deviates to $p_{A}=0$, and the voter accordingly updates that $A$ is sincere and therefore $A$ will win (again this is the only off-path belief that satisfies the Intuitive Criterion as in Proposition 2), he receives the following expected utility,

$$
\begin{aligned}
E U_{A}\left(p_{A}=0 \mid \tau_{A}=S, \pi_{B}\right) & =-\pi_{B}(1-q)-\left(1-\pi_{B}\right)(1-q), \\
& =-(1-q) .
\end{aligned}
$$

In this case politician $A$ can win the election, but this comes at the cost of information once he has won since he had to ban group access to do so. Therefore, he implements $x=0$ since $q>\frac{1}{2}$ and expects to lose on policy with probability $1-q$. Combining these two expected utility expressions yields the incentive compatibility condition for $A$ to continue to pool on the access platform:

$$
-q\left(1-\pi_{B}\right)>-(1-q)
$$

which is satisfied for all $\pi_{B} \in(0,1)$ so long as $q \in\left(\frac{1}{2}, \frac{1}{2-\pi_{B}}\right)$.

Now, the upper bound has changed from the case of symmetric corruption pooling. In that case, $q<\frac{2}{3-\pi}$ supported pooling and in this case $q<\frac{1}{2-\pi_{B}}$ is (necessary and) sufficient. Obviously, $\frac{2}{3-\pi}>\frac{1}{2-\pi_{B}}$, which highlights the fact that the conditions on $q$ to support the access equilibrium are more demanding when $\pi_{A}<\pi_{B}$. In both cases this upper bound is increasing in $\pi_{i}$. Also notice that since in this case $B$ always wants to pool when $A$ does that $\pi_{A}$ makes no difference (it does not restrict the range of parameters in which this pooling on access behavior is an equilibrium), so $\pi_{B}$ is the relevant corruption probability due to how it restricts $A$ 's behavior. That is, only the probability of $B$ being corrupt is relevant to support pooling since $A$ is the politician with the incentive to deviate to a separating strategy.

Asymmetric strategy equilibria. The following result characterizes the conditions under which the two politicians play different strategies. That is, one politician pools on the access platform while the other separates by instituting reform when sincere. We state and prove the result without 
reference to particular politician identity because the result holds for any ordering of politician identity and corruption probabilities by substituting $A$ or $B$ for $i$ or $j$. Notice that this has to do with relaxation of the symmetric strategies assumption in the model presented in the main body of the paper. This result does not depend on whether probabilities of corruption are symmetric or asymmetric. Thus, this result would also hold in the main analysis.

Proposition A.3. Suppose politicians can play asymmetric strategies. Then when $q \in\left(\frac{1}{2-\pi_{j}}, 1\right)$ we can support an equilibrium in which politician $i$ separates (as in a reform equilibrium) and politician $j$ pools (as in an access equilibrium), for all $i \neq j$.

Proof of Proposition A.3. Lemma A.2 implies that corrupt politicians always run on access so we focus on the incentives for sincere politicians. Suppose first that politician $i$ separates by choosing $p_{i}^{*}\left(\tau_{i}\right)=0$ when $\tau_{i}=S$ and $p_{A}^{*}\left(\tau_{i}\right)=1$ when $\tau_{i}=C$. Further, suppose that politician $j$ pools on access so that $p_{B}^{*}\left(\tau_{j}\right)=1$ for all $\tau_{j} \in\{S, C\}$. The voter best responds by electing politician $i$ following observation of $p_{i}^{*}=0$ and electing politician $j$ if both politicians grant access since in this case the voter correctly believes politician $i$ is corrupt while politician $j$, by virtue of pooling, is sincere with probability $\pi_{j}>0$ (i.e., the voter's prior that $j$ is sincere). If both $i$ and $j$ choose to ban access then the voter elects either with equal probability. ${ }^{2}$

First, consider politician $i$ 's expected utility for running on reform and banning access when he is sincere:

$$
\begin{aligned}
E U_{i}\left(p_{i}^{*}=0 \mid \tau_{i}=S, \pi_{j}\right) & =-\pi_{j}(1-q)-\left(1-\pi_{j}\right)(1-q), \\
& =-(1-q) .
\end{aligned}
$$

In this case $i$ always wins the election since $j$ is pooling on access and therefore $i$ is more likely to be sincere from the voter's perspective. However, since $i$ ran on reform he does not receive any information about $\theta$ from the group, implements $x=0$, and mismatches policy and the state with probability $1-q$. In contrast, politician $i$ 's expected utility for deviating to access is given by,

$$
\begin{aligned}
E U_{i}\left(p_{i}=1 \mid \tau_{i}=S, \pi_{j}\right) & =-\pi_{j}(0)-\left(1-\pi_{j}\right)(q), \\
& =-\left(1-\pi_{j}\right) q
\end{aligned}
$$

In this case $i$ loses the election for sure because the voter infers he is corrupt. He loses nothing on policy if politician $j$ is sincere, since in that case $j$ matches policy to the state. If instead politician $j$ is corrupt, then the group bribes $j$ and he implements $x=1$ for sure, which in expectation leads to a policy loss with probability $q$. Thus, politician $i$ will continue to separate when politician $j$

\footnotetext{
${ }^{2}$ The Intuitive Criterion argument in the proof of Proposition 2 implies that if $j$ deviates and runs on reform then the voter places full mass on $j$ being a sincere type.
} 
pools if,

$$
-(1-q)>-\left(1-\pi_{j}\right) q
$$

which is satisfied for all $\pi_{j} \in(0,1)$ so long as $q \in\left(\frac{1}{2-\pi_{j}}, 1\right)$.

Now, given that politician $i$ is separating what are the conditions that support politician $j$ 's pooling on access? First, consider $j$ 's expected utility when sincere of granting access given that $i$ is separating:

$$
\begin{aligned}
E U_{j}\left(p_{j}^{*}=1 \mid \tau_{j}=S, \pi_{i}\right) & =-\pi_{i}(1-q)-\left(1-\pi_{i}\right)(0), \\
& =-\pi_{i}(1-q)
\end{aligned}
$$

In this case, if $i$ is sincere $j$ will lose the election and lose policy utility according to the probability that $i$ mismatches policy to the state given that he will get no further information from the group since access was banned. If $i$ is corrupt then $j$ wins and will match policy to the state thereby losing zero in utility. In contrast, if $j$ deviates and signals $p_{j}=0$ his expected utility is,

$$
\begin{aligned}
E U_{j}\left(p_{j}=0 \mid \tau_{j}=S, \pi_{i}\right) & =-\pi_{i}\left(\frac{1}{2}(1-q)+\frac{1}{2}(1-q)\right)-\left(1-\pi_{i}\right)(1-q) \\
& =-(1-q)
\end{aligned}
$$

The voter updates that $j$ is sincere (since this is the only off-path belief that survives the Intuitive Criterion) and therefore elects $i$ and $j$ with equal probability when $i$ is sincere and also runs on reform. In this case whoever wins will mismatch policy to the state with probability $1-q$. If $i$ is corrupt and grants access then $j$ will win for sure but will not learn anything about $\theta$, implement $x=0$, and this will lead to a loss of one with probability $1-q$. Thus, when $j$ is sincere he always wants to stick to pooling on access given that $i$ is separating since $-\pi_{i}(1-q)>-(1-q)$ for all $\pi_{i} \in(0,1)$.

Overall, we have an equilibrium in which $i$ separates with platform decisions and $j$ pools on access any time that $q>\frac{1}{2-\pi_{j}}$, as stated in the result.

\section{B Costly campaign announcements}

In this section we analyze an alternative model that relaxes platform commitment from the baseline model. To do so we model platforms as costly campaign announcements. That is, in this model there is no commitment to banning interest group access should a politician run on a reform platform and win office. Instead, this platform choice affects the costs interest groups must pay to access politicians that win office. Specifically, when a politician runs on a reform platform interest 
group access costs are higher than when the politician in office ran on an access platform. ${ }^{3}$ In this sense, politician platform announcements are costly.

\section{B.1 The model}

Sequence of play. The costly campaign announcements game is similar to the baseline model. Nature first draws politician types and the state of the world: $\tau_{i} \in\{S, C\}, i \in\{A, B\}$ and $\theta \in\{0,1\}$. Prior probabilities of sincerity and that the state is zero are the same as the baseline: $\pi=\operatorname{Pr}\left(\tau_{i}=S\right)$ and $q=\operatorname{Pr}(\theta=0)>1 / 2$. Then politicians announce reform or access platforms, $p_{i} \in\{0,1\}, i \in$ $\{A . B\}$, respectively. The voter then elects one of the politicians.

The difference between the baseline and this model occurs after the election. Once a politician takes office Nature chooses a cost of access, $\alpha_{G} \sim U[0, \bar{\alpha}]$ where $\bar{\alpha}>1$. This stochastic cost allows the interest group to buy access to politicians even if they ran on reform platforms. The interest group chooses to access the politician, $a_{G} \in\{0,1\}$, and if it does, $a_{G}=1$, then it pays the cost $\left(1-p_{i}\right) \alpha_{G}$. If the politician ran on an access platform, $p_{i}=1$, then the group can access the politician without paying $\alpha_{G}$ and if the politician ran on a reform platform then the group must pay $\alpha_{G}$ to access the politician. Thus, politicians do not commit to banning access as in the baseline model. Instead, running on a reform platform makes it more costly for the group to interact with the politician.

The ex ante likelihood that access costs will be realized sufficiently low for the group to access a politician that ran on a reform platform depends on the magnitude of the upper bound of the $\alpha_{G}$ distribution, $\bar{\alpha}$. In the limit, when $\bar{\alpha} \rightarrow \infty$ this model is equivalent to the baseline model with full platform commitment. When $\bar{\alpha}$ is sufficiently low the group can always access politicians that run on reform platforms.

If the interest group pays $\alpha_{G}$ and accesses the politician, whose type the group knows, the group's private information about $\theta$ is revealed and the group can also choose to offer a bribe, as before. Following this interaction (or lack of interaction) the politician in office sets policy, $x \in\{0,1\}$, the game ends, and payoffs are realized.

Preferences and equilibrium. Only the group's utility function is altered in this set-up. Since the group now makes a choice to access politicians for a potential cost its payoff function is,

$$
u_{G}\left(x, \theta, b, \alpha_{G}\right)=x-a_{G}\left(1-p_{i}\right) \alpha_{G}-\kappa b .
$$

All other players retain their utility functions from the baseline model. We again analyze symmetric pure strategy perfect Bayesian equilibrium in weakly undominated strategies.

\footnotetext{
${ }^{3}$ As will be seen below, we normalize access costs to zero when the politician in office ran on an access platform. The important point is that it is more costly for interest groups to access politicians that ran on reform platforms than those that did not.
} 


\section{B.2 Access and policymaking}

Policymaking behavior is the same as in the baseline model, and stated in Lemma B.1.

Lemma B.1. Corrupt politicians implement $x=1$ if they are bribed and $x=0$ otherwise. Sincere politicians match policy to the state when they learn $\theta, x(\theta)=\theta$, and implement $x=0$ otherwise.

Proof of Lemma B.1. Suppose a corrupt politician wins office. If he receives a bribe then his payoffs for implementing $x=1$ and $x=0$ are given by the following expressions:

$$
\begin{aligned}
& u_{i}\left(x=1 \mid \tau_{i}=C, b=1\right)=1(1)-(1-1) 1=1, \\
& u_{i}\left(x=0 \mid \tau_{i}=C, b=1\right)=0(1)-(1-1) 0=0 .
\end{aligned}
$$

Thus, corrupt politicians always choose $x=1$ when $b=1$. If $b=0$ then the politician's analogous payoffs are given by,

$$
\begin{aligned}
& u_{i}\left(x=1 \mid \tau_{i}=C, b=0\right)=0(1)-(1-0) 1=-1 \\
& u_{i}\left(x=0 \mid \tau_{i}=C, b=0\right)=0(0)-(1-0) 0=0 .
\end{aligned}
$$

Thus, the corrupt politician always chooses $x=0$ when $b=0$.

Now consider a sincere politician. Clearly he strictly prefers to match policy to the state when he learns $\theta$ since $u_{i}\left(x(\theta)=\theta \mid \tau_{i}=S, \theta\right)=0>u_{i}\left(x(\theta)=\theta \mid \tau_{i}=S, \theta\right)=-1$. If he does not learn $\theta$ then his expected payoffs for implementing $x=0$ and $x=1$ are given by,

$$
\begin{aligned}
& E U_{i}\left(x=0 \mid \tau_{i}=S, q\right)=q(-|0-0|)+(1-q)(-|0-1|)=-(1-q), \\
& E U_{i}\left(x=1 \mid \tau_{i}=S, q\right)=q(-|1-0|)+(1-q)(-|1-1|)=-q .
\end{aligned}
$$

Since $q>1 / 2$ the sincere politician strictly prefers to set $x=0$ when he does not learn $\theta$.

In contrast to the baseline model, politicians that ran on reform platforms may interact with the interest group upon winning the election. Whether it is incentive compatible for the interest group to pay for access depends on the politician's type and the realized access cost $\alpha_{G}$. Lemma B.2 characterizes the group's equilibrium access strategy.

Lemma B.2. Suppose a type $\tau_{i}$ politician wins office after running on platform $p_{i}$. In equilibrium, the interest group makes access decisions according to the following strategy:

$a_{G}^{*}\left(\tau_{i}, p_{i}, \theta, \alpha_{G}, \kappa\right)= \begin{cases}1 \text { (Access) } & \text { if } \tau_{i}=S \text { and either } p_{i}=1 \text { or }\left\{p_{i}=0, \theta=1, \text { and } 1 \geq \alpha_{G}\right\} \\ & \text { or } \tau_{i}=C \text { and either } p_{i}=1 \text { or }\left\{p_{i}=0 \text { and } 1 \geq \alpha_{G}+\kappa\right\} \\ 0 \text { (No access }) & \text { otherwise. }\end{cases}$ 
Proof of Lemma B.2. Suppose a sincere politician won office after running on an access platform. If $\theta=0$ then the group's payoffs for paying for access and not are given by,

$$
\begin{aligned}
& u_{G}\left(a_{G}=1 \mid \tau_{i}=S, p_{i}=1, \theta=0, \alpha_{G}, x^{*}(\theta)\right)=0-1(1-1) \alpha_{G}-\kappa(0)=0, \\
& u_{G}\left(a_{G}=0 \mid \tau_{i}=S, p_{i}=1, \theta=0, \alpha_{G}, x^{*}(\theta)\right)=0-0(1-1) \alpha_{G}-\kappa(0)=0 .
\end{aligned}
$$

Thus, when $\theta=0$ and a sincere politician won office after running on an access platform the group is indifferent between paying for access and not and we can support $a_{G}=1$. Now consider the same situation with $\theta=1$. In that case the group's analogous payoffs are,

$$
\begin{aligned}
& u_{G}\left(a_{G}=1 \mid \tau_{i}=S, p_{i}=1, \theta=1, \alpha_{G}, x^{*}(\theta)\right)=1-1(1-1) \alpha_{G}-\kappa(0)=1, \\
& u_{G}\left(a_{G}=0 \mid \tau_{i}=S, p_{i}=1, \theta=1, \alpha_{G}, x^{*}(\theta)\right)=0-0(1-1) \alpha_{G}-\kappa(0)=0 .
\end{aligned}
$$

Thus, when $\theta=1$ the group strictly prefers to access a sincere politician that won office after running on an access platform.

Now suppose that a sincere politician won office after winning on a reform platform. If the group pays for access when $\theta=1$ but not when $\theta=0$, as suggested in the result, the politician learns $\theta$ and will match policy to the state, per Lemma B.1. Thus, the group's payoffs when $\theta=0$ for paying for access and not are given by,

$$
\begin{aligned}
& u_{G}\left(a_{G}=1 \mid \tau_{i}=S, p_{i}=0, \theta=0, \alpha_{G}, x^{*}(\theta)\right)=0-1(1-0) \alpha_{G}-\kappa(0)=-\alpha_{G}, \\
& u_{G}\left(a_{G}=0 \mid \tau_{i}=S, p_{i}=0, \theta=0, \alpha_{G}, x^{*}(\theta)\right)=0-0(1-0) \alpha_{G}-\kappa(0)=0 .
\end{aligned}
$$

Thus, the group never pays for access when $\theta=0$ with a sincere politician in office that ran on a reform platform. When $\theta=1$ the group's analogous payoffs are given by,

$$
\begin{aligned}
& u_{G}\left(a_{G}=1 \mid \tau_{i}=S, p_{i}=0, \theta=1, \alpha_{G}, x^{*}(\theta)\right)=1-1(1-0) \alpha_{G}-\kappa(0)=1-\alpha_{G} \\
& u_{G}\left(a_{G}=0 \mid \tau_{i}=S, p_{i}=0, \theta=1, \alpha_{G}, x^{*}(\theta)\right)=0-0(1-0) \alpha_{G}-\kappa(0)=0
\end{aligned}
$$

Thus, the group strictly prefers to pay for access when $\theta=1$ if a sincere politician won office after running on reform when $1-\alpha_{G} \geq 0$ or $1 \geq \alpha_{G}$. Taken together this implies that the group reveals $\theta$ to sincere politicians whenever the condition is satisfied.

Now suppose a corrupt politician takes office. Regardless of platform the group will not pay for access unless it would subsequently bribe the politician. If the group did not pay for access then the politician will implement $x=0$, yielding the group a payoff of zero. If the group did pay for access but then did not bribe then the politician would still implement $x=0$ but the group would still have to (potentially) pay for access yielding a payoff of either zero (if $p_{i}=1$ ) or $-\alpha_{G}$ 
(if $p_{i}=0$ ). Clearly it is weakly dominant for the group to only pay for access to corrupt politicians if they will subsequently bribe them to implement $x=1$.

Now consider the group's choice to pay for access to a corrupt politician that ran on an access platform. In this case, $\theta$ does not matter as the corrupt politician does not respond to information about the state. The group's payoff for access, given it will subsequently bribe, and not, are,

$$
\begin{gathered}
u_{G}\left(a_{G}=1 \mid \tau_{i}=C, p_{i}=1, \alpha_{G}, x^{*}(\theta), b=1\right)=1-1(1-1) \alpha_{G}-\kappa=1-\kappa, \\
u_{G}\left(a_{G}=0 \mid \tau_{i}=S, p_{i}=1, \alpha_{G}, x^{*}(\theta), b=0\right)=0-0(1-1) \alpha_{G}-\kappa(0)=0 .
\end{gathered}
$$

Thus, the group will pay for access and bribe a corrupt politician that ran on an access platform if and only if $1 \geq \kappa$, which is always satisfied since $\kappa \in(0,1)$.

Finally, consider a corrupt politician that ran on a reform platform. The group's analogous payoffs for paying for access and not are given by,

$$
\begin{gathered}
u_{G}\left(a_{G}=1 \mid \tau_{i}=C, p_{i}=0, \alpha_{G}, x^{*}(\theta), b=1\right)=1-1(1-0) \alpha_{G}-\kappa=1-\alpha_{G}-\kappa, \\
u_{G}\left(a_{G}=0 \mid \tau_{i}=S, p_{i}=0, \alpha_{G}, x^{*}(\theta), b=0\right)=0-0(1-0) \alpha_{G}-\kappa(0)=0 .
\end{gathered}
$$

Thus, the group will pay for access and bribe a corrupt politician that ran on a reform platform if and only if $1 \geq \alpha_{G}+\kappa$.

Lemma B.2 characterizes when the interest group, given policymaking behavior in Lemma B.1, will pay for access. This choice is conditional on politician type, campaign platforms, cost of access, cost of bribery and, in the case of sincere politicians, the state of the world. The essence of Lemma B.2 is that the group will pay for access whenever the realized cost $\alpha_{G}$ does not exceed the potential benefits of doing so. If $\alpha_{G}$ is too large then the group will not seek access to any politicians that ran on a reform platform, regardless of type. Since the cost is stochastic we can also utilize the results in Lemma B.2 to derive ex ante probabilities of politician-interest group interactions even when the politicians ran on reform platforms, which is important for the platform decisions analyzed below.

Corollary B.1. The ex ante probability that sincere politicians that ran on reform platforms will still learn $\theta$ is $1 / \bar{\alpha}$ and the ex ante probability that corrupt politicians that ran on reform platforms will still be bribed is $(1-\kappa) / \bar{\alpha}$.

These ex ante probabilities follow directly from the fact that access costs $\alpha_{G}$ are distributed uniform over the interval $[0, \bar{\alpha}]$ and the group's incentive compatibility conditions. That is, $\frac{1}{\bar{\alpha}}=$ $\operatorname{Pr}\left(\alpha_{G} \leq 1 \mid \bar{\alpha}\right)$, which is required for the group to pay for access to the sincere politician that ran on reform, and $\frac{1-\kappa}{\bar{\alpha}}=\operatorname{Pr}\left(\alpha_{G} \leq(1-\kappa) \mid \bar{\alpha}, \kappa\right)$, which is required for the group to pay for access to 
a corrupt politician that ran on reform. For a sincere politician this means that there is a positive probability he will learn $\theta$ even though he ran on a reform platform and for a corrupt politician it means there is a positive probability he will receive a bribe even if he ran on reform. As $\bar{\alpha}$ increases (decreases) these probabilities decrease (increase). On the extremes, as $\bar{\alpha} \rightarrow \infty$ this model approaches the baseline model in that the ex ante probability the politicians will meaningfully interact with the group if they ran on reform platforms approaches zero. As $\bar{\alpha}$ approaches its lower bound of one sincere politicians are assured to learn $\theta$ even when they ran on reform. The corrupt politician that ran on reform is never guaranteed to be able to access the group since there is still a positive probability that $\alpha_{G}>1-\kappa$ even when $\bar{\alpha}=1$. That said, the ex ante probability is maximized in that case (holding $\kappa$ fixed).

Overall, the policymaking stage of this game is similar to the baseline model. Sincere politicians still match policy to the state when they learn $\theta$ and set $x=0$ otherwise, while corrupt politicians set $x=1$ only when they are bribed. The key difference is that even when politicians run on reform platforms they may interact with the interest group following an electoral victory. The interest group is able to pay an access cost to interact with politicians, though that cost is higher when the politician in office ran on a reform platform. The group is willing to pay the costs for access if those costs are exceeded by the policy benefits the group derives from doing so.

\section{B.3 Signaling with reform}

In this section we analyze platform choices. The two types of pure strategy equilibria presented in the baseline model continue to exist in this model: reform equilibrium and access equilibrium. In addition, there is another pooling equilibrium in this model that did not exist in the baseline model in which both types of politicians run on reform platforms: the anti-interest group equilibrium.

Equilibrium voting behavior. Equivalent to the baseline model the voter attempts to elect sincere politicians.

Lemma B.3. The voter chooses a politician according to the following strategy,

$$
v^{*}\left(p_{A}, p_{B}\right)= \begin{cases}A & \text { if } \operatorname{Pr}\left(\tau_{A}=S \mid p_{A}, p_{B}\right)>\operatorname{Pr}\left(\tau_{B}=S \mid p_{A}, p_{B}\right) \\ B & \text { if } \operatorname{Pr}\left(\tau_{A}=S \mid p_{A}, p_{B}\right)<\operatorname{Pr}\left(\tau_{B}=S \mid p_{A}, p_{B}\right) \\ \left(\frac{1}{2} A, \frac{1}{2} B\right) & \text { if } \operatorname{Pr}\left(\tau_{A}=S \mid p_{A}, p_{B}\right)=\operatorname{Pr}\left(\tau_{B}=S \mid p_{A}, p_{B}\right) .\end{cases}
$$

Proof of Lemma B.3. There are two cases to show: (1) the voter does not want to deviate from voting for the politician that is more likely to be sincere, and (2) the voter does not want to deviate from voting for each politician with equal probability when she believes both are equally likely to be sincere. Denote $\hat{\pi}_{i} \equiv \operatorname{Pr}\left[\tau_{i}=S \mid p_{i}\right]$.

Case (1). In this case the voter believes that one politician is more likely to be sincere. Without 
loss of generality let politician $A$ be the politician the voter believes is more likely to be sincere. This implies that $p_{A} \neq p_{B}$ since if $p_{A}=p_{B}$ the voter would have learned nothing about politician types. Moreover, since $p_{i} \in\{0,1\}$ and we have restricted attention to symmetric pure strategies, the voter must believe that the politician more likely to be sincere is sincere with probability one while the other politician is corrupt with probability one. Thus, in this case $\operatorname{Pr}\left(\tau_{A}=S \mid p_{A}, p_{B}\right)=1$ and $\operatorname{Pr}\left(\tau_{B}=S \mid p_{A}, p_{B}\right)=0$. Suppose first that politician $A$ chose $p_{A}=0$ and politician $B$ chose $p_{B}=1$. Thus, politician $A$ will learn $\theta$ if $\alpha_{G} \leq 1$, which occur with probability $\frac{1}{\bar{\alpha}}$. The voter's expected payoff for electing $A$ over $B$ is then,

$$
\begin{aligned}
E U_{V}\left(v=A \mid \hat{\pi}_{A}, x_{A}^{*}\right) & =\frac{1}{\bar{\alpha}}(q(-|0-0|)+(1-q)(-|1-1|)) \\
& +\left(1-\frac{1}{\bar{\alpha}}\right)(q(-|0-0|)+(1-q)(-|0-1|)) \\
& =-\frac{(\bar{\alpha}-1)(1-q)}{\bar{\alpha}} .
\end{aligned}
$$

In contrast, her expected payoff for electing $B$ over $A$ is,

$$
\begin{aligned}
E U_{V}\left(v=B \mid \hat{\pi}_{A}, x_{B}^{*}\right) & =-q(|1-0|)-(1-q)(|1-1|) \\
& =-q .
\end{aligned}
$$

Thus, it is incentive compatible to elect politician $A$ if,

$$
-\frac{(\bar{\alpha}-1)(1-q)}{\bar{\alpha}} \geq-q,
$$

which is always satisfied since $q>\frac{1}{2}$ and $\bar{\alpha}>1$. Now suppose that $p_{A}=1$ and $p_{B}=0$. In this case the voter's expected payoff for electing $A$ is,

$$
\begin{aligned}
E U_{V}\left(v=A \mid \hat{\pi}_{A}, x_{A}^{*}\right) & =-|\theta-\theta|, \\
& =0 .
\end{aligned}
$$

Her expected payoff for electing $B$ given that $B$ will be bribed even though he ran on reform with 
probability $\frac{1-\kappa}{\bar{\alpha}}$ is,

$$
\begin{aligned}
E U_{V}\left(v=B \mid \hat{\pi}_{B}, x_{B}^{*}\right) & =\frac{1-\kappa}{\bar{\alpha}}(q(-|1-0|)+(1-q)(|-| 1-1 \mid)) \\
& +\left(1-\frac{1-\kappa}{\bar{\alpha}}\right)(q(-|0-0|)+(1-q)(|0-1|)), \\
& =-\left(\frac{1-\kappa}{\bar{\alpha}}\right) q-\left(\frac{\bar{\alpha}+\kappa-1}{\bar{\alpha}}\right)(1-q) .
\end{aligned}
$$

It is incentive compatible to elect politician $A$ if,

$$
0 \geq-\frac{(1-\kappa) q}{\bar{\alpha}}-\frac{(\bar{\alpha}+\kappa-1)(1-q)}{\bar{\alpha}}
$$

which is always satisfied since $\kappa \in(0,1), \bar{\alpha} \geq 1$ and $q \in\left(\frac{1}{2}, 1\right]$. Thus, regardless of the sincere politician's platform the voter never wants to deviate from electing him.

Case (2). In this case the voter believes both politicians are equally likely to be sincere. This implies $p_{A}=p_{B}$. Since the probability of a given politician being sincere is independent across politicians both politician are believed to be sincere with probability $\pi$. This implies the voter's expected payoff for electing either politician is equal. Thus, the voter has no incentive to deviate from choosing $A$ or $B$ with equal probability.

Equilibrium campaign platforms. Proposition 5 states the conditions for equilibrium existence. Ultimately, proposition 5 shows that we can support equilibria that are qualitatively similar to those in the baseline model in a similar model without platform commitment.

Proposition 5. Define $q_{C C}^{\text {Reform }}(\bar{\alpha}):=\frac{2 \bar{\alpha}-2}{3 \bar{\alpha}-2}, \pi_{C C}^{\text {Reform }}(\bar{\alpha}, \kappa):=\frac{\bar{\alpha}+2 \kappa-2}{\bar{\alpha}+\kappa-1}, \kappa_{C C}^{\text {Reform }}(\bar{\alpha}):=\frac{2-\bar{\alpha}}{\bar{\alpha}}, \bar{\alpha}_{C C}^{\text {Access }}(\pi):=$ $\frac{2}{1+\pi}, q_{C C}^{\text {Access }}(\bar{\alpha}, \pi):=\frac{2 \bar{\alpha}-2}{3 \bar{\alpha}-2-\bar{\alpha} \pi}$, and $\kappa_{C C}^{\text {Access }}(\bar{\alpha}):=\frac{2-\bar{\alpha}}{2}$.

- A separating reform equilibrium to the costly campaign announcements game exists if $q \geq$ $q_{C C}^{R e f o r m}(\bar{\alpha}), \pi \leq \pi_{C C}^{R e f o r m}(\bar{\alpha}, \kappa)$, and $\kappa>\kappa_{C C}^{\text {Reform }}(\bar{\alpha})$.

- A pooling access equilibrium to the costly campaign announcements game exists if $\bar{\alpha} \geq$ $\bar{\alpha}_{C C}^{A c c e s s}(\pi), q<q_{C C}^{A c c e s s}(\bar{\alpha}, \pi)$, and $\kappa \geq \kappa_{C C}^{A c c e s s}(\bar{\alpha})$.

Additionally, a pooling anti-interest group equilibrium in which both sincere and corrupt politicians run on reform platforms always exists in the costly campaign announcements game.

Proof of Proposition 5. Consider the environment in the reform equilibrium. Sincere politicians run on reform platforms and corrupt politicians run on access platforms. The voter can infer politician types perfectly and elects a sincere politician when one is running. 
With this in mind, the corrupt politician's payoff for running on access is,

$$
\begin{aligned}
E U_{i}\left(p_{i}=1 \mid \tau_{i}=C, b^{*}, \pi\right) & =\pi(0)+(1-\pi)\left(\frac{1}{2} b^{*}+\frac{1}{2}(0)\right) \\
& =\frac{1}{2}(1-\pi) .
\end{aligned}
$$

If the corrupt politician is running against a sincere politician he will lose for sure and receive zero since he can not be bribed. If instead he is running against another corrupt politician then he wins with probability one-half and is subsequently bribed to set $x=1$, while with complementary probability he loses and receives zero.

If the corrupt politician deviates and runs on a reform platform then his expected payoff is,

$$
\begin{aligned}
E U_{i}\left(p_{i}=0 \mid \tau_{i}=C, b^{*}, \pi\right) & =\pi\left(\frac{1}{2}\left(\frac{1-\kappa}{\bar{\alpha}}\left(b^{*}\right)\right)+\frac{1}{2}(0)\right)+(1-\pi)\left(\frac{1-\kappa}{\bar{\alpha}}\left(b^{*}\right)\right) \\
& =\frac{(1-\kappa)(2-\pi)}{2 \bar{\alpha}}
\end{aligned}
$$

If he faces a sincere politician he wins with probability one-half, in which case he will still receive a bribe with probability $(1-\kappa) / \bar{\alpha}$ and with probability one-half he loses and receives nothing. If he faces another corrupt politician he wins for sure, but is only bribed with probability $\frac{(1-\kappa)}{\bar{\alpha}}$. Combining these expected payoffs yields the incentive compatibility condition that must be satisfied for a corrupt politician to run on an access platform given that sincere politicians run on reform,

$$
\frac{1}{2}(1-\pi) \geq \frac{(1-\kappa)(2-\pi)}{2 \bar{\alpha}}
$$

This condition is satisfied for all $\bar{\alpha}>1$ so long as $\kappa>\frac{2-\bar{\alpha}}{2}$ and $\pi \leq \frac{\bar{\alpha}+2 \kappa-2}{\bar{\alpha}+\kappa-1}$. Define $\kappa^{\operatorname{Reform}}(\bar{\alpha}):=$ $\frac{2-\bar{\alpha}}{2}$ and $\pi^{\operatorname{Reform}}(\bar{\alpha}, \kappa):=\frac{\bar{\alpha}+2 \kappa-2}{\bar{\alpha}+\kappa-1}$. When $\kappa>\kappa^{\operatorname{Reform}}(\bar{\alpha})$ and $\pi \leq \pi^{\operatorname{Reform}}(\bar{\alpha}, \kappa)$ it is incentive compatible for a corrupt politician to run on access when sincere politicians run on reform. As $\kappa$ increases the corrupt politician's incentives to deviate weaken since even if he were to win by running on reform it is less likely the interest group will find bribery incentive compatible (lemma B.2). Holding other parameters fixed, as $\pi$ decreases the incentives for the corrupt politician to deviate also weaken since it is less likely he will be running against a sincere politician (which leads to electoral loss). Conversely, as $\pi$ increases the corrupt politician has stronger incentives to deviate and mimic sincere politicians since that is the only way he could win (and receive a bribe) with positive probability.

Now consider the incentives for a sincere politician. Running on a reform platform does not rule out the possibility that he will still learn $\theta$. Compared to the baseline model this leads to stronger incentives for sincere politicians to run on reform when corrupt politicians run on access. 
A sincere politician's expected payoff for running on reform is given by,

$$
\begin{aligned}
E U_{i}\left(p_{i}=0 \mid \tau_{i}=S, \theta, p_{j}, \pi\right) & =\pi\left(\frac{1}{2}\left(q(0)+(1-q)\left(\frac{1}{\bar{\alpha}}(0)+\frac{\bar{\alpha}-1}{\bar{\alpha}}(-1)\right)\right)\right. \\
& \left.+\frac{1}{2}\left(q(0)+(1-q)\left(\frac{1}{\bar{\alpha}}(0)+\frac{\bar{\alpha}-1}{\bar{\alpha}}(-1)\right)\right)\right) \\
& +(1-\pi)\left(q(0)+(1-q)\left(\frac{1}{\bar{\alpha}}(0)+\frac{\bar{\alpha}-1}{\bar{\alpha}}(-1)\right)\right) \\
& =\frac{(1-\bar{\alpha})(1-q)}{\bar{\alpha}} .
\end{aligned}
$$

If he faces another sincere politician then he wins the election with probability one-half. Should he win he will always match policy correctly when $\theta=0$ regardless of whether he learns $\theta$ from the group. If $\theta=1$ then he may learn $\theta$ from the group (with probability $\frac{1}{\alpha}$ ) in which case he will match policy to the state and lose nothing, but he may not learn $\theta$ and instead set $x=0$ by following his prior about $\theta$ and lose one from that mismatch. With probability one-half he will lose to another sincere politician, but since a sincere politician takes office he receives the same expected utility as if he had won. Finally, if the sincere politician running on reform faces a corrupt politician running on access then he will win the election for sure and have the same policy payoffs as when he wins against another sincere politician.

If the sincere politician deviates and runs on access then his expected payoffs are given by,

$$
\begin{aligned}
E U_{i}\left(p_{i}=1 \mid \tau_{i}=S, \theta, p_{j}, \pi\right) & =\pi\left(q(0)+(1-q)\left(\frac{1}{\bar{\alpha}}(0)+\frac{\bar{\alpha}-1}{\bar{\alpha}}(-1)\right)\right) \\
& +(1-\pi)\left(\frac{1}{2}(q(0)+(1-q)(0))+\frac{1}{2}(q(-1)+(1-q)(0))\right) \\
& =\pi\left(\frac{(1-\bar{\alpha})(1-q)}{\bar{\alpha}}\right)-\frac{1}{2}(1-\pi) q .
\end{aligned}
$$

When the sincere politician faces another sincere politician he loses for sure and receives policy payoffs analogous to those when he runs on his equilibrium reform platform. When he faces a corrupt politician he wins with probability one-half, in which case he learns $\theta$ and can match policy to the state since he ran on an access platform. However, he may lose to a corrupt politician, in which case the winner is bribed and the sincere politician loses one when $\theta=0$. Combining these yields the incentive compatibility condition that must be satisfied for sincere politicians to stick with running on reform when corrupt politicians run on access,

$$
\frac{(1-\bar{\alpha})(1-q)}{\bar{\alpha}} \geq \pi\left(\frac{(1-\bar{\alpha})(1-q)}{\bar{\alpha}}\right)-\frac{1}{2}(1-\pi) q .
$$


This condition is satisfied when $q \geq \frac{2 \bar{\alpha}-2}{3 \bar{\alpha}-2}$. Define $q^{\operatorname{Reform}}(\bar{\alpha}):=\frac{2 \bar{\alpha}-2}{3 \bar{\alpha}-2}$ as the lower bound on $q$ such that a sincere politician will continue to run on reform when corrupt politicians run on access. Note that $\frac{d q^{\text {Reform }}(\bar{\alpha})}{d \bar{\alpha}}>0$ so the lower bound on $q$ that supports sincere politician's running on reform is increasing in $\bar{\alpha}$, which implies that it is increasing as the likelihood of learning $\theta$ even after running on reform decreases. Moreover, $q^{\operatorname{Reform}}(\bar{\alpha}) \rightarrow 2 / 3$ as $\bar{\alpha} \rightarrow \infty$, which highlights that as $\bar{\alpha}$ grows arbitrarily large the reform equilibrium in this model is equivalent to the analogous equilibrium of the baseline model.

Now consider the other equilibrium from the baseline model: the pooling access equilibrium. Both types of politicians run on access platforms, which implies that the voter is unable to distinguish politician types and therefore elects either politician with equal probability. Additionally, the off-path beliefs that support this equilibrium are such that a deviation to a reform platform leads the voter to place full mass on the deviating politician being a sincere type. This implies that a deviation to reform leads the deviating politician to be elected with certainty.

First consider a corrupt politician. Given that sincere politicians also run on access platforms, a corrupt politician's expected payoff for running on access is given by,

$$
\begin{aligned}
E U_{i}\left(p_{i}=1 \mid \tau_{i}=C, p_{j}^{*}, \pi\right) & =\pi\left(\frac{1}{2} b^{*}+\frac{1}{2}(0)\right)+(1-\pi)\left(\frac{1}{2} b^{*}+\frac{1}{2}(0)\right) \\
& =\frac{1}{2}
\end{aligned}
$$

Regardless of whether he runs against a sincere politician or another corrupt politician he wins with probability one-half since the voter does not learn politician types. If he wins then he is bribed, implements $x=1$, and receives a payoff of one. If he loses then he is not bribed and receives nothing. Thus, his expected payoff is just the ex ante probability he wins, which is one-half.

If instead the corrupt politician deviates to running on reform then the voter updates that he is sincere and he wins the election with certainty. However, he has decreased the likelihood that he will be bribed by running on reform, which yields an expected payoff of,

$$
\begin{aligned}
E U_{i}\left(p_{i}=0 \mid \tau_{i}=C, p_{j}^{*}, \kappa, \bar{\alpha}\right) & =\pi\left(\frac{1-\kappa}{\bar{\alpha}}\left(b^{*}\right)+\frac{\bar{\alpha}+\kappa-1}{\bar{\alpha}}(0)\right)+(1-\pi)\left(\frac{1-\kappa}{\bar{\alpha}}\left(b^{*}\right)+\frac{\bar{\alpha}+\kappa-1}{\bar{\alpha}}(0)\right) \\
& =\frac{1-\kappa}{\bar{\alpha}}
\end{aligned}
$$

Regardless of the other politician's type the corrupt politician wins the election since he ran on reform and the voter believes he is sincere. However, he can only be bribed if the group's access costs, combined with the cost of bribery $\kappa$, is realized sufficiently low, which, from Lemma B.2, occurs with ex ante probability $\frac{1-\kappa}{\bar{\alpha}}$. The product of this probability and the benefit from being bribed, which is one, yields the corrupt politician's expected payoff for this deviation. Combining 
these expected payoffs provides the incentive compatibility condition that must hold for the corrupt politician to stick with running on access when sincere politicians also run on access,

$$
\frac{1}{2} \geq \frac{1-\kappa}{\bar{\alpha}}
$$

This condition is satisfied so long as $\kappa \geq \frac{2-\bar{\alpha}}{2}$. Define $\kappa^{\text {Access }}(\bar{\alpha}):=\frac{2-\bar{\alpha}}{2}$ as the threshold on $\kappa$ such that if $\kappa \geq \kappa^{\text {Access }}(\bar{\alpha})$ then a corrupt politician will continue to run on access when sincere politicians run on access. The likelihood that this condition is satisfied is increasing in both $\bar{\alpha}$, since the lower bound on $\kappa$ is decreasing in $\bar{\alpha}$, and $\kappa .{ }^{4}$ The intuition for this dynamic is that the likelihood of a corrupt politician being bribed after running on reform is decreasing in both $\bar{\alpha}$ and $\kappa$. A larger $\bar{\alpha}$ raises the probability that realized access costs $\alpha_{G}$ will be too large for the group to pay. A larger $\kappa$ directly reduces the likelihood that the group will bribe a corrupt politician that ran on reform due to increasing costs of doing so. Thus, once either $\bar{\alpha}$ or $\kappa$ becomes too large $(\bar{\alpha}>2$ or $\kappa>1 / 2$ ) there is no incentive for the corrupt politician to deviate to reform even though that would lead to his taking office for sure. Once again, this highlights the fact that this model without platform commitment approximates the baseline model with full commitment as $\bar{\alpha}$ increases and, in the case of corrupt politicians in particular, as bribery becomes more expensive.

Now consider the incentives for sincere politicians in this environment. The upside for sincere politicians is that if they win they will learn $\theta$ for sure since they ran on access platforms. The downside risk is that since they have not identified themselves as sincere to the voter that a corrupt politician may take office. A sincere politician's expected payoff for running on access given that all other politicians do as well is given by,

$$
\begin{aligned}
E U_{i}\left(p_{i}=1 \mid \tau_{i}=S, p_{j}^{*}, \theta, \pi\right) & =\pi\left(\frac{1}{2}(0)+\frac{1}{2}(0)\right)+(1-\pi)\left(\frac{1}{2}(0)+\frac{1}{2}(q(-1)+(1-q)(0))\right) \\
& =-\frac{1}{2}(1-\pi) q
\end{aligned}
$$

If the sincere politician faces another sincere politician then regardless of who wins, they learn $\theta$ and match policy to the state, yielding no policy losses. If instead he faces a corrupt politician then when he wins (with probability one-half) he learns $\theta$ and loses nothing, but if the corrupt politician takes office and gets bribed then the sincere politician loses utility when $\theta=0$, which yields overall expected losses of $\frac{1}{2}(1-\pi) q$.

If instead the sincere politician deviates to running on reform then he will win the election with certainty, but will also lower the likelihood that he learns $\theta$ from the interest group. His expected

\footnotetext{
${ }^{4}$ In fact, once $\bar{\alpha}$ is larger than two the condition is trivially satisfied since $\kappa>0$. Similarly, once $\kappa>\frac{1}{2}$ the condition is trivially satisfied since $\frac{2-\bar{\alpha}}{2} \rightarrow 1 / 2$ as $\bar{\alpha} \rightarrow 1$ (its lower bound).
} 
payoffs in this case are given by,

$$
\begin{aligned}
E U_{i}\left(p_{i}=0 \mid \tau_{i}=S, p_{j}^{*}, \theta, \bar{\alpha}\right) & =\pi\left(q(0)+(1-q)\left(\frac{1}{\bar{\alpha}}(0)+\frac{\bar{\alpha}-1}{\bar{\alpha}}(-1)\right)\right) \\
& +(1-\pi)\left(q(0)+(1-q)\left(\frac{1}{\bar{\alpha}}(0)+\frac{\bar{\alpha}-1}{\bar{\alpha}}(-1)\right)\right) \\
& =\frac{(1-\bar{\alpha})(1-q)}{\bar{\alpha}} .
\end{aligned}
$$

Regardless of the type of opponent, the sincere politician that deviates to reform wins with certainty. When $\theta=0$ policy will match the state whether or not he learns $\theta$ since he either follows his information or, when he does not learn $\theta$, he always sets $x=0$ following his prior. When $\theta=1$ he only matches policy to the state if he learns $\theta$, which happens with probability $1 / \bar{\alpha}$, and otherwise he mismatches and loses one. Combining these expected payoffs yields the incentive compatibility condition that must be satisfied for the sincere politician to stick with access:

$$
-\frac{1}{2}(1-\pi) q \geq \frac{(1-\bar{\alpha})(1-q)}{\bar{\alpha}}
$$

This condition is satisfied when $q<\frac{2 \bar{\alpha}-2}{3 \bar{\alpha}-2-\bar{\alpha} \pi}$ and $\bar{\alpha} \geq \frac{2}{1+\pi}$. Define the thresholds $q^{\text {Access }}(\bar{\alpha}, \pi):=$ $\frac{2(1-\bar{\alpha})}{2-\bar{\alpha}(3-\pi)}$ and $\bar{\alpha}^{\operatorname{Access}}(\pi):=\frac{2}{1+\pi}$. So long as $q<q^{\operatorname{Access}}(\bar{\alpha}, \pi)$ and $\bar{\alpha} \geq \bar{\alpha}^{\operatorname{Access}}(\pi)$ then sincere politicians will run on access when corrupt politicians run on access. The upper bound on $q$ is increasing in both $\bar{\alpha}$ and $\pi$. As $\bar{\alpha}$ increases the probability that $\alpha_{G}$ will be realized such that the sincere politician will still learn $\theta$ after running on reform decreases. This implies that the politician's beliefs that $\theta=0$ must be stronger (i.e., $q$ must be higher) to induce the politician to deviate to reform since it is more likely that if he does so he will not learn $\theta$ and implement $x=0$ once he wins office. Similarly, as $\pi$ increases it is more likely that even if the sincere politician loses the election he will lose to another sincere politician, who will learn $\theta$ and match policy to the state. This implies that the incentives to deviate to reform to ensure winning are weaker and therefore the threshold on $q$ to support running on access is less stringent (i.e., the upper bound on $q$ is higher). Additionally, notice that $\frac{2(1-\bar{\alpha})}{2-\bar{\alpha}(3-\pi)} \rightarrow \frac{2}{3-\pi}$ as $\bar{\alpha} \rightarrow \infty$, which is exactly the relevant condition in the baseline model with full commitment. The lower bound on $\bar{\alpha}$ to support pooling on access platforms is decreasing in $\pi$. Thus, as the likelihood of running against another sincere politician increases the probability that the politician would learn $\theta$ should he deviate to reform and win can be higher (i.e., $\bar{\alpha}$ can be lower) and he would still forego that possibility and run on an access platform when corrupt politicians also run on access, since the likelihood of losing to a corrupt politician, should he lose, is lower. ${ }^{5}$

\footnotetext{
${ }^{5}$ Notice also that once $\bar{\alpha}>2$ the condition on $\bar{\alpha}$ is always trivially satisfied since $\pi>0$.
} 
Finally, consider the anti-interest group equilibrium in which all politicians run on reform platforms. In this case the voter can not discern politician types and the probability that sincere (corrupt) politicians learn $\theta$ (are bribed) if they win the election is lower than if they had run on access platforms. The off-path beliefs that support this equilibrium are such that a deviation to access leads the voter to believe the deviating politician is corrupt with probability one. This implies that a deviation to an access platform leads the deviating politician to lose the election with certainty. For sincere politicians, then, there is no incentive to deviate to an access platform as they would lose the election for sure while sticking with reform preserves a positive probability of winning the election and learning $\theta$. Corrupt politicians also have no incentive to deviate since in that case they lose with certainty, can not be bribed, and receive nothing whereas if they stick with reform then there is a positive probability of winning the election and being bribed. Thus, when there is a positive probability of either still learning $\theta$, in the case of sincere politicians, or still being bribed, in the case of corrupt politicians, no politicians have an incentive to deviate from a reform platform when all other politicians are also running on reform.

\section{B.4 Voter welfare}

Proposition 6 states the main welfare results. The dynamics for voter welfare are largely the same as in the baseline model.

Proposition 6. Define $\pi_{\text {Access }}^{\text {Welfare }}(\bar{\alpha}, q):=\frac{2(1-\bar{\alpha})+q(3 \bar{\alpha}-2)}{1-\bar{\alpha}+q(2 \bar{\alpha}-1)}$ and $\pi_{\text {Anti-IG }}^{\text {Welfare }}(\bar{\alpha}, q, \kappa):=\frac{1+2 q(\bar{\alpha}+\kappa-1)-\bar{\alpha}-\kappa}{1+q(2 \bar{\alpha}-1)-\bar{\alpha}}$. In terms of ex ante voter welfare, reform equilibrium is preferred to access equilibrium when both exist if $\pi<\pi_{\text {Access }}^{\text {Welfare }}(\bar{\alpha}, q)$ and reform equilibrium is preferred to anti-interest group equilibrium when both exist if $\pi>\pi_{\text {Anti-IG }}^{\text {Welfare }}(\bar{\alpha}, q, \kappa)$.

Proof of Proposition 6. Consider the voter's ex ante welfare from the reform equilibrium,

$$
W_{V}^{\operatorname{Reform}}(p, x)=\left(\pi^{2}+2(1-\pi) \pi\right)\left(\frac{(1-\bar{\alpha})(1-q)}{\bar{\alpha}}\right)-q(1-\pi)^{2} .
$$

The voter is able to perfectly infer politician types in a reform equilibrium. If a sincere politician is running - which occurs with probability $\pi^{2}+2(1-\pi) \pi$ - then the voter elects a sincere politician for sure. However, because that politician ran on a reform platform they may not learn $\theta$, which yields an expected payoff that is decreasing in $\bar{\alpha}$. If instead no sincere politician is running then a corrupt politician is elected - which occurs with probability $(1-\pi)^{2}$ - and since he ran on access will be bribed and set $x=1$, yielding expected losses $q$ (the probability $x=1$ mismatches the state).

The only difference in voter welfare between this model and the baseline is that the payoff associated with electing a sincere politician is scaled by $\bar{\alpha}$. That is, with costly campaign announcements, but no platform commitment, the voter's trade-off between improved screening and 
informed policymaking is weaker. Since sincere politicians that run on reform still learn $\theta$ with some positive probability, the voter's ex ante welfare from electing a sincere politician that ran on reform is higher than when there is full platform commitment (so long as $\bar{\alpha}$ is finite). However, the larger $\bar{\alpha}$ becomes the lower the probability of a sincere politician learning $\theta$ once in office and, therefore, welfare in the costly campaign announcements game approaches welfare in the full commitment environment. To see this, note that as $\bar{\alpha} \rightarrow \infty, \frac{(1-\bar{\alpha})(1-q)}{\bar{\alpha}} \rightarrow-(1-q)$, which is the same payoff as that in the baseline model.

In an access equilibrium the voter's ex ante welfare is given by,

$$
W_{V}^{\text {Access }}(p, x)=-(1-\pi) q
$$

Since the voter cannot discern politician types in this equilibrium she elects either politician with equal probability and her welfare depends solely on whether the politician elected is sincere or corrupt. If a sincere politician is elected then she loses nothing since that politician will learn $\theta$ and match policy to the state. If instead she happens to elect a corrupt politician, which will be the case with probability $1-\pi$, that politician implements $x=1$, which mismatches the state with probability $q$. In this case, voter welfare is equivalent to access equilibrium welfare in the baseline model since in this case the interest group also gains access to the politician in office with certainty.

Finally, in an anti-interest group equilibrium the voter cannot distinguish politician types and therefore elects either politician with equal probability. Since both politicians run on reform platforms voter welfare depends on whether the winning politician was sincere (probability $\pi$ ) or corrupt (probability $1-\pi$ ) as well as the probability that the winning politician learns $\theta$ (probability $1 / \bar{\alpha}$ ) or is bribed (probability $1-\kappa / \bar{\alpha}$ ), respectively. Sincere politicians that win and do not learn $\theta$ and corrupt politicians that win and are not bribed almost implement $x=0$. Otherwise, if a sincere politician wins and learns $\theta$ then he matches policy to the state and if a corrupt politician wins and is bribed then he implements $x=1$. Thus, the voter's ex ante welfare in an anti-interest group equilibrium is,

$$
\begin{aligned}
W_{V}^{\mathrm{Anti-IG}}(p, x) & =\pi\left(\frac{\bar{\alpha}-1}{\bar{\alpha}}(-(1-q))\right)-(1-\pi)\left(\frac{1-\kappa}{\bar{\alpha}}(-q)+\frac{\bar{\alpha}+\kappa-1}{\bar{\alpha}}(-(1-q))\right) \\
& =\pi\left(\frac{(1-\bar{\alpha})(1-q)}{\bar{\alpha}}\right)+(1-\pi)\left(\frac{q(\kappa-1)}{\bar{\alpha}}+\frac{(1-q)(1-\bar{\alpha}-\kappa)}{\bar{\alpha}}\right) .
\end{aligned}
$$

With the relevant voter welfare expressions in hand we can now turn to equilibrium comparisons. Consider the reform equilibrium and the access equilibrium. Combining the two relevant welfare expressions yields the condition that dictates whether the voter is better off in a reform 
equilibrium or an access equilibrium when both exist:

$$
\left(\pi^{2}+2(1-\pi) \pi\right)\left(\frac{(1-\bar{\alpha})(1-q)}{\bar{\alpha}}\right)-q(1-\pi)^{2}>-(1-\pi) q .
$$

If inequality 2 holds then the voter prefers a reform equilibrium to an access equilibrium. If it is reversed then access equilibrium is welfare-preferred. Inequality (2) is satisfied for all $\bar{\alpha}>$ 1 whenever $q>\frac{2 \bar{\alpha}-2}{3 \bar{\alpha}-2}$, which is exactly the existence condition for reform equilibria, and $\pi<$ $\frac{2(1-\bar{\alpha})+q(3 \bar{\alpha}-2)}{1-\bar{\alpha}+q(2 \bar{\alpha}-1)}:=\pi_{\text {Access }}^{\text {Welfare }}(\bar{\alpha}, q)$, yielding the result.

Now consider the separating reform equilibrium as compared to the anti-interest group equilibrium. Combining the two relevant expressions from above yields the inequality that dictates when reform equilibrium is welfare-preferred to anti-interest group equilibrium,

$$
\left(\pi^{2}+2(1-\pi) \pi\right)\left(\frac{(1-\bar{\alpha})(1-q)}{\bar{\alpha}}\right)-q(1-\pi)^{2}>\pi\left(\frac{(1-\bar{\alpha})(1-q)}{\bar{\alpha}}\right)+(1-\pi)\left(\frac{q(\kappa-1)}{\bar{\alpha}}+\frac{(1-q)(1-\bar{\alpha}-\kappa)}{\bar{\alpha}}\right) .
$$

If this inequality holds then the reform equilibrium is preferred to the anti-interest group equilibrium when both exist. Otherwise, the anti-interest group equilibrium is welfare-preferred. Inequality (3) is satisfied for all $\kappa \in(0,1), \bar{\alpha}>1$, and $q \in\left(\frac{1}{2}, 1\right)$ if $\pi>\frac{1+2 q(\bar{\alpha}+\kappa-1)-\bar{\alpha}-\kappa}{1+q(2 \bar{\alpha}-1)-\bar{\alpha}}:=$ $\pi_{\text {Anti-IG }}^{\text {Welfare }}(\bar{\alpha}, q, \kappa)$. Taken together, all of these conditions combine to form the result.

\section{Dynamic political agency}

\section{C.1 Equilibrium existence}

Proposition 7. Define $q_{D}^{\text {Reform }}(\pi, \delta, \varepsilon):=\frac{\delta(\varepsilon-1)+1}{(\delta+1)(\delta(\varepsilon-1)+1)+(\delta-1) \delta \pi}$. A separating reform equilibrium to the dynamic no-commitment game exists if $q \geq q_{D}^{\text {Reform }}(\pi, \delta, \varepsilon)$. Additionally, an access equilibrium always exists.

Proof of Proposition 7. First consider a reform equilibrium in which sincere types choose $p_{t}=0$ at all $t$ and corrupt types choose $p_{t}=1$. This implies that the voter always learns the incumbent's type on the path of play. Therefore, the voter always retains the incumbent when $p_{t}=0$ and never retains the incumbent when $p_{t}=1$.

We denote the voter's discounted present value for electing a sincere (corrupt) type as $U_{V}^{R}(S)$ 
$\left(U_{V}^{R}(C)\right)$ and the value for a random challenger as $\bar{U}_{V}^{R}$. These can be defined recursively as

$$
\begin{aligned}
U_{V}^{R}(S)= & (1-q)\left(0+\delta\left(\varepsilon\left((1-q)+\delta \bar{U}_{V}^{R}\right)+(1-\varepsilon) U_{V}^{R}(S)\right)\right)+ \\
& q\left(1+\delta\left(\varepsilon\left((1-q)+\delta \bar{U}_{V}^{R}\right)+(1-\varepsilon) U_{V}^{R}(S)\right)\right) \\
U_{V}^{R}(C)= & (1-q)\left(1+\delta \bar{U}_{V}^{R}\right)+q\left(0+\delta \bar{U}_{V}^{R}\right) \\
\bar{U}_{V}^{R}= & \pi U_{V}^{R}(S)+(1-\pi) U_{V}^{R}(C) .
\end{aligned}
$$

The explanations for these continuation values are as follows. For $U_{V}^{R}(S)$ we consider a sincere type taking office. In a reform equilibrium this type denies access and chooses $x_{t}=0$. Furthermore, sincere types are always retained. With probability $(1-q)$ the state was $\theta_{t}=1$ and the voter gets an instantaneous payoff of zero. The voter still retains the incumbent in this case. In the next period, with probability $\varepsilon$ the sincere type becomes corrupt in the next period after being retained, grants access, and chooses $x=1$. This gives the voter an expected utility of $(1-q)$ in period $t+1$. This is discounted by $\delta$. This voter will replace the incumbent in $t+1$ following that choice so she gets the payoff $\bar{U}_{V}^{R}$ from starting with a random challenger at time $t+2$, discounted again by $\delta$. With probability $(1-\varepsilon)$, the retained incumbent remains sincere and the voter's continuation value remains $U_{V}^{R}(S)$, discounted by one period. With probability $q$ the state was $\theta_{t}=0$ and the voter gets an instantaneous payoff of 1 rather than 0 . Since the incumbent is still retained the voter's utility starting in the next period is the same as above. To explain $U_{V}^{R}(C)$ we consider a corrupt politician taking office. This politician always grants access and chooses $x_{t}=1$. With probability $(1-q)$ we have $\theta_{t}=1$ and the voter gets a payoff of 1 . The incumbent is still removed and the voter's continuation value is then $\bar{U}_{V}^{R}$, her value from a random challenger, discounted for one period. With probability $q$ the state is $\theta_{t}=0$ and the voter gets a payoff of 0 , still removes the incumbent, and once again gets a discounted continuation value equal to $\bar{U}_{V}^{R}$. Finally, $\bar{U}_{V}^{R}$ is computed simply by taking a weighted average of continuation values for electing sincere and corrupt types, weighted by the probability of each type.

We derive reduced forms of the continuation values by solving the system above for each of the continuation values. Solving this system for the three value functions yields

$$
\begin{aligned}
U_{V}^{R}(S) & =\frac{\delta \varepsilon+\delta \pi q-\delta q \varepsilon-\delta q+q}{(1-\delta)(\delta \varepsilon-\delta+\delta \pi+1)} \\
U_{V}^{R}(C) & =\frac{\delta \varepsilon-\delta+\delta \pi q-\delta q \varepsilon+\delta q-q+1}{(1-\delta)(\delta \varepsilon-\delta+\delta \pi+1)} \\
\bar{U}_{V}^{R} & =\frac{\delta \varepsilon-\delta+\delta \pi-\delta \pi q+2 \pi q-\pi-\delta q \varepsilon+\delta q-q+1}{(1-\delta)(\delta \varepsilon-\delta+\delta \pi+1)} .
\end{aligned}
$$

It is easily verified that $U_{V}^{R}(S)>U_{V}^{R}(C)$ for any allowed values of the parameters, which implies 
in this case that the voter has a strict incentive to retain an incumbent believed to be sincere. Since beliefs are degenerate after observing the access choice, the voter retains an incumbent who denies access regardless of her information about the policy choice and outcome. Furthermore, since the game begins with a randomly drawn incumbent ${\overline{U_{V}}}^{R}$ is also the voter's expected welfare in a reform equilibrium.

The corrupt type of politician will always grant access in this equilibrium. The corrupt type of incumbent's equilibrium payoff is equal to $1+\delta \bar{U}_{V}^{R}$ since it takes a bribe in the current period and then immediately leaves office. The payoff to deviating in one time period would be $0+\delta 1+$ $\delta^{2}{\overline{U_{V}}}^{R}$ since it would forgo a bribe in the current period in exchange for a bribe in the next period. This deviation would not be a best response for any discount factor so by the one-stage deviation principle the corrupt type would not deviate from this equilibrium.

To understand the sincere type's decision we recursively define the sincere incumbent's value function from the reform equilibrium, denoted as $U_{S}^{R}$ as

$$
U_{S}^{R}=q+\delta\left(\varepsilon\left(1+\delta{\overline{U_{V}}}^{R}\right)+(1-\varepsilon) U_{S}^{R}\right)
$$

Though the sincere type of politician's utility in the current period is identical to the voter's, the sincere type's continuation value differs because of the knowledge that her type may change in the future. The explanation for the sincere type's continuation value is as follows. The sincere type denies access and chooses $x_{t}=0$. With probability $q$ this choice is correct (i.e. $\theta_{t}=0$ ) and the policy payoff is one. Thus, the expected policy payoff in the current period is $q$. Furthermore, the sincere incumbent is always retained. After being retained, she becomes corrupt with probability $\varepsilon$, at which point she takes a bribe valued at 1 and then leaves office in the next period, after which she receives a continuation value identical to the voter's continuation value for electing a random challenger. With probability $(1-\varepsilon)$ she remains sincere and the continuation value in the next period is the same as in the current period.

Substituting the derived value of ${\overline{U_{V}}}^{R}$ and solving for $U_{S}^{R}$ yields

$$
U_{S}^{R}=\frac{\delta^{2} \varepsilon-\delta^{2} \varepsilon^{2}-\delta \varepsilon+\delta^{3} \pi q \varepsilon-2 \delta^{2} \pi q \varepsilon+\delta^{2} \pi q-\delta \pi q+\delta^{3} q \varepsilon^{2}-\delta^{3} q \varepsilon+2 \delta^{2} q \varepsilon-\delta^{2} q-\delta q \varepsilon+2 \delta q-q}{(\delta-1)(\delta \varepsilon-\delta+1)(\delta \varepsilon-\delta+\delta \pi+1)} .
$$

The payoff to deviating by granting access is $1+\delta U_{V}^{R}$ since the sincere type's payoff is the same as the voter's when she is out of office. Thus, the sincere type of politician prefers denying access in the reform equilibrium to deviating if

$$
U_{S}^{R} \geq 1+\delta U_{V}^{R}
$$

Substituting (7) and (6) for $U_{S}^{R}$ and $U_{V}^{R}$ and solving for $q$ yields our condition for supporting the 
reform equilibrium in this game in the form of a cutoff for $q$.

$$
q \geq \frac{\delta(\varepsilon-1)+1}{(\delta+1)(\delta(\varepsilon-1)+1)+(\delta-1) \delta p}
$$

An access equilibrium always exists in the dynamic game. In this equilibrium profile, both types grant access. Furthermore, the voter makes retention decisions solely on the basis of observed outcomes: as long as access is granted she retains the incumbent when she learns her utility in that period is 1 and replaces the incumbent when she learns her utility in that period is 0 . If access is granted and she does not learn the policy choice or outcome from that period (which occurs with probability $1-r$ ), she is indifferent between replacing and retaining the incumbent, so will retain the incumbent in this situation. Finally, if the voter observed an incumbent who denied access off the path of play, she would believe that incumbent to be sincere and would retain the incumbent: this is demanded by the Intuitive Criterion since denying access is equilibrium dominated for the corrupt type.

The reasoning for the existence of the access equilibrium is as follows. First, the argument for the corrupt type in the separating equilibrium implies that the corrupt type would not deviate to denying access even if it guaranteed her reelection. For the sincere type, granting access guarantees the best policy outcome in the current period. Furthermore, since the voter updates solely on policy outcomes (and retains when she learns nothing), this guarantees reelection for the sincere type. Thus, there is no gain to deviating to denying access for either type.

In the graphical examples we are interested in the limit of equilibria as $\varepsilon \rightarrow 0$. This follows in this case from taking the limit of $q_{D}^{\text {Reform }}$ as $\varepsilon \rightarrow 0$ which yields the next result.

Corollary C.1. In the limit as $\varepsilon \rightarrow 0$ there is a reform equilibrium if $q \geq \frac{1}{1+\delta-\pi \delta}$.

Proof. This follows from taking $\lim _{\mathcal{\varepsilon} \rightarrow 0} \frac{\delta(\varepsilon-1)+1}{(\delta+1)(\delta(\varepsilon-1)+1)+(\delta-1) \delta \pi}$.

\section{C.2 Voter welfare}

Proposition 8. There exists a cutoff $q_{D}^{W}(\pi, \delta, \varepsilon, r)$ such that the reform equilibrium produces a higher ex ante expected utility to the voter than the access equilibrium if and only if $q \geq$ $q_{D}^{W}(\pi, \delta, \varepsilon, r)$. Furthermore, when the reform equilibrium exists, this condition always holds as $r \rightarrow 0$ and never holds as $r \rightarrow 1$.

Proof of Proposition 8. To compute voter welfare in the access equilibrium, we define the voter's discounted present value for electing a sincere type in the access equilibrium as $U_{V}^{A}(S)$, the present value for a corrupt type as $U_{V}^{A}(C)$, and the value for a random politician as $\bar{U}_{V}^{A}$. These are defined 
as follows:

$$
\begin{aligned}
U_{V}^{A}(S) & =1+\delta\left(\varepsilon U_{V}^{A}(C)+(1-\varepsilon) U_{V}^{A}(S)\right) \\
U_{V}^{A}(C) & =(1-q)\left(1+\delta U_{V}^{A}(C)\right)+q\left(0+\delta\left(r \bar{U}_{V}^{A}+(1-r) U_{V}^{A}(C)\right)\right) \\
\bar{U}_{V}^{A} & =\pi U_{V}^{A}(S)+(1-\pi) U_{V}^{A}(C) .
\end{aligned}
$$

Solving this system for the continuation values gives us

$$
\begin{aligned}
U_{V}^{A}(S) & =\frac{\delta \varepsilon-\delta+\delta \pi q r-\delta q \varepsilon+1}{(1-\delta)(\delta \varepsilon-\delta+\delta \pi q r+1)} \\
U_{V}^{A}(C) & =\frac{\delta \varepsilon-\delta+\delta \pi q r-\delta q \varepsilon+\delta q-q+1}{(1-\delta)(\delta \varepsilon-\delta+\delta \pi q r+1)} \\
\bar{U}_{V}^{A} & =\frac{\delta \varepsilon-\delta-\delta \pi q+\delta \pi q r+\pi q-\delta q \varepsilon+\delta q-q+1}{(1-\delta)(\delta \varepsilon-\delta+\delta \pi q r+1)} .
\end{aligned}
$$

The explanation for the continuation values is as follows. $U_{V}^{A}(S)$ is the value for electing a sincere type in an access equilibrium. This type always matches the policy to the state of the world so the payoff in the current period is equal to 1 . Furthermore, the sincere incumbent is always retained. The sincere incumbent is corrupt in the next period with probability $\varepsilon$ and sincere in the next period with probability $(1-\varepsilon)$, giving the voter the corresponding continuation values discounted by one period. $U_{V}^{A}(C)$ is the voter's value for electing a corrupt type in the access equilibrium. The corrupt type grants access and sets policy to $x_{t}=1$. With probability $(1-q)$ this policy matches the true state, giving the voter an instantaneous payoff of 1 . In this case the voter retains the Incumbent and the game continues once again giving the voter $U_{V}^{A}(C)$. With probability $q$ this policy does not match the state and the voter's payoff is zero. With probability $r$ the voter learns this payoff, removes the Incumbent, and gets her value for electing a random challenger, which is $\bar{U}_{V}^{A}$. With probability $(1-r)$ she does not learn her payoff, retains the Incumbent, and the game continues giving the voter $U_{V}^{A}(C)$ again. Finally, $\bar{U}_{V}^{A}$ is a probability-weighted average of values for electing each type. Since the first period begins with a random incumbent, $\bar{U}_{V}^{A}$ is also the voter's ex ante expected utility for playing the access equilibrium.

The reform equilibrium is preferred to the access equilibrium if

$$
\bar{U}_{V}^{R}>\bar{U}_{V}^{A}
$$

Substituting the solutions for $\bar{U}_{V}^{R}$ and $\bar{U}_{V}^{A}$ gives

$$
\frac{\delta \varepsilon-\delta+\delta \pi-\delta \pi q+2 \pi q-\pi-\delta q \varepsilon+\delta q-q+1}{(1-\delta)(\delta \varepsilon-\delta+\delta \pi+1)}>\frac{\delta \varepsilon-\delta-\delta \pi q+\delta \pi q r+\pi q-\delta q \varepsilon+\delta q-q+1}{(1-\delta)(\delta \varepsilon-\delta+\delta \pi q r+1)}
$$


Define $\Delta(\pi, q, \delta, r, \varepsilon)$ as the difference in voter values for the reform and access equilibria:

$$
\begin{aligned}
\Delta(\pi, q, \delta, r, \varepsilon)= & \frac{\delta \varepsilon-\delta+\delta \pi-\delta \pi q+2 \pi q-\pi-\delta q \varepsilon+\delta q-q+1}{(1-\delta)(\delta \varepsilon-\delta+\delta \pi+1)} \\
& -\frac{\delta \varepsilon-\delta-\delta \pi q+\delta \pi q r+\pi q-\delta q \varepsilon+\delta q-q+1}{(1-\delta)(\delta \varepsilon-\delta+\delta \pi q r+1)}
\end{aligned}
$$

Note that $\Delta(\cdot)$ is continuous with respect to q. We now take limits of $\Delta(\cdot)$ for the extreme values of $q$ :

$$
\begin{aligned}
\lim _{q \rightarrow 1 / 2} \Delta(\pi, q, \delta, r, \varepsilon) & =-\frac{\pi(\delta(r-2)+2)}{2(1-\delta)(\delta(\pi r+2 \varepsilon-2)+2)}<0 \\
\lim _{q \rightarrow 1} \Delta(\pi, q, \delta, r, \varepsilon) & =\frac{\delta \pi(1-r)(\delta(\varepsilon-1)+(\delta-1) \pi+1)}{(1-\delta)(\delta(\pi+\varepsilon-1)+1)(\delta(\pi r+\varepsilon-1)+1)}>0
\end{aligned}
$$

where both inequalities follow easily from the bounds on the parameters. By the Intermediate Value Theorem, there must be some value $q^{*} \in(1 / 2,1)$ making the voter indifferent between equilibria (i.e. a point at which $\Delta\left(\pi, q^{*}, \delta, r, \varepsilon\right)=0$ for given values of $\pi, \delta, r$ and $\varepsilon$.

Additionally, we have

$$
\frac{\partial \Delta(\pi, q, \delta, r, \varepsilon)}{\partial q}=\frac{\pi\left(\frac{2}{\delta(\pi+\varepsilon-1)+1}-\frac{\delta(\delta+q r(\delta(\pi q r-2)+2)+\delta \varepsilon(2 q r-1)+\varepsilon-2)+1}{(\delta(\pi q r+\varepsilon-1)+1)^{2}}\right)}{1-\delta}>0
$$

which shows that $\Delta(\pi, q, \delta, r, \varepsilon)$ is increasing in $q$. Thus for $q>q^{*}$ the reform equilibrium is strictly preferred and for $q<q^{*}$ the access equilibrium is strictly preferred. Setting $q_{D}^{W}(\pi, \delta, \varepsilon, r)=q^{*}$ completes the proof of the first statement.

Next, to prove that the reform equilibrium is always preferred when $r=0$, we note that

$$
\Delta(\pi, q, \delta, 0, \varepsilon)=\frac{p(\delta(-\varepsilon)+\delta+q((\delta+1)(\delta(\varepsilon-1)+1)+(\delta-1) \delta p)-1)}{(1-\delta)(\delta(\varepsilon-1)+1)(\delta(p+\varepsilon-1)+1)} .
$$

Setting $\Delta(\pi, q, \delta, 0, \varepsilon)>0$ and solving for $q$ yields $q>\frac{\delta \varepsilon-\delta+1}{\delta^{2} \varepsilon-\delta^{2}+\delta \varepsilon+\delta^{2} \pi-\delta p+1}$ which is implied by the existence conditions in Proposition 7, indicating that when both equilibria exist and $r=0$ the reform equilibrium is preferred. Since $\Delta$ is continuous in $r$ this also implies that the reform equilibrium is preferred when $r$ is sufficiently close to zero.

Finally, to prove the the access equilibrium is always preferred when $r=1$, we note that

$$
\Delta(\pi, q, \delta, 1, \varepsilon)=\frac{\pi(1-q)\left(\delta^{2} q(\pi+\varepsilon-1)+\delta(q-2 \pi q-\varepsilon+1)-1\right)}{(1-\delta)(\delta(\pi+\varepsilon-1)+1)(\delta(\pi q+\varepsilon-1)+1)} .
$$

Setting $\Delta(\pi, q, \delta, 1, \varepsilon)=0$ and solving for $q$ yields either $q=1$ or $q=\frac{\delta \varepsilon-\delta+1}{\delta(\delta \varepsilon-\delta+\delta \pi-2 \pi+1)}$. We show 
that $q=1$ is the only valid solution since $\frac{\delta \varepsilon-\delta+1}{\delta(\delta \varepsilon-\delta+\delta \pi-2 \pi+1)} \notin(1 / 2,1)$. First, setting

$$
\frac{\delta \varepsilon-\delta+1}{\delta(\delta \varepsilon-\delta+\delta \pi-2 \pi+1)}>\frac{1}{2}
$$

and solving for $\delta$ gives $\delta<\frac{2 \pi-1}{\pi+\varepsilon-1} \cdot{ }^{6}$ Second, setting

$$
\frac{\delta \varepsilon-\delta+1}{\delta(\delta \varepsilon-\delta+\delta \pi-2 \pi+1)}<1
$$

and solving for $\delta$ yields $\delta>\frac{2 \pi-1}{\pi+\varepsilon-1}$ which contradicts the requirement for $\frac{\delta \varepsilon-\delta+1}{\delta(\delta \varepsilon-\delta+\delta \pi-2 \pi+1)}>\frac{1}{2}$. Thus, $\frac{\delta \varepsilon-\delta+1}{\delta(\delta \varepsilon-\delta+\delta \pi-2 \pi+1)} \notin(1 / 2,1)$ meaning that the only valid solution for $\Delta(\pi, q, \delta, 1, \varepsilon)=0$ is $q=1$, which shows that the access equilibrium is always preferred for $q \in(1 / 2,1)$.

\footnotetext{
${ }^{6}$ Notably, this is only possible for $\pi<\frac{1}{2}$ given that we must have $\varepsilon<\pi$.
} 